\title{
International Union of Basic and Clinical Pharmacology. LXXIX. Cannabinoid Receptors and Their Ligands: Beyond $\mathrm{CB}_{1}$ and $\mathrm{CB}_{2}$
}

\author{
R. G. Pertwee, A. C. Howlett, M. E. Abood, S. P. H. Alexander, V. Di Marzo, M. R. Elphick, P. J. Greasley, H. S. Hansen, G. Kunos,
} K. Mackie, R. Mechoulam, and R. A. Ross

School of Medical Sciences, Institute of Medical Sciences, University of Aberdeen, Foresterhill, Aberdeen, United Kingdom (R.G.P., R.A.R); Department of Physiology and Pharmacology, Wake Forest University Health Sciences, Winston-Salem, North Carolina (A.C.H.); Center for Substance Abuse Research, Temple University, Philadelphia, Pennsylvania (M.E.A.); Lipid Signalling in Health and Disease, School of Biomedical Sciences, University of Nottingham Medical School, Nottingham, United Kingdom (S.P.H.A.); Endocannabinoid Research Group, Division of Pharmacology "L Donatelli," Department of Experimental Medicine, Second University of Naples, Naples, Italy (V. Di M.); School of Biological and Chemical Sciences, Queen Mary University of London, London, United Kingdom (M.R.E.); Lead Generation Department, AstraZeneca R\&D Mölndal, Mölndal, Sweden (P.J.G.); Department of Pharmacology and Pharmacotherapy, Faculty of Pharmaceutical Sciences, University of Copenhagen, Copenhagen, Denmark (H.S.H.); Laboratory of Physiologic Studies, National Institute on Alcohol Abuse and Alcoholism, Bethesda, Maryland (G.K.); Department of Psychological and Brain Sciences, Gill Center for Biomolecular Science, Indiana University, Bloomington, Indiana (K.M.); and Medical Faculty, Hebrew University, Ein Kerem Campus, Jerusalem, Israel (R.M.)

Abstract .................................................. 590

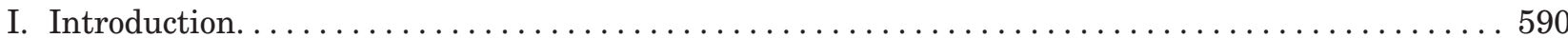

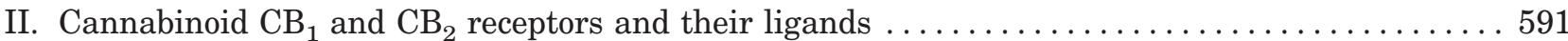

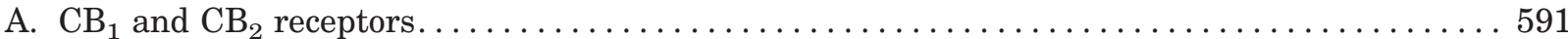

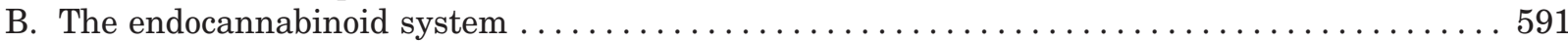

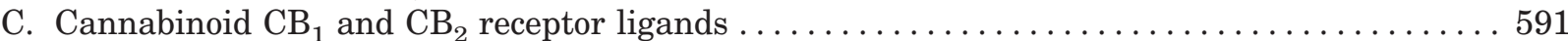

1. Agonists that target $\mathrm{CB}_{1}$ and $\mathrm{CB}_{2}$ receptors with similar potency $\ldots \ldots \ldots \ldots \ldots \ldots 1$

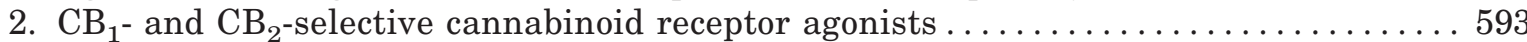

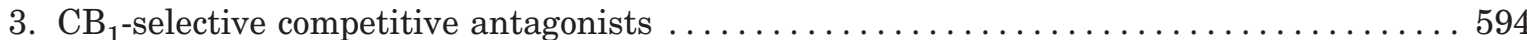

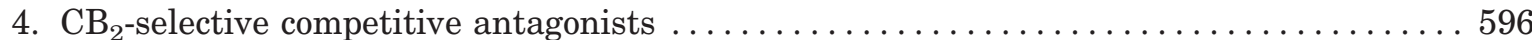

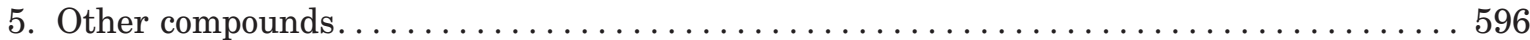

D. $\mathrm{CB}_{1}$ receptor homomers and heteromers: nomenclature and pharmacology $\ldots \ldots \ldots \ldots \ldots 596$

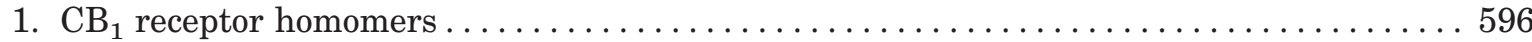

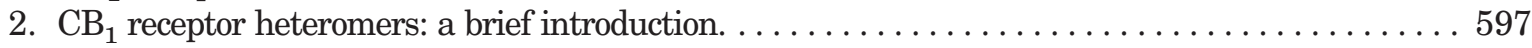

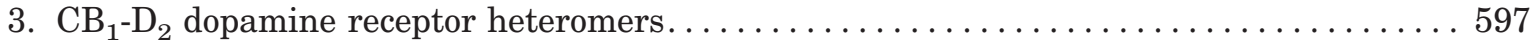

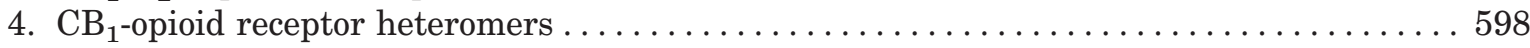

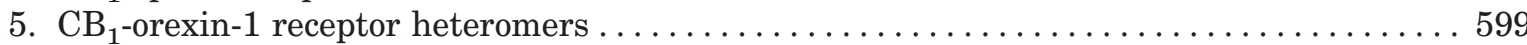

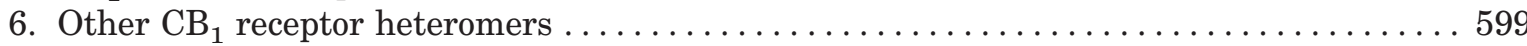

III. The extent to which $\mathrm{CB}_{1}$ and $\mathrm{CB}_{2}$ receptor ligands target non-CB${ }_{1}$, non- $\mathrm{CB}_{2}$ receptors

and ion channels ............................................... 599

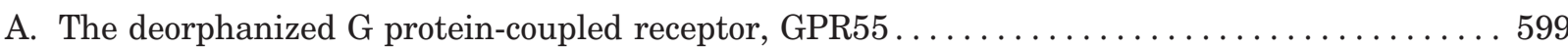

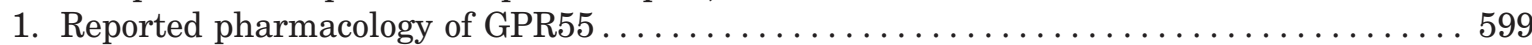

2. Anandamide ..............................................6600

3. 2-Arachidonoyl glycerol ............................................... 600

4. Lysophosphatidyl inositol . . . . . . . . . . . . . . . . . . . . . . . . . . . . 601

5. $\Delta^{9}$-Tetrahydrocannabinol . . . . . . . . . . . . . . . . . . . . . . . . . . . 601

6. Abnormal-cannabidiol . . . . . . . . . . . . . . . . . . . . . . . . . . . . . . . . 601

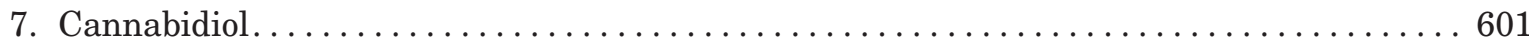

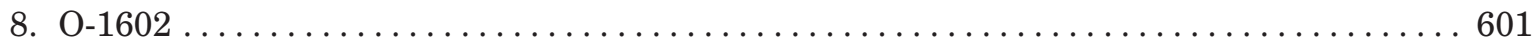

Address correspondence to: Prof. R. G. Pertwee, School of Medical Sciences, Institute of Medical Sciences, University of Aberdeen, Foresterhill, Aberdeen AB25 2ZD, Scotland, UK. E-mail: rgp@abdn.ac.uk

This article is available online at http://pharmrev.aspetjournals.org.

doi:10.1124/pr.110.003004. 


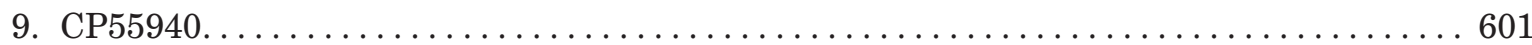

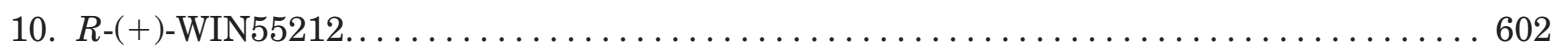

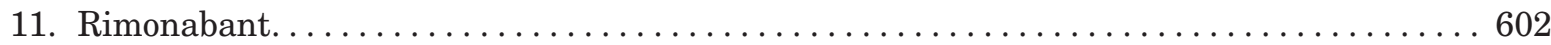

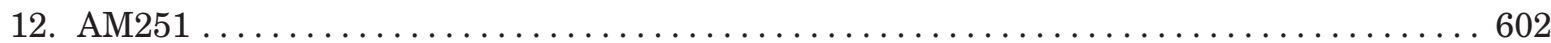

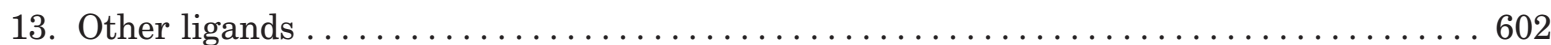

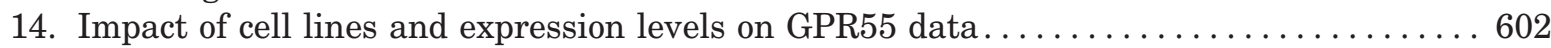

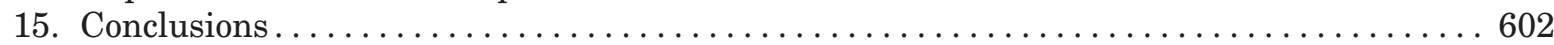

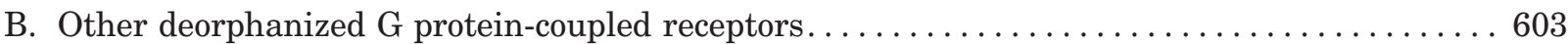

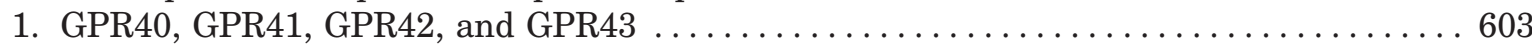

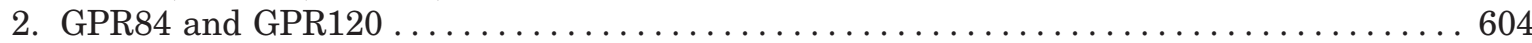

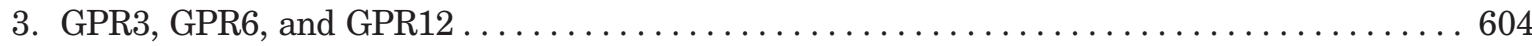

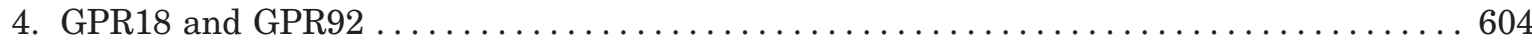

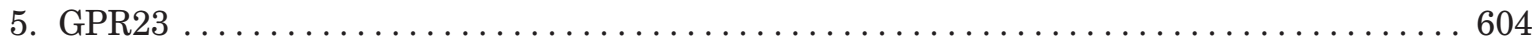

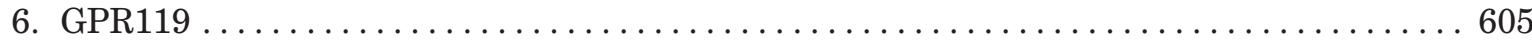

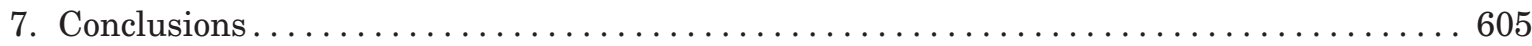

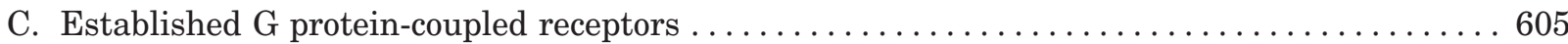

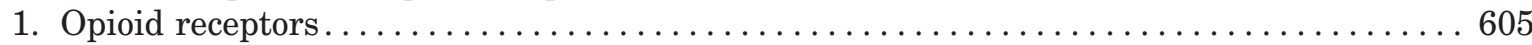

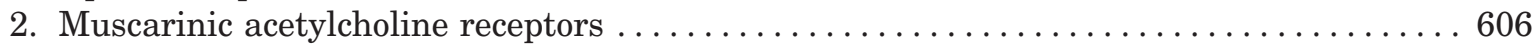

3. Other established G protein-coupled receptors $\ldots \ldots \ldots \ldots \ldots \ldots \ldots \ldots \ldots \ldots \ldots \ldots 6$

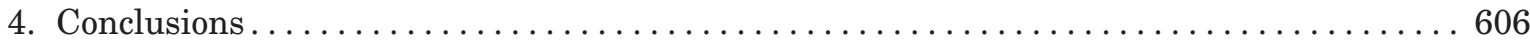

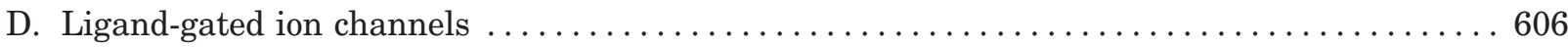

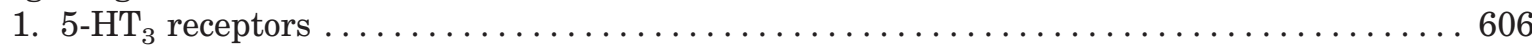

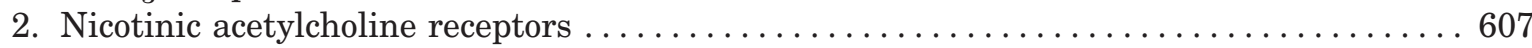

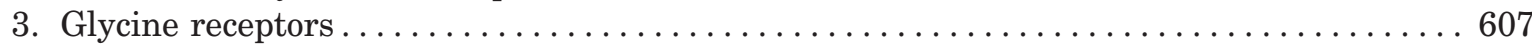

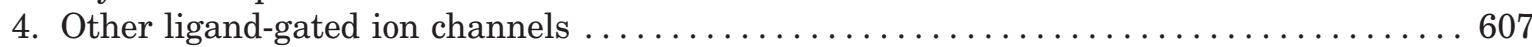

5. Conclusions .............................................. 608

E. TRPV1 and other transient receptor potential channels . . . . . . . . . . . . . . 608

1. Transient receptor potential channels: a brief introduction $\ldots \ldots \ldots \ldots \ldots \ldots \ldots \ldots \ldots 6$

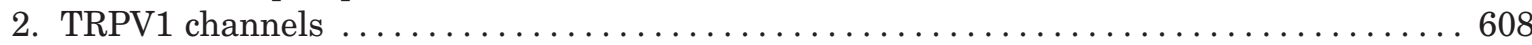

3. Other TRPV channels. ...................................... 610

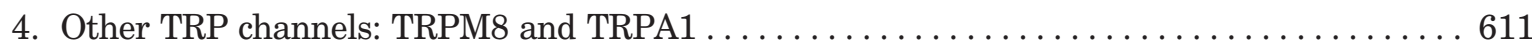

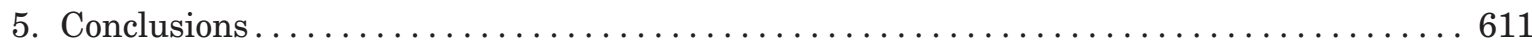

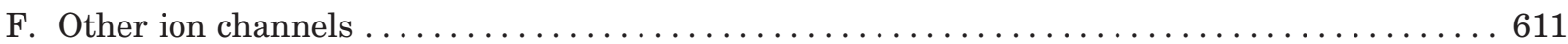

1. Calcium channels .......................................... 611

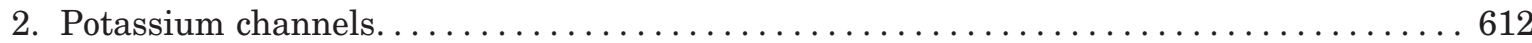

3. Sodium channels ............................................6 613

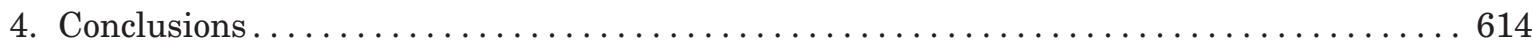

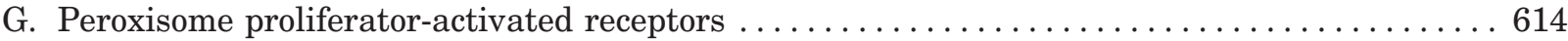

1. Direct evidence for peroxisome proliferator-activated receptor activation or occupancy by cannabinoids and related molecules...................... 614

2. Indirect evidence for cannabinoid activation of peroxisome proliferator-activated

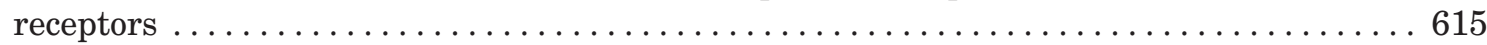

3. Reporter gene assays and metabolism of endocannabinoids $\ldots \ldots \ldots \ldots \ldots \ldots \ldots \ldots 615$

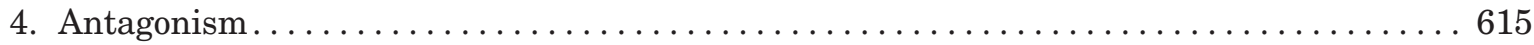

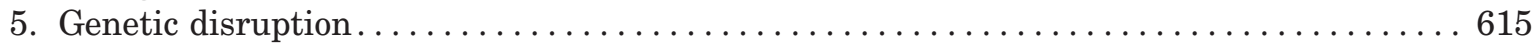

6. Amplification of endocannabinoid levels and peroxisome proliferator-activated receptors . . . . 615

7. Regulation by peroxisome proliferator-activated receptors and peroxisome proliferator-activated receptor ligands of the endocannabinoid system $\ldots \ldots \ldots \ldots \ldots 616$

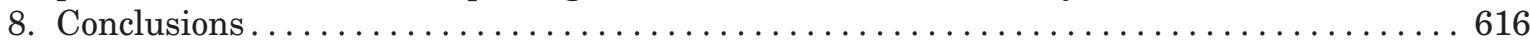

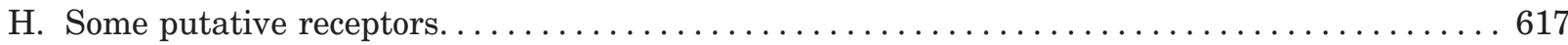

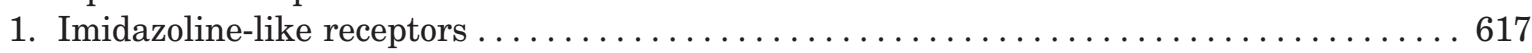

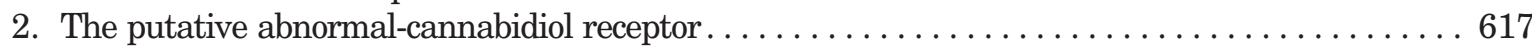

3. A putative receptor for anandamide and $R$-(+)-WIN55212 $\ldots \ldots \ldots \ldots \ldots \ldots \ldots \ldots \ldots 6 \ldots \ldots$

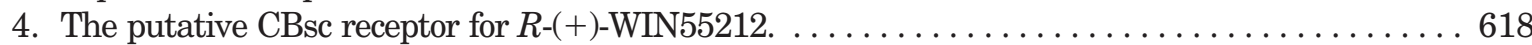

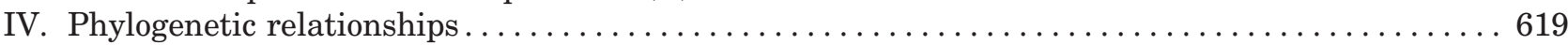

A. $\mathrm{CB}_{1}, \mathrm{CB}_{2}$, and other rhodopsin $\alpha$ group-type $\mathrm{G}$ protein-coupled receptors $\ldots \ldots \ldots \ldots \ldots 619$

B. GPR55 and other rhodopsin $\delta$ group-type $G$ protein-coupled receptors $\ldots \ldots \ldots \ldots \ldots \ldots 620$ 


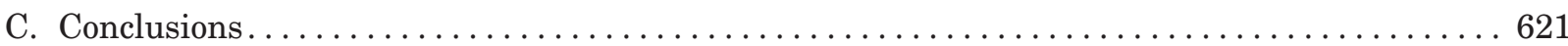

V. Cannabinoid receptor nomenclature: $\mathrm{CB}$ or not CB? That is the question ........... 621

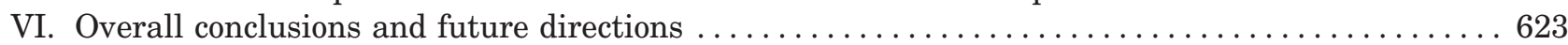

Acknowledgments . . . . . . . . . . . . . . . . . . . . . . . . . . . . . . . . . . . . 624

References .................................................... 624

\begin{abstract}
There are at least two types of cannabinoid receptors $\left(\mathrm{CB}_{1}\right.$ and $\left.\mathrm{CB}_{2}\right)$. Ligands activating these $\mathrm{G}$ protein-coupled receptors (GPCRs) include the phytocannabinoid $\Delta^{9}$-tetrahydrocannabinol, numerous synthetic compounds, and endogenous compounds known as endocannabinoids. Cannabinoid receptor antagonists have also been developed. Some of these ligands activate or block one type of cannabinoid receptor more potently than the other type. This review summarizes current data indicating the extent to which cannabinoid receptor ligands undergo orthosteric or allosteric interactions with non$\mathrm{CB}_{1}$, non- $\mathrm{CB}_{2}$ established GPCRs, deorphanized receptors such as GPR55, ligand-gated ion channels, transient receptor potential (TRP) channels, and other ion channels or peroxisome proliferator-activated nuclear receptors. From these data, it is clear that some ligands that interact similarly with $\mathrm{CB}_{1}$ and/or $\mathrm{CB}_{2}$ receptors are likely to dis-
\end{abstract}

play significantly different pharmacological profiles. The review also lists some criteria that any novel " $\mathrm{CB}_{3}$ " cannabinoid receptor or channel should fulfil and concludes that these criteria are not currently met by any non-CB ${ }_{1}$, non$\mathrm{CB}_{2}$ pharmacological receptor or channel. However, it does identify certain pharmacological targets that should be investigated further as potential $\mathrm{CB}_{3}$ receptors or channels. These include TRP vanilloid 1 , which possibly functions as an ionotropic cannabinoid receptor under physiological and/or pathological conditions, and some deorphanized GPCRs. Also discussed are 1) the ability of $\mathrm{CB}_{1}$ receptors to form heteromeric complexes with certain other GPCRs, 2) phylogenetic relationships that exist between $\mathrm{CB}_{1} / \mathrm{CB}_{2}$ receptors and other GPCRs, 3) evidence for the existence of several as-yet-uncharacterized non- $\mathrm{CB}_{1}$, non- $\mathrm{CB}_{2}$ cannabinoid receptors; and 4) current cannabinoid receptor nomenclature.

\section{Introduction}

The main purpose of this review is to consider current knowledge about the extent to which established canna-

\footnotetext{
${ }^{1}$ Abbreviations: $\Delta^{9}$-THC, (-)- $\Delta^{9}$-tetrahydrocannabinol; 2-AG, 2-arachidonoyl glycerol; abn-CBD, abnormal-cannabidiol; ACEA, arachidonyl-2'-chloroethylamide; AM1241, $R$-3-(2-iodo-5-nitrobenzoyl)-1methyl-2-piperidinylmethyl)- $1 H$-indole; AM251, $N$-(piperidin-1-yl)-5-(4iodophenyl)-1-(2,4-dichlorophenyl)-4-methyl- $1 H$-pyrazole-3-carboxamide; AM281, 1-(2,4-dichlorophenyl)-5-(4-iodophenyl)-4-methyl- $N$-4-morpholinyl-1H-pyrazole-3-carboxamide; AM404, $N$-(4-hydroxyphenyl)5Z,8Z,11Z,14Z-eicosatetraenamide; AM630, [6-iodo-2-methyl-1-[2(4-morpholinyl)ethyl]-1H-indol-3-yl](4-methoxyphenyl)methanone (6-iodopravadoline); CHO, Chinese hamster ovary; COX, cyclooxygenase; CP55940, (-)-cis-3-[2-hydroxy-4-(1,1-dimethylheptyl)phenyl]trans-4-(3-hydroxypropyl)cyclohexanol; CT-3, ajulemic acid; DAMGO, $\left[\mathrm{D}-\mathrm{Ala}^{2}, N-\mathrm{Me}-\mathrm{Phe}^{4}, \mathrm{Gly}^{5}\right.$-ol]-enkephalin; DRG, dorsal root ganglion; ERK, extracellular-signal regulated kinase; FAAH, fatty acid amide hydrolase; FRET, fluorescence resonance energy transfer; FTY720, 2-amino-2-(2-[4-octylphenyl] ethyl)-1,3-propanediol; GLP-1, glucagonlike peptide-1; GPCR, G protein-coupled receptor; GTP $\gamma \mathrm{S}$, guanosine 5'-O-(3-thio)triphosphate; GW6471, [(2S)-2-[[(1Z)-1-methyl-3-oxo-3-[4(trifluoromethyl)phenyl)-1-propenyl] amino]-3-[4-[2-(5-methyl-2phenyl-4-oxazolyl)ethoxyphenylpropyl]-carbamic acid ethyl ester; GW7647, 2-[[4-[2-[[(cyclohexylamino)carbonyl](4-cyclohexylbutyl)amino] ethyl]-phenyl]thio]-2-methylpropanoic acid; GW9662, 2-chloro-5nitro- $N$-phenylbenzamide; HEK, human embryonic kidney; HU-210, (6aR)-trans-3-(1,1-dimethylheptyl)-6a, 7,10,10a-tetrahydro-1-hydroxy-6,6-dimethyl-6H-dibenzo[b, $d]$ pyran-9-methanol; HU-243, $\left[{ }^{3} \mathrm{H}\right](6 \mathrm{a} R)$ trans-3-(1,1-dimethylheptyl)-6a,7,10,10a-tetrahydro-1-hydroxy-6, 6-dimethyl-6H-dibenzo[b,d]pyran-9-methanol; HU-308, \{4-[4-(1, 1-dimethylheptyl)-2,6-dimethoxy-phenyl]-6,6-dimethyl-bicyclo[3.1.1] hept-2-en-2-yl\}-methanol; HU-331, $3 S, 4 R$-p-benzoquinone3-hydroxy-2-p-mentha-(1,8)-dien-3-yl-5-pentyl; JTE-907, $N$-(1, 3-benzodioxol-5-ylmethyl)-1,2-dihydro-7-methoxy-2-oxo-8-(pentyloxy)-3-quinolinecarboxamide; JWH-015, (2-methyl-1-propyl-1H-indol3-yl)-1-naphthalenylmethanone; JWH-133, $(6 \mathrm{a} R, 10 \mathrm{a} R)$-3-(1,1-dimethylbutyl)-6a,7,10,10a-tetrahydro-6,6,9-trimethyl-6H-dibenzo
}

binoid $\mathrm{CB}_{1}$ and $\mathrm{CB}_{2}$ receptor ligands target non- $\mathrm{CB}_{1}$, non- $\mathrm{CB}_{2}$ receptors or ion channels (section III). These considerations are preceded by a brief overview of the pharmacology of cannabinoid $\mathrm{CB}_{1}$ and $\mathrm{CB}_{2}$ receptors and their ligands and by a discussion of the evidence that $\mathrm{CB}_{1}$ receptors form heteromeric complexes with

$[b, d]$ pyran; LOX, lipoxygenase; LPA, lysophosphatidic acid; LPI, lysophosphatidyl inositol; LY320135, 4-[[6-methoxy-2-(4-methoxyphenyl)3-benzofuranyl]carbonyl]benzonitrile; MAPK, mitogen-activated protein kinase; MK886, 1-[(4-chlorophenyl)methyl]-3-[(1,1-dimethylethyl)thio]- $\alpha$, $\alpha$-dimethyl-5-(1-methylethyl)- $1 H$-indole-2-propanoic acid; NAGly, $N$ arachidonoyl glycine; NESS O327, $N$-piperidinyl-[8-chloro-1-(2, 4-dichlorophenyl)-1,4,5,6-tetrahydrobenzo[6,7]cyclohepta[1,2-c] pyrazole-3-carboxamide]; NMDA, $N$-methyl-D-aspartate; noladin ether, 2-arachidonyl glyceryl ether; O-1602, 5-methyl-4-[(1R,6R)3-methyl-6-(prop-1-en-2-yl)cyclohex-2-enyl] benzene-1,3-diol; O-1918, 1,3-dimethoxy-5-methyl-2-[(1R,6R)-3-methyl-6-(1-methylethenyl)2-cyclohexen-1-yl]benzene; O-2050, $(6 \mathrm{a} R, 10 \mathrm{a} R)-3$-(1-methanesulfonylamino-4-hexyn-6-yl)-6a,7,10,10a-tetrahydro-6,6,9-trimethyl-6Hdibenzo $[b, d]$ pyran; OX, orexin; PPAR, peroxisome proliferator-activated receptor; $R$-(+)-WIN55212, $R$-(+)-[2,3-dihydro-5-methyl-3-(4-morpholinylmethyl)pyrrolo[1,2,3-de]-1,4-benzoxazin-6-yl]-1-naphthalenylmethanone mesylate; RhoA, Ras homolog gene family, member A; Sch.225336, $N$-[1(S)-[4-[[4-methoxy-2-[(4-methoxyphenyl)sulfonyl] phenyl]sulfonyl]phenyl]ethyl]methanesulfonamide); Sch.356036, $N$-[1(S)-[4-[[4-chloro-2-[(2-fluorophenyl)sulfonyl]phenyl] sulfonyl] phenyl]ethyl]methanesulfonamide; Sch.414319, $N$-[1(S)-[4-[[4-chloro-2-[(2fluorophenyl)sulfonyl]phenyl]sulfonyl]phenyl]ethyl]-1,1,1-trifluromethanesulfonamide; siRNA, small interfering RNA; SKF97541, 3-aminopropyl(methyl)phosphinic acid; SR141716A, rimonabant; SR144528, $N$-((1S)-endo-1,3,3-trimethyl bicyclo heptan-2-yl]-5-(4-chloro-3methylphenyl)-1-(4-methylbenzyl)-pyrazole-3-carboxamide); T0070907, 2-chloro-5-nitro- $N$-4-pyridinyl-benzamide; TM, transmembrane; TRP, transient receptor potential; TRPA, transient receptor potential ankyrin; TRPM, transient receptor potential melastatin; UCM707, (5Z,8Z,11Z,14Z)- $N$-(3-furanylmethyl)-5,8,11,14-eicosatetraenamide; URB597, cyclohexylcarbamic acid 3'-carbamoyl-biphenyl-3-yl ester. 
certain other receptors (section II). Also discussed in this review is the extent to which phylogenetic relationships exist between cannabinoid $\mathrm{CB}_{1}$ or $\mathrm{CB}_{2}$ receptors and other receptors (section IV). It ends by addressing the questions, first of whether cannabinoid $\mathrm{CB}_{1}$ and $\mathrm{CB}_{2}$ receptors should be renamed (section $\mathrm{V}$ ), and second, of whether any non- $\mathrm{CB}_{1}$, non- $\mathrm{CB}_{2}$ receptor or channel should be reclassified as a cannabinoid " $\mathrm{CB}_{3}$ " receptor or channel (section VI). The terms " $\mathrm{CB}_{1}$-selective" and " $\mathrm{CB}_{2}$-selective" have been used in this review to describe compounds that interact more potently with one cannabinoid receptor $\left(\mathrm{CB}_{1}\right.$ or $\left.\mathrm{CB}_{2}\right)$ than with the other, irrespective of whether any of these compounds target $\mathrm{CB}_{1}$ or $\mathrm{CB}_{2}$ receptors more potently than a non- $\mathrm{CB}_{1}$, non- $\mathrm{CB}_{2}$ receptor or channel. Receptor nomenclature in this article complies with the recommendations of the International Union of Basic and Clinical Pharmacology nomenclature and also conforms to Alexander et al. (2009).

\section{Cannabinoid $\mathrm{CB}_{1}$ and $\mathrm{CB}_{2}$ Receptors and their Ligands}

\section{A. $C B_{1}$ and $C B_{2}$ Receptors}

The discovery in 1990 that an orphan G protein-coupled receptor (SKR6) derived from a rat cerebral cortex cDNA library mediates pharmacological effects of (-)$\Delta^{9}$-tetrahydrocannabinol $\left(\Delta^{9}-\mathrm{THC}^{1}\right)$, the main psychoactive constituent of cannabis, established the identity of the first cannabinoid receptor, which we now refer to as $\mathrm{CB}_{1}$ (Matsuda et al., 1990). Three years later, in 1993, a $\mathrm{G}$ protein-coupled receptor (CX5) expressed in the human promyelocytic leukemic cell line HL60 was identified as a second cannabinoid receptor and named $\mathrm{CB}_{2}$ (Munro et al., 1993). $\mathrm{CB}_{1}$ and $\mathrm{CB}_{2}$ receptors are members of the superfamily of $\mathrm{G}$ protein-coupled receptors (GPCRs). As discussed in greater detail elsewhere (Howlett et al., 2002; Howlett, 2005), both these receptors inhibit adenylyl cyclase and activate mitogen-activated protein kinase by signaling through $\mathrm{G}_{\mathrm{i} / \mathrm{o}}$ proteins, which for the $\mathrm{CB}_{1}$ receptor can also mediate activation of A-type and inwardly rectifying potassium currents and inhibition of $\mathrm{N}$ - and $\mathrm{P} / \mathrm{Q}$-type calcium currents. In addition, $\mathrm{CB}_{1}$ receptors can signal through $\mathrm{G}_{\mathrm{s}}$ proteins (Glass and Felder, 1997; Maneuf and Brotchie, 1997; Calandra et al., 1999; Jarrahian et al., 2004). The ability of $\mathrm{CB}_{1}$ and $\mathrm{CB}_{2}$ receptors to signal through $\mathrm{G}_{\mathrm{i} / \mathrm{o}}$ proteins and, further downstream, through adenylyl cyclase is frequently exploited in two widely used in vitro bioassays: the $\left[{ }^{35} \mathrm{~S}\right] \mathrm{GTP} \gamma \mathrm{S}$ binding assay and the cAMP assay (Howlett et al., 2002; Pertwee, 2005a). As well as orthosteric site(s), the $\mathrm{CB}_{1}$ receptor possesses one or more allosteric sites that can be targeted by ligands in a manner that enhances or inhibits the activation of this receptor by direct agonists (Price et al., 2005a; Adam et al., 2007; Horswill et al., 2007; Navarro et al., 2009).
$\mathrm{CB}_{1}$ receptors are found mainly at the terminals of central and peripheral neurons, where they usually mediate inhibition of ongoing release of a number of different excitatory and inhibitory neurotransmitters (for review, see Howlett et al., 2002; Pertwee and Ross, 2002; Szabo and Schlicker, 2005). The distribution of these receptors within the central nervous system is such that their activation can affect processes such as cognition and memory, alter the control of motor function, and induce signs of analgesia. As to $\mathrm{CB}_{2}$ receptors, these are located predominantly in immune cells and, when activated, can modulate immune cell migration and cytokine release both outside and within the brain (for review, see Howlett et al., 2002; Cabral and Staab, 2005; Pertwee, 2005a). There is also evidence that 1 ) some $\mathrm{CB}_{1}$ receptors are expressed by non-neuronal cells, including immune cells (Howlett et al., 2002), and 2) that $\mathrm{CB}_{2}$ receptors are expressed by some neurons, both within the brain and elsewhere (Skaper et al., 1996; Ross et al., 2001a; Van Sickle et al., 2005; Wotherspoon et al., 2005; Beltramo et al., 2006; Gong et al., 2006; Baek et al., 2008). The role of neuronal $\mathrm{CB}_{2}$ receptors remains to be established.

Finally, several polymorphisms in the genes of $\mathrm{CB}_{1}$ (CNR1) and $\mathrm{CB}_{2}(C N R 2)$ receptors and in their proteins have been identified. Some of these have been linked to certain disorders that for CNR1 include 1) schizophrenia and 2) depression in Parkinson's disease and for CNR2 include postmenopausal osteoporosis (for review, see Norrod and Puffenbarger, 2007; Henquet et al., 2008; Bab et al., 2009).

\section{B. The Endocannabinoid System}

The cloning of the $\mathrm{CB}_{1}$ receptor was followed by the discovery that mammalian tissues can both synthesize cannabinoid receptor agonists and release them onto cannabinoid receptors. The first of these "endocannabinoids" to be identified were $N$-arachidonoylethanolamine (anandamide) and 2-arachidonoyl glycerol (2-AG) (Devane et al., 1992; Mechoulam et al., 1995; Sugiura et al., 1995), both of which are synthesized on demand in response to elevations of intracellular calcium (for review, see Di Marzo et al., 2005). Other compounds may also serve as endocannabinoids. These include $N$-dihomo- $\gamma$-linolenoylethanolamine, $\mathrm{N}$-docosatetraenoylethanolamine, $\mathrm{O}$-arachidonoylethanolamine (virodhamine), oleamide, $N$-arachidonoyl dopamine and $N$-oleoyl dopamine (for review, see Pertwee, 2005b). Endocannabinoids and their receptors constitute the "endocannabinoid system."

\section{Cannabinoid $C B_{1}$ and $C B_{2}$ Receptor Ligands}

1. Agonists that Target $C B_{1}$ and $C B_{2}$ Receptors with Similar Potency. Several cannabinoid receptor agonists possess similar affinities for $\mathrm{CB}_{1}$ and $\mathrm{CB}_{2}$ receptors (Table 1). When classified according to their chemical structures (Fig. 1), these agonists fall essentially into four main groups: classical, nonclassical, aminoal- 
TABLE 1

Some $K_{\mathrm{i}}$ values of cannabinoid $\mathrm{CB}_{1} / \mathrm{CB}_{2}$ receptor ligands for the in vitro displacement of a tritiated compound ${ }^{a}$ from specific binding sites on rat, mouse, or human $\mathrm{CB}_{1}$ and $\mathrm{CB}_{2}$ receptors

Unless otherwise indicated in the Reference column, see Pertwee, 2005a for references. Structures of the compounds listed are shown in Figs. 1 to 5.

\begin{tabular}{|c|c|c|c|}
\hline \multirow{2}{*}{ Cannabinoid Receptor Ligand } & \multicolumn{2}{|c|}{$K_{\mathrm{i}}$} & \multirow{2}{*}{ Reference } \\
\hline & $\mathrm{CB}_{1}$ & $\mathrm{CB}_{2}$ & \\
\hline & \multicolumn{2}{|c|}{$n M$} & \\
\hline \multicolumn{4}{|l|}{ Section II.C.1 } \\
\hline$(-)-\Delta^{9}-\mathrm{THC}$ & $5.05-80.3$ & $3.13-75.3$ & See Pertwee, 2008a for references \\
\hline HU-210 & $0.06-0.73$ & $0.17-0.52$ & \\
\hline CP55940 & $0.5-5.0$ & $0.69-2.8$ & \\
\hline$R$-(+)-WIN55212 & $1.89-123$ & $0.28-16.2$ & \\
\hline Anandamide & $61-543$ & 279-1940 & \\
\hline $2-\mathrm{AG}$ & $58.3,472$ & 145,1400 & \\
\hline \multicolumn{4}{|l|}{ Section II.C.2 } \\
\hline \multicolumn{4}{|c|}{ Agonists with higher $\mathrm{CB}_{1}$ than $\mathrm{CB}_{2}$ affinity } \\
\hline ACEA & $1.4,5.29$ & $195,>2000$ & \\
\hline Arachidonylcyclopropylamide & 2.2 & 715 & \\
\hline$R-(+)$-methanandamide & $17.9-28.3$ & $815-868$ & \\
\hline Noladin ether & 21.2 & $>3000$ & \\
\hline \multicolumn{4}{|c|}{ Agonists with higher $\mathrm{CB}_{2}$ than $\mathrm{CB}_{1}$ affinity } \\
\hline JWH-133 & 677 & 3.4 & \\
\hline HU-308 & $>10000$ & 22.7 & \\
\hline JWH-015 & 383 & 13.8 & \\
\hline AM1241 & 280 & 3.4 & \\
\hline \multicolumn{4}{|l|}{ Section II.C.3 } \\
\hline Rimonabant (SR141716A) & $1.8-12.3$ & $514-13,200$ & \\
\hline AM251 & 7.49 & 2290 & \\
\hline AM281 & 12 & 4200 & \\
\hline LY320135 & 141 & 14,900 & \\
\hline Taranabant & $0.13,0.27$ & 170,310 & Fong et al., 2007 \\
\hline NESS 0327 & 0.00035 & 21 & \\
\hline O-2050 & $2.5,1.7$ & 1.5 & $\begin{array}{l}\text { Martin et al., 2002; A. Thomas and R. G. Pertwee, } \\
\text { unpublished data }\end{array}$ \\
\hline \multicolumn{4}{|l|}{ Section II.C.4 } \\
\hline SR144528 & $50.3->10,000$ & $0.28-5.6$ & \\
\hline AM630 & 5152 & 31.2 & \\
\hline JTE-907 & 2370 & 35.9 & \\
\hline \multicolumn{4}{|l|}{ Section II.C.5 } \\
\hline $11-\mathrm{OH}-\Delta^{8}-\mathrm{THC}$ & 25.8 & 7.4 & \\
\hline Ajulemic acid & $5.7,32.3$ & $56.1,170.5$ & $\begin{array}{l}\text { Dyson et al., 2005; see also Pertwee, 2005a, for } \\
\text { references }\end{array}$ \\
\hline Cannabinol & $120-1130$ & $96-301$ & See Pertwee, 2008 for references \\
\hline Cannabigerol & 81 & 2600 & Cascio et al., 2010 \\
\hline Cannabidiol & $4350->10,000$ & $2399->10,000$ & See Pertwee, 2008 for references \\
\hline$N$-Arachidonoyl dopamine & 250 & 12,000 & Bisogno et al., 2000 \\
\hline Virodhamine & 912 & N.D. & Steffens et al., 2005 \\
\hline
\end{tabular}

kylindole, and eicosanoid (for review, see Pertwee, 1999, 2005a, 2008a,b; Howlett et al., 2002).

- The classical group consists of dibenzopyran derivatives. It includes $\Delta^{9}$-THC, the main psychoactive constituent of cannabis, and (6aR)-trans-3-(1,1-dimethylheptyl)-6a, 7,10,10a-tetrahydro-1-hydroxy-6,6-dimethyl- $6 \mathrm{H}$ dibenzo[b, $d]$ pyran-9-methanol (HU-210), a synthetic analog of $(-)-\Delta^{8}$-tetrahydrocannabinol. HU-210 displays high affinity for $\mathrm{CB}_{1}$ and $\mathrm{CB}_{2}$ receptors and also high potency and relative intrinsic activity as a cannabinoid receptor agonist. These properties are all thought to result mainly from the presence of its dimethylheptyl side chain. $\Delta^{9}$-THC possesses significantly lower $\mathrm{CB}_{1}$ and $\mathrm{CB}_{2}$ affinity than HU-210 and lower relative intrinsic activity at these receptors, an indication that $\Delta^{9}$-THC is a cannabinoid receptor partial agonist. Moreover, it displays even less relative intrinsic activity at $\mathrm{CB}_{2}$ than at $\mathrm{CB}_{1}$ receptors.

- The nonclassical group contains bicyclic and tricyclic analogs of $\Delta^{9}$-THC that lack a pyran ring. A well known member of this group is (-)-cis-3-[2hydroxy-4-(1,1-dimethylheptyl)phenyl]-trans-4(3-hydroxypropyl)cyclohexanol (CP55940). This has been found to have slightly lower $\mathrm{CB}_{1}$ and $\mathrm{CB}_{2}$ affinities than HU-210 in some investigations but does seem to possess HU-210-like $\mathrm{CB}_{1}$ and $\mathrm{CB}_{2}$ receptor relative intrinsic activity.

- Members of the aminoalkylindole group of cannabinoid $\mathrm{CB}_{1} / \mathrm{CB}_{2}$ receptor agonists have structures that differ markedly from those of both classical and nonclassical cannabinoids. The best known member of this group is $R$-(+)-[2,3-dihydro-5methyl-3-(4-morpholinylmethyl)pyrrolo[1,2,3-de]1,4-benzoxazin-6-yl]-1-naphthalenylmethanone mesylate $[R-(+)-W I N 55212]$. This displays CP55940- 
<smiles>CCCCCc1cc(O)c2c(c1)OC(C)(C)C1CCC(I)=CC21</smiles><smiles>CCCCCCC(C)(C)c1cc(O)c2c(c1)OC(C)(C)[C@@H]1CC=C(CO)C[C@H]21</smiles>

HU-210

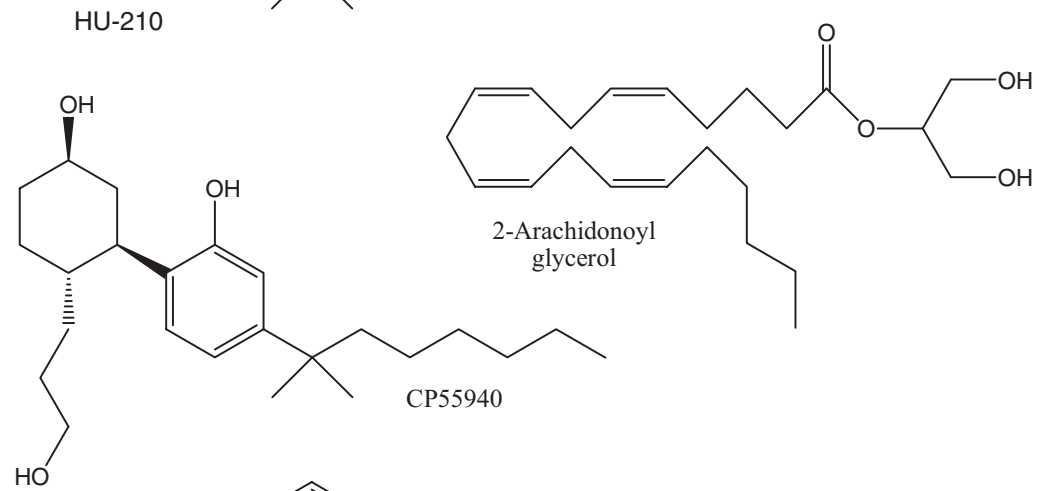<smiles>[Y16][Y16]#N</smiles>

FIG. 1. The structures of (-)- $\Delta^{9}$-tetrahydrocannabinol $\left[(-)-\Delta^{9}-\mathrm{THC}\right], \mathrm{HU}-210, \mathrm{CP5} 5940, R-(+)-W I N 55212$, anandamide, and 2-AG.

and HU-210-like relative intrinsic activity at both $\mathrm{CB}_{1}$ and $\mathrm{CB}_{2}$ receptors. However, unlike HU-210 and CP55940, it has been found in some investigations to possess slightly higher $\mathrm{CB}_{2}$ than $\mathrm{CB}_{1}$ affinity.

- Members of the eicosanoid group of cannabinoid $\mathrm{CB}_{1} / \mathrm{CB}_{2}$ receptor agonists have structures quite unlike those of classical, nonclassical, or aminoalkylindole cannabinoids. Two prominent members of this group are the endocannabinoids anandamide and 2-AG. Like $\Delta^{9}$-THC, anandamide behaves as a $\mathrm{CB}_{1}$ and $\mathrm{CB}_{2}$ receptor partial agonist and displays lower relative intrinsic activity for $\mathrm{CB}_{2}$ than for $\mathrm{CB}_{1}$. Its affinity for the $\mathrm{CB}_{1}$ receptor is also similar to that of $\Delta^{9}$-THC. This eicosanoid does, however, have slightly lower receptor affinity for $\mathrm{CB}_{2}$ than for $\mathrm{CB}_{1}$ and consequently displays less affinity for the $\mathrm{CB}_{2}$ receptor than $\Delta^{9}$-THC. 2-AG also has slightly less receptor affinity for $\mathrm{CB}_{2}$ than for $\mathrm{CB}_{1}$. It seems to have lower $\mathrm{CB}_{1}$ receptor potency than CP55940 but higher $\mathrm{CB}_{1}$ and $\mathrm{CB}_{2}$ receptor potency than anandamide and higher $\mathrm{CB}_{1}$ receptor relative intrinsic activity than anandamide or CP55940.

2. $\mathrm{CB}_{1^{-}}$and $\mathrm{CB}_{2}$-Selective Cannabinoid Receptor Agonists. Compounds that are significantly more potent at activating $\mathrm{CB}_{1}$ than $\mathrm{CB}_{2}$ receptors include three synthetic analogs of anandamide (Table 1 and Fig. 2): $R-(+)-$ methanandamide, arachidonyl-2'-chloroethylamide (ACEA), and arachidonylcyclopropylamide (Abadji et al., 1994; Hillard et al., 1999). Each of these compounds possesses significant 

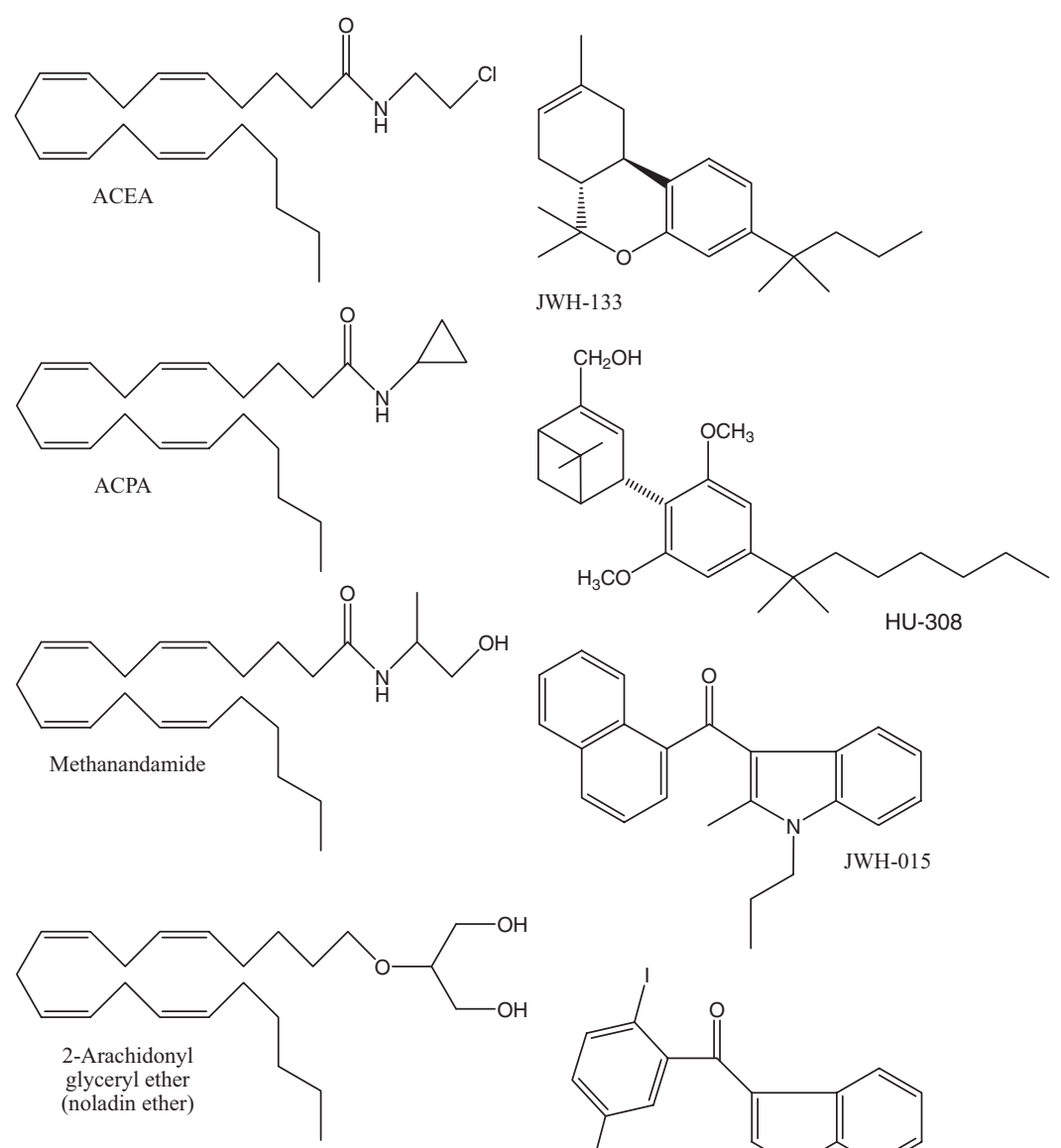<smiles>CCCn1c(C)c(C(=O)c2cccc3ccccc23)c2ccccc21</smiles>

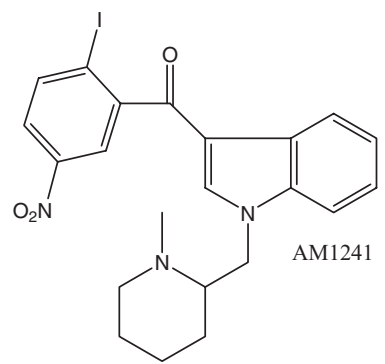

FIG. 2. The structures of the $\mathrm{CB}_{1}$-selective agonists ACEA, arachidonylcyclopropylamide (ACPA), methanandamide, and noladin ether and of the $\mathrm{CB}_{2}$-selective agonists JWH-133, HU-308, JWH-015, and AM1241.

potency and relative intrinsic activity as a $\mathrm{CB}_{1}$ receptor agonist. ACEA and arachidonylcyclopropylamide are both substrates for the anandamide-metabolizing enzyme fatty acid amide hydrolase, whereas this enzyme does not readily hydrolyze $R$-(+)-methanandamide. Noladin ether (2-arachidonyl glyceryl ether) (Hanus et al., 2001) is also a $\mathrm{CB}_{1}$-selective agonist. It has been reported to possess CP55940-like $\mathrm{CB}_{1}$ receptor relative intrinsic activity but less potency as a $\mathrm{CB}_{1}$ receptor agonist than either CP55940 or 2-AG (Suhara et al., 2000, 2001; Savinainen et al., 2001, 2003). As to $\mathrm{CB}_{2}$-selective agonists (Table 1 and Fig. 2), those most frequently used as pharmacological tools are $(6 \mathrm{a} R, 10 \mathrm{a} R)$-3-(1,1-dimethylbutyl)6a,7,10,10a-tetrahydro-6,6,9-trimethyl-6H-dibenzo[b, $d]$ pyran (JWH-133; a classical cannabinoid), \{4-[4-(1, 1-dimethylheptyl)-2,6-dimethoxy-phenyl]-6,6-dimethylbicyclo[3.1.1] hept-2-en-2-yl\}-methanol (HU-308; a nonclassical cannabinoid), and (2-methyl-1-propyl$1 H$-indol-3-yl)-1-naphthalenylmethanone (JWH-015) and $R$-3-(2-iodo-5-nitrobenzoyl)-1-methyl-2-piperidinylmethyl)- $1 H$-indole (AM1241) (aminoalkylindoles) (for review, see Pertwee, 1999, 2005a, 2008b; Howlett et al., 2002).
3. $C B_{1}$-Selective Competitive Antagonists. As discussed in greater detail elsewhere (Pertwee, 1999, 2005a, 2008b; Howlett et al., 2002; Fong et al., 2007), the diarylpyrazole rimonabant (SR141716A), $N$-(piperidin-1-yl)-5-(4-iodophenyl)-1-(2,4-dichlorophenyl)-4-methyl-1H-pyrazole-3-carboxamide (AM251), 1-(2,4-dichlorophenyl)-5-(4-iodophenyl)-4-methyl- $N$-4morpholinyl- $1 H$-pyrazole-3-carboxamide (AM281), 4-[[6methoxy-2-(4-methoxyphenyl)-3-benzofuranyl]carbonyl] benzonitrile (LY320135), and taranabant (Fig. 3) can all block agonist-induced activation of cannabinoid $\mathrm{CB}_{1}$ receptors in a competitive manner and bind with significantly greater affinity to cannabinoid $\mathrm{CB}_{1}$ than cannabinoid $\mathrm{CB}_{2}$ receptors (Table 1 ). Although these compounds lack any ability to activate $\mathrm{CB}_{1}$ receptors when administered alone, there is evidence that in some $\mathrm{CB}_{1}$ receptor-containing tissues, they can induce responses opposite in direction from those elicited by a $\mathrm{CB}_{1}$ receptor agonist (Pertwee, 2005c; Fong et al., 2007). In some instances, at least, this may reflect an ability of these compounds to decrease the spontaneous coupling of $\mathrm{CB}_{1}$ receptors to their effector mechanisms that it is thought can occur in the absence of 
<smiles>Cc1c(C(=O)NN2CCCCC2)nn(-c2ccc(Cl)cc2Cl)c1-c1ccc(I)cc1C(=O)NN1CCCCC1</smiles><smiles>COc1ccc(-c2oc3cc(OC)ccc3c2C(=O)c2ccc(C#N)cc2)cc1</smiles>

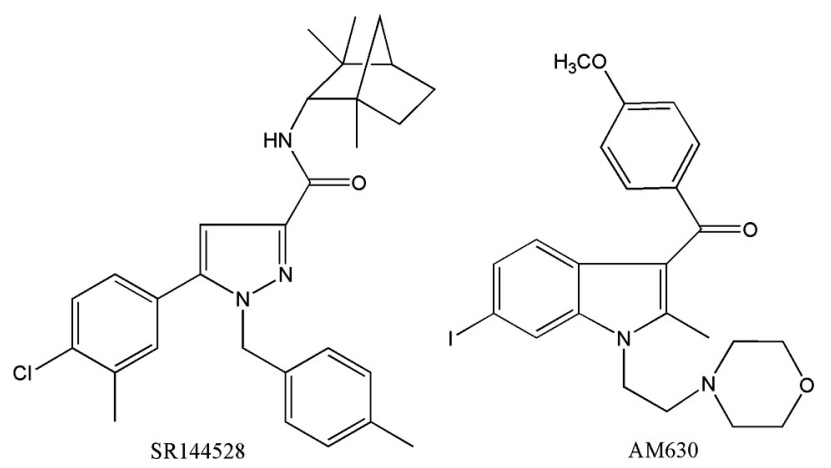

FIG. 3. The structures of the $\mathrm{CB}_{1}$-selective antagonists/inverse agonists, rimonabant, AM251, AM281, LY320135, and taranabant and of the $\mathrm{CB}_{2}$-selective antagonists/inverse agonists SR144528 and AM630.

exogenously added or endogenously released $\mathrm{CB}_{1}$ agonists. There is also evidence that at least one of these compounds, rimonabant, can produce inverse cannabimimetic effects in a $\mathrm{CB}_{1}$ receptor-independent manner (Breivogel et al., 2001; Savinainen et al., 2003; Cinar and Szücs, 2009).

Some $\mathrm{CB}_{1}$ receptor competitive antagonists have been developed that lack any detectable ability to induce signs of inverse agonism at the $\mathrm{CB}_{1}$ receptor when administered alone. One example of such a "neutral" antagonist (Table 1 ) is $N$-piperidinyl-[8-chloro-1-(2,4-dichlorophenyl)-1,4,5, 6-tetrahydrobenzo[6,7]cyclohepta[1,2-c]pyrazole-3-carboxamide] (NESS O327) (Fig. 4), which is a structural analog of rimonabant and displays markedly higher affinity for $\mathrm{CB}_{1}$ than for $\mathrm{CB}_{2}$ receptors. This compound behaves as $\mathrm{CB}_{1}$ receptor antagonist both in vitro and in vivo and yet, by itself, does not affect $\left[{ }^{35} \mathrm{~S}\right] \mathrm{GTP} \gamma \mathrm{S}$ binding to rat cerebellar membranes (Ruiu et al., 2003). Several other compounds have been reported to behave as neutral cannabinoid $\mathrm{CB}_{1}$ receptor antagonists (Pertwee, 2005a). These include $(6 \mathrm{a} R, 10 \mathrm{a} R)$-3-(1-methanesulfonylamino-4-

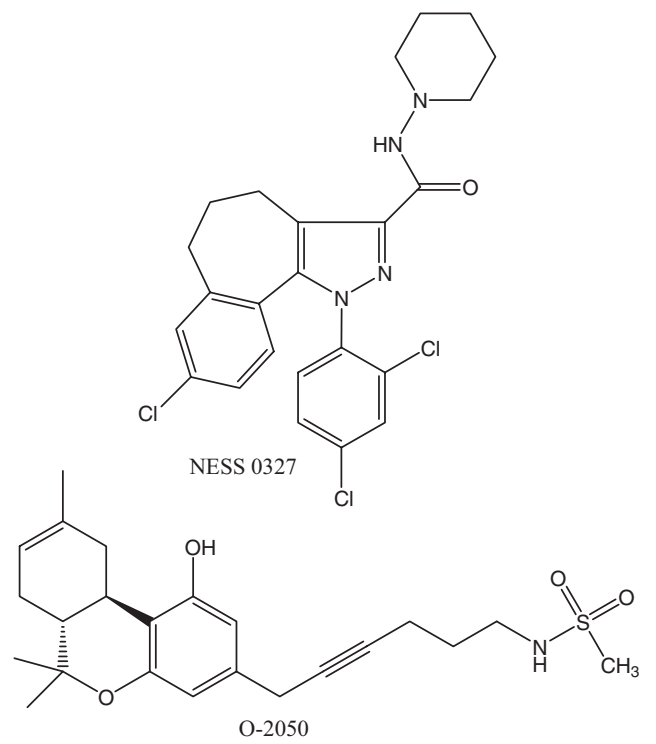

FIG. 4. The structures of NESS O327 and O-2050. 
hexyn-6-yl)-6a, 7,10,10a-tetrahydro-6,6,9-trimethyl$6 H$-dibenzo[b,d]pyran (O-2050) (Fig. 4), a sulfonamide analog of $\Delta^{8}$-tetrahydrocannabinol with an acetylenic side chain. It is noteworthy that the classification of this compound as a neutral antagonist is based on a very limited set of data, prompting a need for further research into its $\mathrm{CB}_{1}$ receptor pharmacology.

4. $\mathrm{CB}_{2}$-Selective Competitive Antagonists. [6-Iodo-2methyl-1-[2-(4-morpholinyl)ethyl]- $1 H$-indol-3-yl] (4-methoxyphenyl)methanone (6-iodopravadoline) (AM630) and the diarylpyrazole $N$-[(1S)-endo-1,3,3trimethyl bicyclo [2.2.1]heptan-2-yl]-5-(4-chloro-3methylphenyl)-1-(4-methylbenzyl)-pyrazole-3-carboxamide (SR144528) (Fig. 3) are both more potent at blocking $\mathrm{CB}_{2}$ than $\mathrm{CB}_{1}$ receptor activation. They display much higher affinity for $\mathrm{CB}_{2}$ than for $\mathrm{CB}_{1}$ receptors (Table 1) and block agonist-induced $\mathrm{CB}_{2}$ receptor activation in a competitive manner (for review, see Pertwee, 1999, 2005a, 2008b; Howlett et al., 2002). Both these compounds are thought to be $\mathrm{CB}_{2}$ receptor inverse agonists rather than neutral antagonists, because when administered by themselves, they can produce inverse cannabimimetic effects in $\mathrm{CB}_{2}$ receptor-expressing tissues (RinaldiCarmona et al., 1998; Ross et al., 1999). Other notable examples of $\mathrm{CB}_{2}$-selective cannabinoid receptor antagonists/ inverse agonists include $N$-(1,3-benzodioxol-5-ylmethyl)-1,2dihydro-7-methoxy-2-oxo-8-(pentyloxy)-3-quinolinecarboxamide (JTE-907) (Iwamura et al., 2001) (Table 1) and the triaryl bis-sulfones $N$-[1(S)-[4-[[4-methoxy-2-[(4-methoxyphenyl)sulfonyl]phenyl] sulfonyl]phenyl]ethyl]methanesulfonamide) (Sch.225336), N-[1(S)-[4-[[4-chloro-2-[(2fluorophenyl)sulfonyl]phenyl] sulfonyl]phenyl]ethyl] methanesulfonamide (Sch.356036), and $N$-[1(S)-[4-[[4chloro-2-[(2-fluorophenyl)sulfonyl]phenyl] sulfonyl]phenyl] ethyl]-1,1,1-trifluoromethanesulfonamide (Sch.414319) (for review, see Lunn et al., 2008). A neutral antagonist that selectively targets the $\mathrm{CB}_{2}$ receptor has not yet been developed.

5. Other Compounds. Several other compounds that target cannabinoid $\mathrm{CB}_{1}$ and/or $\mathrm{CB}_{2}$ receptors with significant potency are mentioned in one or more subsequent sections of this review. The structures of these compounds and their affinities for $\mathrm{CB}_{1}$ and/or $\mathrm{CB}_{2}$ receptors are shown in Fig. 5 and Table 1, respectively. Two of these compounds, 11-hydroxy- $\Delta^{8}$-tetrahydrocannabinol and ajulemic acid (CT-3), are classical cannabinoids. 11-Hydroxy- $\Delta^{8}$-tetrahydrocannabinol possesses slightly greater potency than $\Delta^{9}$-THC as an inhibitor of adenylyl cyclase in murine neuroblastoma cells (Howlett, 1987). Compared with CP55940, ajulemic acid displays similar relative intrinsic activity but lower potency at both $\mathrm{CB}_{1}$ and $\mathrm{CB}_{2}$ receptors (Dyson et al., 2005). Three of the other compounds are plant cannabinoids (phytocannabinoids). They include cannabinol, which seems to be a $\mathrm{CB}_{1}$ receptor partial agonist (for review, see Pertwee, 1999). There have also been reports that cannabinol behaves as a reasonably potent $\mathrm{CB}_{2}$ receptor agonist in the cAMP assay but as a $\mathrm{CB}_{2}$ receptor inverse agonist in the $\left[{ }^{35} \mathrm{~S}\right] \mathrm{GTP} \gamma \mathrm{S}$ assay (for review, see Pertwee, 1999). The other two phytocannabinoids, cannabidiol and cannabigerol, seem to be $\mathrm{CB}_{1}$ receptor antagonists/inverse agonists (Thomas et al., 2007; Cascio et al., 2010). In contrast, two structural analogs of cannabidiol, abnormal-cannabidiol and 5-methyl-4-[(1R,6R)-3-methyl-6(prop-1-en-2-yl)cyclohex-2-enyl]benzene-1,3-diol (O1602) (Fig. 5) that are mentioned in sections III.A.6, III.A.7, III.A.8, and/or III.H.2, lack significant affinity for the $C_{1}$ receptor (for review, see Pertwee, 2004, 2005a). Cannabidiol has also been reported to display significant potency in vitro as a $\mathrm{CB}_{2}$ receptor antagonist/inverse agonist (for review, see Thomas et al., 2007).

Two other compounds listed in Table 1 are the endogenous eicosanoids virodhamine and $N$-arachidonoyl dopamine. In one investigation, virodhamine was found to activate $\mathrm{CB}_{2}$ receptors and to exhibit either partial agonist or antagonist activity at $\mathrm{CB}_{1}$ receptors (Porter et al., 2002). However, in another investigation, it was found to behave as a $\mathrm{CB}_{1}$ receptor antagonist/inverse agonist (Steffens et al., 2005). As for $N$-arachidonoyl dopamine, there is evidence that this is a moderately potent $\mathrm{CB}_{1}$ receptor agonist (for review, see Bradshaw and Walker, 2005). It is also noteworthy that $N$-oleoyl dopamine (sections III.B and III.E) possesses some affinity for the $\mathrm{CB}_{1}$ receptor (Bradshaw and Walker, 2005). However, four other pharmacologically active endogenous acylethanolamides mentioned in sections III and/or IV do not seem to display significant affinity for $\mathrm{CB}_{1}$ and/or $\mathrm{CB}_{2}$ receptors. These are linoleoyl ethanolamide, oleoyl ethanolamide, palmitoyl ethanolamide, and stearoyl ethanolamide (Lin et al., 1998; Maccarrone et al., 2002; Pertwee, 2004; Bradshaw and Walker, 2005). There have been reports too by Yin et al. (2009) and Kapur et al. (2009) that neither $\mathrm{CB}_{1}$ nor $\mathrm{CB}_{2}$ receptors are activated by the putative endogenous GPR55 agonist lysophosphatidyl inositol (section III.A).

\section{D. $C B_{1}$ Receptor Homomers and Heteromers: Nomenclature and Pharmacology}

1. $C B_{1}$ Receptor Homomers. $\mathrm{CB}_{1}$ receptor homomers were originally identified as immunoreactive, high apparent molecular mass $(180-220 \mathrm{kDa})$ bands on SDS-polyacrylamide gel electrophoresis (Mukhopadhyay et al., 2000). The multimeric form from rat brain and mouse neuroblastoma cells was resistant to dissociation by conditions expected to disrupt disulfide bonds, or ionic or hydrophobic protein interactions in detergent solution (Mukhopadhyay et al., 2000). However, the multimeric form from post mortem human brain seemed to be sensitive to sulfhydryl reagents when solubilized (De Jesús et al., 2006). An antibody that selectively recognized the high molecular mass form was used to determine that $\mathrm{CB}_{1}$ multimers exhibited the same anatomical distribution as mixed forms in the brain, lending credence to the idea that $\mathrm{CB}_{1}$ receptors exist as homomers in vivo (Wager-Miller et al., 2002; 


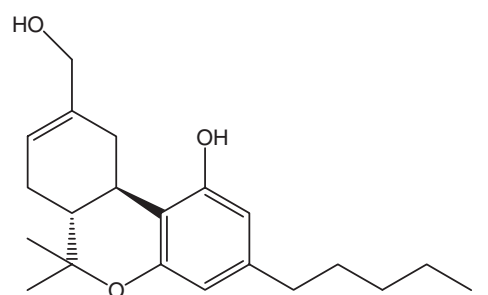

11-Hydroxy- $\Delta^{8}$-tetrahydrocannabinol<smiles>CCCCCc1cc(O)c2c(c1)OC(C)(C)c1ccc(C)cc1-2</smiles>

Cannabinol<smiles>CCCCCc1cc(O)c(CC=C(C)CCC=C(C)C)c(O)c1</smiles>
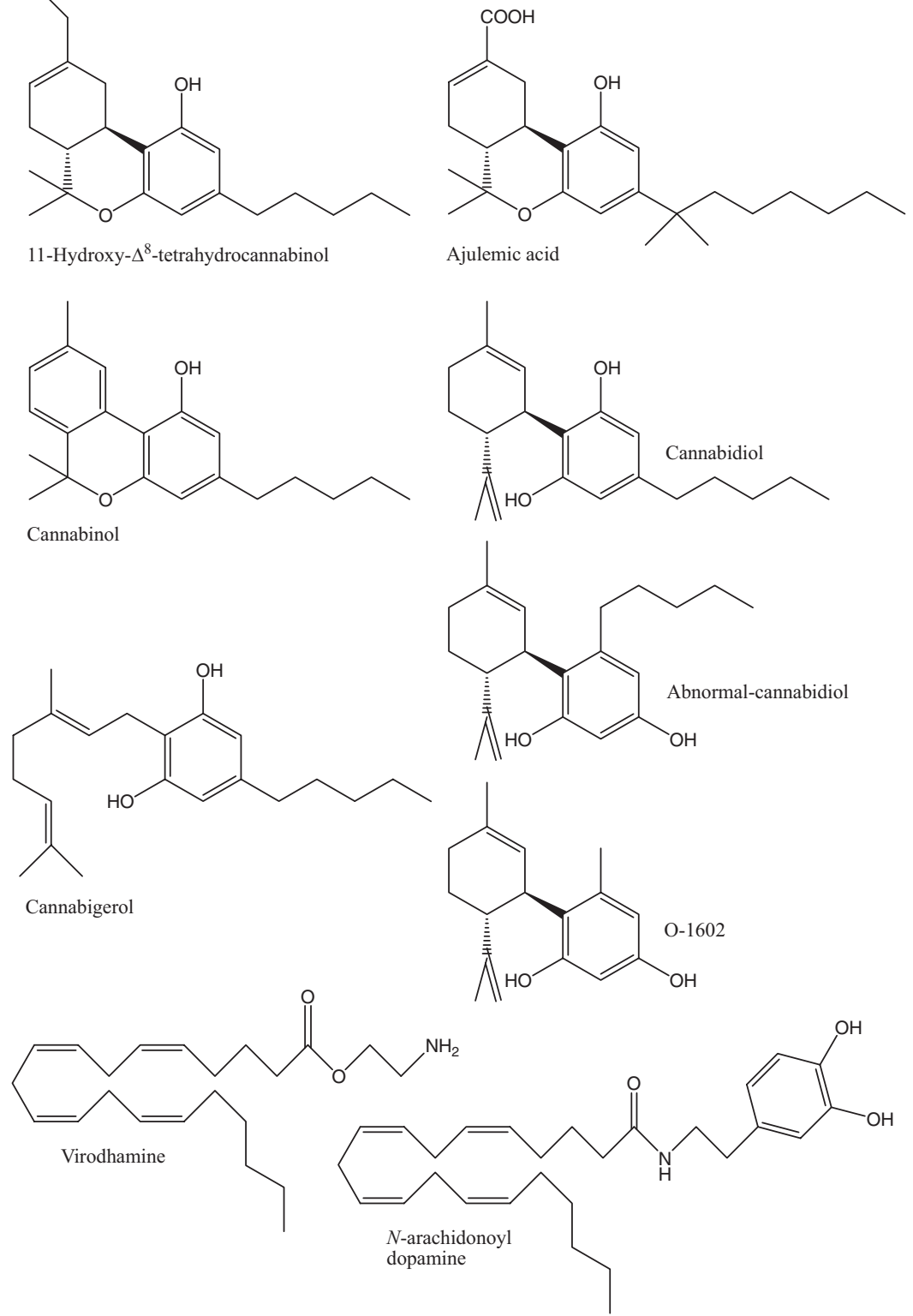<smiles>CCCCCc1cc(O)cc(O)c1[C@@H]1C=C(C)CC[C@H]1CC</smiles><smiles>CC1=CC(c2c(C)cc(O)cc2O)[C@H](C2CC2)CC1</smiles>

FIG. 5. The structures of (-)-11-hydroxy- $\Delta^{8}$-tetrahydrocannabinol, ajulemic acid, cannabinol, cannabidiol, abnormal-cannabidiol, O-1602, cannabigerol, virodhamine, and $N$-arachidonoyl dopamine.

Mackie, 2005). Insufficient evidence currently exists to allow any firm conclusions to be drawn about whether monomeric and homomeric forms exhibit differential signal transduction or intracellular trafficking patterns, or how interconversion is physiologically regulated.

2. $C B_{1}$ Receptor Heteromers: A Brief Introduction. $\mathrm{CB}_{1}$ receptors associate with other GPCRs to form heteromeric complexes (within 50-100 $\AA$ ) as detected by fluorescence (FRET) or bioluminescence resonance energy transfer (Ellis et al., 2006; Rios et al., 2006; Carriba et al., 2008; Marcellino et al., 2008). Guidelines for the nomenclature of associated GPCR proteins define receptor heteromers as "macromolecular complexes composed of functional receptor units with biochemical properties that are different from those of its individual components" (Ferré et al., 2009a). A multimeric complex would be expected to influ- 
agonist quinpirole, or both together (Marcellino et al., 2008). However, coimmunoprecipitatable complexes solubilized from a HEK293 cell heterologous expression system were promoted by the presence of agonists for both $\mathrm{D}_{2}$ and $\mathrm{CB}_{1}$ receptors (Kearn et al., 2005). Signal transduction in response to agonist stimulation of either $\mathrm{CB}_{1}$ or $\mathrm{D}_{2}$ receptors expressed alone in HEK293 cells is characterized by the $\mathrm{G}_{\mathrm{i} / \mathrm{o}}$-dependent inhibition of forskolin-activated adenylyl cyclase (Jarrahian et al., 2004; Kearn et al., 2005). However, coexpression of both $\mathrm{CB}_{1}$ and $\mathrm{D}_{2}$ receptors caused the effect of CP55940 on cAMP production to switch from inhibition to stimulation (Jarrahian et al., 2004). Combining agonists for both $\mathrm{CB}_{1}$ and $\mathrm{D}_{2}$ receptors also promoted a stimulation of cAMP accumulation when both receptors were expressed (Kearn et al., 2005). Synergistic activation of MAPK was also observed in response to simultaneous stimulation by both cannabinoid and dopaminergic agonists (Kearn et al., 2005). Neither the stimulation of cAMP production nor the activation of MAPK was pertussis toxin-sensitive, suggesting that $\mathrm{G}_{\mathrm{i} / \mathrm{o}}$ proteins were not required for the heterodimer responses to agonists in the HEK293 cell model (Kearn et al., 2005). However, $\mathrm{G} \alpha_{\mathrm{i} 1}$ overexpression inhibited cAMP production, suggesting that $C B_{1}-D_{2}$ receptor heteromers could interact with $\mathrm{G}_{\mathrm{s}}$ only if the environment is not rich in $\mathrm{G}_{\mathrm{i}}$ (Jarrahian et al., 2004). Desensitization of the $\mathrm{D}_{2}$-dopamine receptors by pretreatment with quinpirole reversed the ability of CP55940 to stimulate cAMP production (Jarrahian et al., 2004). Evidence can be found to support the hypothesis that $\mathrm{CB}_{1}-\mathrm{D}_{2}$ receptor heteromers function in vivo to convert the $G$ protein preference from $G_{i}$ to $G_{s}$. CP55940 decreased the high and low $K_{\mathrm{d}}$ affinities for dopamine (a function of the receptor-G protein interaction) in equilibrium binding assays of $\mathrm{D}_{2}$ receptors in rat striatal membranes (Marcellino et al., 2008). Cannabinoid and $\mathrm{D}_{2}$ agonists converged to inhibit forskolin-activated adenylyl cyclase as a subadditive response in rodent and monkey striatal membranes (Meschler and Howlett, 2001). In cultured striatal cells, costimulation by dopaminergic and cannabinoid agonists converted the response from a $\mathrm{G}_{\mathrm{i}}{ }^{-}$ mediated inhibition to a $\mathrm{G}_{\mathrm{s}}$-mediated stimulation of cAMP production (Glass and Felder, 1997). $R$-(+)-WIN55212stimulation was reported to increase cAMP accumulation in globus pallidus slices (Maneuf and Brotchie, 1997). Observations of cannabinoid-stimulated protein kinase A activation suggests that cAMP production is a viable signaling mechanism in basal ganglia (Andersson et al., 2005; Borgkvist et al., 2008). However, caution should be observed in interpreting in vivo data, in that $\mathrm{D}_{1}$ dopamine (Bidaut Russell and Howlett, 1991; Meschler and Howlett, 2001) and $A_{2 A}$ adenosine receptors (Carriba et al., 2007, 2008; Marcellino et al., 2008) might contribute as components of a heteromeric complex. Immunocytochemical studies suggest that coexpression of $\mathrm{CB}_{1}$ and $\mathrm{D}_{2}$ receptors occurs on the output neurons of the olfactory tubercle, striatum, hippocampus, or neocortex (Hermann et al., 2002). Colocalization of $\mathrm{CB}_{1}$ and $\mathrm{D}_{2}$ receptors has been clearly identified in immunoelectron micrographs at the plasma membrane and endomembrane in dendritic spines in the nucleus accumbens (Pickel et al., 2006). However, it should be noted that these receptors can also be found individually distant from each other in the same soma or dendrite, or trans-synaptically (Pickel et al., 2006).

4. $C B_{1}$-Opioid Receptor Heteromers. $\mathrm{CB}_{1}$-opioid receptor heteromer formation was detected by an increased bioluminescence resonance energy transfer signal in HEK293 cells coexpressing recombinant yellow fluorescent protein-tagged $\mathrm{CB}_{1}$ and luciferase fused with $\mu$-, $\delta$-, or $\kappa$-opioid receptors (Rios et al., 2006). However, functional interaction between $\mathrm{CB}_{1}$ and opioid receptors has thus far been reported only for the $\mathrm{CB}_{1}-\mu$-opioid receptor pair. $\mathrm{CB}_{1^{-}}$ $\mu$-opioid receptor association may be a factor in intracellular compartmentalization (Canals and Milligan, 2008). Morphine-stimulated $\left.{ }^{35} \mathrm{~S}\right] \mathrm{GTP} \gamma \mathrm{S}$ binding in HEK293 cells coexpressing $\mathrm{CB}_{1}$ receptors and $\mu$-opioid receptors was attenuated by $R$-(+)-WIN55212 when calculated as a percentage of basal binding (Rios et al., 2006). However, coexpression of $\mathrm{CB}_{1}$ receptors with $\mu$-opioid receptors in HEK293 cells increased basal $\left[{ }^{35} \mathrm{~S}\right] \mathrm{GTP}$ SS binding such that subsequent stimulation by the $\mu$-opioid receptor agonist $\left[\mathrm{D}-\mathrm{Ala}^{2}, N-\mathrm{Me}-\mathrm{Phe}^{4}, \mathrm{Gly}^{5}\right.$-ol]-enkephalin (DAMGO) seemed to be reduced with respect to basal levels (Canals and Milligan, 2008). Basal $\left[{ }^{35} \mathrm{~S}\right] \mathrm{GTP} \gamma \mathrm{S}$ binding in the $\mathrm{CB}_{1}$ expressing cells was reversed by the $\mathrm{CB}_{1}$ antagonist LY320135, suggesting that the exogenously expressed $\mathrm{CB}_{1}$ receptors were able to constitutively activate a pool of $G$ proteins (Canals and Milligan, 2008). $\mathrm{CB}_{1}$ receptor expression could constitutively reduce morphine- or DAMGOstimulated MAPK activation in the absence of cannabinoid agonists, and this effect could be blocked by rimonabant but not by the putative neutral $\mathrm{CB}_{1}$ receptor antagonist, O-2050 (Canals and Milligan, 2008). Cannabinoid or opioid agonist actions in the coexpressed receptor model mutually reduced the ability of agonists at the heteroreceptor to activate MAPK (Rios et al., 2006). In Neuro-2A cells expressing $\mathrm{CB}_{1}$ receptors and $\mu$-opioid receptors, simultaneous application of agonists for both receptors suppressed Src and signal transducer and activator of transcription 3 phosphorylation and neurite outgrowth in a reciprocal manner. These findings, in total, would be consistent with mutual heterotropic allosterism. Nevertheless, caution must be exercised when interpreting signal transduction outcomes in heterologous expression systems, because the influence of membrane localization, protein stoichiometry, and accessory proteins may be missing (Shapira et al., 1998, 2000). Finally, $\mathrm{CB}_{1}-\mu$-opioid receptor heteromers may function in cellular models that endogenously express both receptors. In SK-N-SH neuroblastoma and rat striatal membranes, stimulation of $\left[{ }^{35} \mathrm{~S}\right] \mathrm{GTP} \gamma \mathrm{S}$ binding by the $\mathrm{CB}_{1}$ agonist $R$-(+)-WIN55212 was reduced by the $\mu$-opioid receptor agonist DAMGO, as was DAMGO-induced stimulation of $\left[{ }^{35} \mathrm{~S}\right] \mathrm{GTP} \gamma \mathrm{S}$ binding by $R$-(+)-WIN55212 (Rios et al., 2006). Furthermore, immunoelectron microscopy studies demonstrated that $\mathrm{CB}_{1}$ receptors and $\mu$-opioid recep- 
tors colocalize in dendritic spines of the medium spiny neurons of the striatum as well as in interneurons of the dorsal horn of the spinal cord (Rodríguez et al., 2001; Salio et al., 2001; Pickel et al., 2004). However, in interpreting in vivo data, researchers should be cognizant that these receptors are also distributed individually and transsynaptically (Pickel et al., 2004).

5. $\mathrm{CB}_{1}$-Orexin-1 Receptor Heteromers. Evidence for $\mathrm{CB}_{1}$-orexin-1 (OX1) receptor heteromers comes from observations that when expressed in $\mathrm{CHO}$ cells, these receptors appear as clusters at the plasma membrane in immunoelectron micrographs (Hilairet et al., 2003). FRET studies demonstrated close proximity of the $\mathrm{CB}_{1}$ - and OX1-fluorescent fusion proteins expressed in HEK293 cells (Ellis et al., 2006). Although agonists activated MAPK in both of these receptors when expressed individually in CHO cells, coexpression resulted in a 100 -fold increase in MAPK sensitivity to orexin $\mathrm{A}$, a response that was reversed by the $\mathrm{CB}_{1}$ antagonist rimonabant or by pertussis toxin treatment (Hilairet et al., 2003). On the other hand, coexpression had no appreciable effect on the potency of CP55940 to stimulate MAPK or to inhibit adenylyl cyclase (Hilairet et al., 2003). $\mathrm{CB}_{1}$ and $\mathrm{OX} 1$ receptors were coexpressed predominantly in intracellular vesicles (Ellis et al., 2006). Treatment with antagonists for either receptor $\left(\mathrm{CB}_{1}\right.$, rimonabant; OX1, SB674042) promoted trafficking of both receptors to the cell surface (Ellis et al., 2006), suggesting that $\mathrm{CB}_{1}-\mathrm{OX} 1$ receptor heteromerization influences cellular translocation of these receptors.

6. Other $C B_{1}$ Receptor Heteromers. Evidence that $\mathrm{CB}_{1}$ and GPCRs, in addition to $\mathrm{D}_{2}$, opioid, or OX1 receptors, may form receptor heteromers is based upon pharmacological cross-talk data, and until other kinds of data become available to support the existence of receptor heteromers, judgement on these pairs must be withheld. The $\mathrm{GABA}_{\mathrm{B}}$ antagonist phaclofen noncompetitively antagonized $R$-(+)-WIN55212-stimulated $\left[{ }^{35} \mathrm{~S}\right] \mathrm{GTP} \gamma \mathrm{S}$ binding in hippocampal membranes, and a $\mathrm{CB}_{1}$ antagonist competitively antagonized the response to 3 -aminopropyl(methyl) phosphinic acid (SKF97541) (Cinar et al., 2008). Agoniststimulation of $\mathrm{CB}_{1}$ and $\mathrm{GABA}_{\mathrm{B}}$ receptors, both endogenously expressed in cerebellar granule cells, resulted in a subadditive inhibition of adenylyl cyclase (Childers et al., 1993.; Pacheco et al., 1993). The response to agonists for $\alpha_{2}$-adrenoceptor- or somatostatin receptor-mediated inhibition of $\mathrm{N}$-type $\mathrm{Ca}^{2+}$ channels was reduced by expression of exogenous $\mathrm{CB}_{1}$ receptors in superior cervical ganglia neurons (Pan et al., 1998; Vásquez and Lewis, 1999). This effect of $\mathrm{CB}_{1}$ receptor expression could be reversed by overexpression of exogenous $\mathrm{G} \alpha_{\mathrm{oB}}, \mathrm{G} \beta_{1}$, and $\mathrm{G} \gamma_{3}$ (Vásquez and Lewis, 1999), suggesting that these receptors may exist in a complex with shared $\mathrm{G}_{\mathrm{i} / \mathrm{o}}$ proteins required for $\mathrm{Ca}^{2+}$ channel regulation. The multiplicity of possible receptor "modules" that comprise functional units of signal transduction activity with other receptors, ion channels, and signal transducing effectors points to the complexity involved in interpreting data from in vivo studies (Fuxe et al., 2008; Ferré et al., 2009b). Future investigations must determine the proximity of these receptors to each other, and provide definitive evidence for heterotropic allosteric interactions before these protein pairs can be advanced as receptor heteromer candidates.

\section{The Extent to Which $\mathrm{CB}_{1}$ and $\mathrm{CB}_{2}$ Receptor Ligands Target Non-CB , Non-CB $_{2}$ Receptors and Ion Channels}

\section{A. The Deorphanized G Protein-Coupled Receptor, GPR55}

Human GPR55 (hGPR55) was originally isolated in 1999 as an orphan GPCR with high levels of expression in human striatum (Sawzdargo et al., 1999) (GenBank accession no. NM_005683.3) and its gene mapped to human chromosome 2q37. GPR55 belongs to group $\delta$ of the rhodopsin-like (class A) receptors (Fredriksson et al., 2003b) and shows low sequence identity to both $\mathrm{CB}_{1}(13.5 \%)$ and $\mathrm{CB}_{2}(14.4 \%)$ receptors, which belong to group $\alpha$ of the class A GPCRs. A genetics study (McPartland et al., 2006) has investigated the origins of the cannabinoid system and has concluded with respect to GPR55 that there is no significant sequence similarity between itself and $\mathrm{CB}_{1}$ or $\mathrm{CB}_{2}$. In particular, there is little sequence similarity in the areas responsible for ligand binding. Initial characterization of human GPR55 identified it as a potential member of either the purinergic or chemokine receptor family based on amino acid homology. However, it is most closely related (30\% similarity) to GPR23/LPA 4 (GenBank accession no.

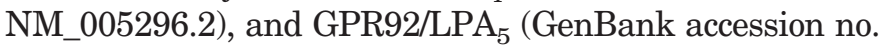
NM_ 020400.5) which have been shown to be lysophosphatidic acid (LPA) receptors (Noguchi et al., 2003; Kotarsky et al., 2006; Lee et al., 2006) (sections III.B.4 and III.B.5). It also shares $29 \%$ identity with $\mathrm{P} 2 \mathrm{Y} 5 / \mathrm{LPA}_{6}$ (GenBank accession no. NM_005767.4), also shown to be a LPA receptor (Pasternack et al., 2008), 27\% identity with GPR35 (GenBank accession no. NM_005301.2), and 23\% identity with the CCR4 chemokine receptor (GenBank accession no. NM_005508.4) (Sawzdargo et al., 1999).

1. Reported Pharmacology of GPR55. The current pharmacology of ligands at GPR55 is complicated and inconsistent. There are 11 reports containing data relating to ligand activity at GPR55. These reports use eight different cell backgrounds and six different assay endpoints that are all dependent on functional assays. So far, no binding data have been published. There are few examples of more than one laboratory repeating similar studies using equivalent cell background and assay technology. A range of assay strategies have been used to investigate the pharmacology of GPR55 and the mechanism of downstream signaling by this receptor remains uncertain. Using an approach that uses 12-amino acid peptides equivalent to the $\mathrm{C}$-terminal sequences of the $\mathrm{G}$ proteins $\mathrm{G} \alpha_{\mathrm{i} 1 / 2}, \mathrm{G} \alpha_{\mathrm{i} 3}, \mathrm{G} \alpha_{\mathrm{s}}$, and $\mathrm{G} \alpha_{13}$, as well as antibodies raised against those same peptides, it was demonstrated that the $\mathrm{G}$ protein preferentially coupling to GPR55 in $\left[{ }^{35} \mathrm{~S}\right] \mathrm{GTP} \gamma \mathrm{S}$ binding assays was $\mathrm{G} \alpha_{13}$ 
(Ryberg et al., 2007). GPR55 has also been shown by other methods to use $G_{q}, G_{12}$, or $G_{13}$ for signal transduction, which results in downstream activation of RhoA and PLC (Lauckner et al., 2008; Henstridge et al., 2009; Kapur et al., 2009). This signaling mode is associated with temporal changes in cytoplasmic calcium, membrane-bound diacylglycerol, and plasma membrane topology. Involvement of the actin cytoskeleton has also been reported by Lauckner et al. (2008). The reported activities of different ligands at GPR55 in various assays are summarized below and in Table 2.

2. Anandamide. The endocannabinoid ligand anandamide (section II.C.1) possesses significant affinity for both $\mathrm{CB}_{1}$ and $\mathrm{CB}_{2}$ receptors with slightly greater affinity for $\mathrm{CB}_{1}$ than for $\mathrm{CB}_{2}$ (Table 1). Using a $\left[{ }^{35} \mathrm{~S}\right] \mathrm{GTP} \gamma \mathrm{S}$ binding assay, Ryberg et al. (2007) found that this ligand has an $\mathrm{EC}_{50}$ of 18 $\mathrm{nM}$ at GPR55 expressed in HEK293 cells and that it seems to have a higher potency for GPR55 than for either $\mathrm{CB}_{1}$ or $\mathrm{CB}_{2}$. Employing calcium mobilization assays, several other groups have demonstrated anandamide-induced GPR55 activation in HEK293 cells at a concentration of $5 \mu \mathrm{M}$ and in EA.hy926 cells $\left(\mathrm{EC}_{50}=7.3 \mu \mathrm{M}\right)$, suggesting lower or similar potency to that reported for anandamide at $\mathrm{CB}_{1}$ and $\mathrm{CB}_{2}$ receptors (Lauckner et al., 2008; Waldeck-Weiermair et al., 2008). Henstridge et al. (2009) have also reported calcium oscillations in response to anandamide treatment in GPR55-expressing HEK293 cells. However, they could not demonstrate specificity for GPR55 because similar oscillations were seen in untransfected control cells. In contrast, three groups have reported that anandamide did not increase ERK1/2 phosphorylation via GPR55 in either HEK293 or U2OS cells (Oka et al., 2007, 2009; Lauckner et al., 2008; Kapur et al., 2009), whereas Waldeck-Weiermair et al. (2008) did observe ERK1/2 phosphorylation at $10 \mu \mathrm{M}$ in EA.hy926 cells. Several groups have also used $\beta$-arrestin and internalization assays to assess the properties of anandamide at GPR55. Although Yin et al. (2009) reported weak agonist activity by anandamide, Kapur et al. (2009) found no evidence of anandamide dependent $\beta$-arrestin recruitment or of GPR55 receptor internalization. At $1 \mu \mathrm{M}$, anandamide was shown to activate RhoA in a GPR55-dependent manner in transfected HEK293 cells (Ryberg et al., 2007), whereas Waldeck-Weiermair et al. (2008) have demonstrated nuclear factor of activated T-cell activation using 10 $\mu \mathrm{M}$ anandamide in GPR55-expressing EA.hy926 cells.

3. 2-Arachidonoyl Glycerol. The endocannabinoid ligand 2-AG (section II.C.1) binds to both $\mathrm{CB}_{1}$ and $\mathrm{CB}_{2}$ receptors with slightly greater affinity for $\mathrm{CB}_{1}$ than for $\mathrm{CB}_{2}$ (Table 1). 2-AG has been reported to be a $3 \mathrm{nM}$ agonist of GPR55 in HEK293 cells using $\left[{ }^{35} \mathrm{~S}\right] \mathrm{GTP} \gamma \mathrm{S}$ binding as the assay (Ryberg et al., 2007). However, in contrast to anandamide, no effect on calcium mobilization by $2-\mathrm{AG}$ at $5 \mu \mathrm{M}$ was seen in HEK293 cells (Lauckner et al., 2008). Henstridge et al. (2009) reported calcium oscillations in the presence of 3 to $30 \mu \mathrm{M}$ 2-AG in GPR55-transfected HEK293 cells but could not demonstrate specific involvement of GPR55. 2-AG did not increase ERK1/2 phosphorylation in GPR55-expressing HEK293 or U2OS cells. In addition, 2-AG did not affect either $\beta$-arrestin recruitment

TABLE 2

Reported activities of cannabinoid receptor ligands at recombinant GPR55 in various assays

The structures of all compounds listed are shown in Figures 1-5.

\begin{tabular}{|c|c|c|c|c|c|c|}
\hline Ligand & $\begin{array}{l}{\left[{ }^{35} \text { S }\right] \text { GTP } \gamma \mathrm{S}} \\
\text { Binding }\end{array}$ & $\begin{array}{c}\text { ERK1/2 } \\
\text { Phosphorylation }\end{array}$ & {$\left[\mathrm{Ca}^{2+}\right]_{\mathrm{i}}$ Mobilization } & $\beta$-Arrestin & $\begin{array}{c}\text { GPR55 } \\
\text { Internalization }\end{array}$ & $\begin{array}{c}\text { RhoA } \\
\text { Activation }\end{array}$ \\
\hline LPI & $\mathrm{EC}_{50}=1 \mu \mathrm{M}^{a}$ & $\begin{array}{c}\mathrm{EC}_{50}=200 \mathrm{nM}^{a} \\
1 \mu \mathrm{M}^{d, f} \\
3 \mu \mathrm{M}^{c}\end{array}$ & $\begin{array}{c}30 \mathrm{nM}^{a} \\
3 \mu \mathrm{M}^{g, h} \\
\mathrm{EC}_{50}=49 \mathrm{nM}^{i} \\
10 \mu \mathrm{M}^{j}\end{array}$ & $\begin{array}{l}\mathrm{EC}_{50}=3.6 \mu \mathrm{M}^{b} \\
\mathrm{EC}_{50}=1.2 \mu \mathrm{M}^{c}\end{array}$ & $3 \mu \mathrm{M}^{c}$ & $1 \mu \mathrm{M}^{d, e}$ \\
\hline Anandamide & $\mathrm{EC}_{50}=18 \mathrm{nM}^{k}$ & $10 \mu \mathrm{M}^{j}$ & $\begin{array}{c}5 \mu \mathrm{M}^{g} \\
\mathrm{EC}_{50}=7.3 \mu \mathrm{M}^{j}\end{array}$ & $\begin{array}{l}\text { Very weak agonist }{ }^{b} \\
\text { N.E. } .^{c}\end{array}$ & N.E..$^{c}$ & $1 \mu \mathrm{M}^{k}$ \\
\hline 2-AG & $\mathrm{EC}_{50}=3 \mathrm{nM}^{k}$ & N.E..$^{a, c}$ & N.E. ${ }^{h, i}$ & N.E. ${ }^{c}$ & N.E..$^{c}$ & N.T. \\
\hline$\Delta^{9}$-THC & $\mathrm{EC}_{50}=8 \mathrm{nM}^{k}$ & N.E. ${ }^{a}$ & $5 \mu \mathrm{M}^{g, h}$ & N.E. ${ }^{c}$ & N.E. ${ }^{c}$ & $5 \mu \mathrm{M}^{g}$ \\
\hline Cannabidiol & $\mathrm{IC}_{50}=350 \mathrm{nM}^{k}$ & $1 \mu \mathrm{M}$ antagonist ${ }^{d}$ & N.E. $g$ & N.E. ${ }^{c}$ & N.E. ${ }^{c}$ & $1-10 \mu \mathrm{M}$ antagonist ${ }^{d, k}$ \\
\hline Abn-CBD & $\mathrm{EC}_{50}=2.5 \mu \mathrm{M}^{k}$ & N.E. ${ }^{a}$ & N.E. ${ }^{g}$ & N.E..$^{b, c}$ & N.T. & N.T. \\
\hline O-1602 & $\begin{aligned} \mathrm{EC}_{50} & =13 \mathrm{nM}^{k} \\
\mathrm{EC}_{50} & =2.5 \mathrm{nM}^{l}\end{aligned}$ & $1 \mu \mathrm{M}^{d}$ & $10 \mu \mathrm{M}^{j}$ & N.E. ${ }^{c}$ & N.T. & $1 \mu \mathrm{M}^{d, e, f}$ \\
\hline CP55940 & $\mathrm{EC}_{50}=5 \mathrm{nM}^{k}$ & $10 \mu \mathrm{M}$ antagonist ${ }^{c}$ & $10 \mu \mathrm{M}$ antagonist ${ }^{i}$ & $K_{\mathrm{i}} \sim 200 \mathrm{nM}^{c}$ & $K_{\mathrm{i}} \sim 200 \mathrm{nM}^{c}$ & N.T. \\
\hline Rimonabant & N.T. & N.E. ${ }^{a}$ & $1-2 \mu \mathrm{M}$ antagonist $\mathrm{t}^{g, h, j}$ & $\begin{array}{l}\mathrm{EC}_{50}=9.3 \mu \mathrm{M}^{b} \\
\mathrm{EC}_{50}=3.9 \mu \mathrm{M}^{c}\end{array}$ & $30 \mu \mathbf{M}^{c}$ & N.T. \\
\hline AM251 & $\mathrm{EC}_{50}=39 \mathrm{nM}^{k}$ & N.E. ${ }^{a}$ & N.T. & $\begin{array}{c}3 \mu \mathrm{M}^{b} \\
9.6 \mu \mathrm{M}^{c}\end{array}$ & $30 \mu \mathbf{M}^{c}$ & N.T. \\
\hline AM281 & $\mathrm{EC}_{50}>30 \mu \mathrm{M}^{k}$ & N.T. & N.T. & N.E.c ${ }^{c}$ & N.E. ${ }^{c}$ & N.T. \\
\hline
\end{tabular}

N.E., no effect; N.T., not tested.

a Oka et al. (2007): hGPR55 stably transfected in HEK293 cells with a tetracycline-inducible promoter.

${ }^{b}$ Yin et al. (2009): hGPR55 transiently transfected in HEK293 cells.

${ }^{c}$ Kapur et al. (2009): hGPR55E stably transfected in HEK293 cells ( $\beta$-arrestin assay) or U2OS cells ( $\beta$-arrestin and GPR55 internalization assays).

${ }^{d}$ Whyte et al. (2009): human osteoclast primary cultures.

e Whyte et al. (2009): mouse osteoclast primary cultures.

${ }^{f}$ Pietr et al. (2009): BV-2 (mouse microglial cell line).

${ }^{g}$ Lauckner et al. (2008): hGPR55 transiently transfected in HEK293 cells.

${ }^{h}$ Lauckner et al. (2008): mouse DRG primary cultures.

${ }^{i}$ Henstridge et al. (2009): hGPR55 stably transfected in HEK293 cells.

${ }^{j}$ Waldeck-Weiermair et al. (2008): EA.hy926 (human umbilical vein derived endothelial cell line).

${ }^{k}$ Ryberg et al. (2007): hGPR55 transiently transfected in HEK293s cells.

${ }^{l}$ Johns et al. (2007): hGPR55 transiently transfected in HEK293T cells. 
or GPR55 receptor internalization (Kapur et al., 2009; Yin et al., 2009).

4. Lysophosphatidyl Inositol. LPI has consistently been shown to be an agonist of GPR55. Thus, LPI ( $1 \mu \mathrm{M})$ can stimulate $\left[{ }^{35} \mathrm{~S}\right] \mathrm{GTP} \gamma \mathrm{S}$ binding to GPR55-expressing cell membranes (Oka et al., 2007) and has also been found to activate ERK1/2 in GPR55-transfected HEK293 cells with an $\mathrm{EC}_{50}$ of $200 \mathrm{nM}$ as well as in GPR55-expressing U2OS cells and in human osteoclasts when tested at 10 and $1 \mu \mathrm{M}$, respectively (Oka et al., 2007; Kapur et al., 2009; Whyte et al., 2009). Apparent GPR55-mediated calcium mobilization by LPI has been reported in EA.hy926 cells at $10 \mu \mathrm{M}$ (Waldeck-Weiermair et al., 2008), in mouse dorsal root ganglia at $3 \mu \mathrm{M}$ (Lauckner et al., 2008), and in HEK293 cells with $\mathrm{EC}_{50}$ values of 30 and $49 \mathrm{nM}$ (Oka et al., 2007; Henstridge et al., 2009). When using either $\beta$-arrestin recruitment or GPR55 receptor internalization assays, LPI was active as an apparent GPR55 agonist between 1 to $3 \mu \mathrm{M}$ (Henstridge et al., 2009; Kapur et al., 2009; Yin et al., 2009). LPI has also been reported to induce GPR55-mediated activation of RhoA in transfected HEK293 cells (Henstridge et al., 2009), as well as in human and mouse osteoclasts (Whyte et al., 2009). Evidence has also recently emerged that the endogenous compound, 2-arachidonoyl lysophosphatidyl inositol, activates GPR55 more potently than LPI in HEK293 cells and, hence, that this ligand may be the true intrinsic natural ligand for GPR55 (Oka et al., 2009).

5. $\Delta^{9}$-Tetrahydrocannabinol. The principal psychoactive component of the cannabis plant, $\Delta^{9}$-THC (section II.C.1), binds equally well to cannabinoid $\mathrm{CB}_{1}$ and $\mathrm{CB}_{2}$ receptors (Table 1). This cannabinoid has been reported to display significant potency as an agonist at GPR55 with an $\mathrm{EC}_{50}$ of $8 \mathrm{nM}$ in a $\left.{ }^{[35} \mathrm{S}\right] \mathrm{GTP} \gamma \mathrm{S}$ binding assay performed with HEK293 cells (Ryberg et al., 2007). Using $5 \mu \mathrm{M} \Delta^{9}$ THC, Lauckner et al. (2008) reported a modest increase in intracellular calcium in both mouse and human GPR55expressing HEK293 cells as well as in mouse dorsal root ganglia. In contrast, using GPR55 internalization and $\beta$-arrestin recruitment assays, Kapur et al. (2009) detected no sign of $\Delta^{9}$-THC-induced activation of GPR55, whereas Yin et al. (2009) reported very weak GPR55-mediated $\beta$-arrestin recruitment in response to this ligand.

6. Abnormal-Cannabidiol. Abnormal-cannabidiol (abnCBD; section II.C.5 and Fig. 5) lacks significant affinity for $\mathrm{CB}_{1}$ and $\mathrm{CB}_{2}$ receptors but has been reported to have a number of in vivo effects through one or more as yet undefined receptors (section III.H.2). Both Johns et al. (2007) and Ryberg et al. (2007) have reported $\left[{ }^{35} \mathrm{~S}\right] \mathrm{GTP} \gamma \mathrm{S}$ binding data for this ligand at GPR55 expressed in HEK293 cells, albeit indicating 1000-fold different potencies $\left(\mathrm{EC}_{50}=2.5 \mathrm{nM}\right.$ and $2.5 \mu \mathrm{M}$, respectively). No effect of this ligand on GPR55-mediated ERK1/2 activation was seen at a concentration of $1 \mu \mathrm{M}$ (Oka et al., 2007) and no abn-CBD-induced GPR55mediated mobilization of calcium was observed at $3 \mu \mathrm{M}$ (Lauckner et al., 2008). Furthermore, no GPR55-medi- ated activity of abn-CBD was seen when this ligand was tested in $\beta$-arrestin recruitment assays (Kapur et al., 2009; Yin et al., 2009).

7. Cannabidiol. The phytocannabinoid cannabidiol (section II.C.5), which has therapeutic potential as an anti-inflammatory agent, displays relatively low affinity for $\mathrm{CB}_{1}$ and $\mathrm{CB}_{2}$ receptors (Table 1). Ryberg et al. (2007) demonstrated that cannabidiol could antagonize the stimulation of $\left[{ }^{35} \mathrm{~S}\right] \mathrm{GTP} \gamma \mathrm{S}$ binding by anandamide, CP55940, and O-1602 in GPR55-transfected HEK293 cells with an $\mathrm{IC}_{50}$ of $350 \mathrm{nM}$. No confirmatory data from other laboratories are available using cannabidiol as an antagonist in transfected cells. However, Whyte et al. (2009) have reported that cannabidiol displays GPR55 antagonist activity in human osteoclasts at $1 \mu \mathrm{M}$ using ERK1/2 phosphorylation and RhoA activation assays. Cannabidiol had no GPR55 agonist activity when assayed in calcium mobilization assays at $3 \mu \mathrm{M}$ or when tested in $\beta$-arrestin recruitment assays (Kapur et al., 2009; Yin et al., 2009). Collectively, these data demonstrate that cannabidiol is an antagonist of GPR55.

8. O-1602. O-1602 is an analog of abn-CBD in which the pentyl group has been replaced by a methyl group (section II.C.5 and Fig. 5). O-1602 has been reported to have activity at a non- $\mathrm{CB}_{1} / \mathrm{CB}_{2}$ receptor in the vasculature, the putative abnormal-cannabidiol receptor (section III.H.2). Using $\left[{ }^{35} \mathrm{~S}\right] \mathrm{GTP} \gamma \mathrm{S}$ binding assays, two independent groups have reported nanomolar activity of this compound at GPR55 expressed in HEK293 cells. Ryberg et al. (2007) determined an $\mathrm{EC}_{50}$ of $13 \mathrm{nM}$, whereas Johns et al. (2007) found an $\mathrm{EC}_{50}$ of $1.4 \mathrm{nM}$. O-1602 has been shown to promote apparent GPR55mediated ERK1/2 phosphorylation in human osteoclasts as well as RhoA activation at $1 \mu \mathrm{M}$ in HEK293 cells and in human and mouse osteoclasts. Oka et al. (2007) reported no effect of O-1602 on calcium mobilization in GPR55-transfected HEK293 cells at $1 \mu \mathrm{M}$, whereas Waldeck-Weiermair et al. (2008) did see a calcium signal in GPR55-expressing EA.hy926 cells in response to this compound at $10 \mu \mathrm{M}$. Collectively, these data support O-1602 as an agonist of GPR55, coupling signaling via G protein activation to RhoA. Using $\beta$-arrestin recruitment assays, however, neither Yin et al. (2009) nor Kapur et al. (2009) observed any activity for O-1602 at GPR55.

9. CP55940. The potent cannabinoid receptor agonist CP55940 (section II.C.1) has high affinity for both CB $_{1}$ and $\mathrm{CB}_{2}$ receptors (Table 1 ) and is widely used in cannabinoid research as a pharmacological tool. Using a $\left.{ }^{35} \mathrm{~S}\right] \mathrm{GTP} \gamma \mathrm{S}$ binding assay, a potency $\left(\mathrm{EC}_{50}=5 \mathrm{nM}\right)$ similar to its potency as a $\mathrm{CB}_{1}$ and $\mathrm{CB}_{2}$ receptor agonist has been demonstrated for CP55940 at GPR55 (Ryberg et al., 2007). Unfortunately, no confirmatory $\left[{ }^{35} \mathrm{~S}\right] \mathrm{GTP} \gamma \mathrm{S}$ binding data are available from other groups. However, this ligand has been investigated in other assays. Alone, CP55940 failed to demonstrate any agonist activity in either ERK1/2 activation (Oka et al., 2007) or calcium mobilization GPR55 
assays (Lauckner et al., 2008), although it did antagonize apparent GPR55-mediated ERK1/2 phosphorylation at a concentration of $10 \mu \mathrm{M}$ (Kapur et al., 2009).

10. $R$-(+)-WIN55212. $R$-(+)-WIN55212 (section II.C.1 and Table 1) is a potent, nonselective $\mathrm{CB}_{1}$ and $\mathrm{CB}_{2}$ receptor agonist that has been used in many studies of cannabinoid receptor function. The available data for $R$-(+)-WIN55212 activity at GPR55 are highly consistent, most laboratories finding no effect of this cannabinoid on any of the GPR55 assay end points used (Oka et al., 2007; Ryberg et al., 2007; Lauckner et al., 2008; Kapur et al., 2009).

11. Rimonabant. Rimonabant (section II.C.3. and Table 1) is a potent $\mathrm{CB}_{1}$ receptor antagonist that was developed as an antiobesity agent. No $\left[{ }^{35} \mathrm{~S}\right] \mathrm{GTP} \gamma \mathrm{S}$ binding data on this compound at GPR55 have been published. However, signs of GPR55 antagonism have been detected at 1 $\mu \mathrm{M}$ in EA.hy926 cells and at $2 \mu \mathrm{M}$ in HEK293 cells and mouse dorsal root ganglia using calcium mobilization assays (Lauckner et al., 2008; Waldeck-Weiermair et al., 2008). In contrast, Henstridge et al. (2010) reported agonist activity for rimonabant in the range of $100 \mathrm{nM}$ to 3 $\mu \mathrm{M}$, as indicated by elevations of intracellular calcium in GPR55-expressing HEK293 cells. GPR55 agonist activity by rimonabant is also reported for $\beta$-arrestin recruitment with $\mathrm{EC}_{50}$ values of 9.3 and $3.9 \mu \mathrm{M}$ (Kapur et al., 2009; Yin et al., 2009). Likewise, Kapur et al. (2009) have reported receptor internalization at $30 \mu \mathrm{M}$ rimonabant in GPR55-expressing HEK293 and U2OS cells, consistent with the findings of Henstridge et al. (2010) that this compound can act as a GPR55 agonist. In addition, Henstridge et al. (2010) demonstrated that rimonabant activates ERK1/2, cAMP response element-binding protein phosphorylation, and nuclear factor $\kappa$-light-chain-enhancer of activated B cells via GPR55 and also that it induces GPR55 internalization.

12. AM251. Like rimonabant, AM251 (section II.C.3 and Table 1) is a potent $\mathrm{CB}_{1}$ receptor antagonist. It has been shown in a $\left[{ }^{35} \mathrm{~S}\right] \mathrm{GTP} \gamma \mathrm{S}$ binding assay using transfected HEK293 cells to be a high-potency agonist of GPR55 $\left(\mathrm{EC}_{50}=39 \mathrm{nM}\right)$ (Ryberg et al., 2007). Henstridge et al. (2009) have reported an $\mathrm{EC}_{50}$ of $612 \mathrm{nM}$ for calcium mobilization in GPR55-expressing HEK293 cells. AM251 promotes $\beta$-arrestin recruitment with $\mathrm{EC}_{50}$ values of 3 and $9.6 \mu \mathrm{M}$ (Kapur et al., 2009; Yin et al., 2009) and GPR55 internalization (Kapur et al., 2009; Henstridge et al., 2010).

13. Other Ligands. Using a $\left.{ }^{35} \mathrm{~S}\right] \mathrm{GTP} \gamma \mathrm{S}$ binding assay, Ryberg et al. (2007) found that hGPR55 stably transfected into HEK293 cells was activated by nanomolar concentrations of the following lipids: noladin ether (section II.C.2 and Table 1) and virodhamine (section II.C.5 and Table 1), both of which are cannabinoid receptor agonists, and the non- $\mathrm{CB}_{1} /$ $\mathrm{CB}_{2}$ receptor ligands, oleoyl ethanolamide and palmitoyl ethanolamide. Palmitoyl ethanolamide, which is of interest because of its potent anti-inflammatory, antiexcitotoxic, and antihyperalgesic properties (Skaper et al., 1996; Jaggar et al., 1998), also displays significant potency as a PPAR $\alpha$ agonist (section III.G). It was originally thought to be an endogenous ligand for the $\mathrm{CB}_{2}$ receptor (Facci et al., 1995). However, subsequent studies showed it to have little affinity for this receptor (Showalter et al., 1996; Griffin et al., 2000).

14. Impact of Cell Lines and Expression Levels on GPR55 Data. It is well known that cell lines present inconsistent phenotypes over time. For example, Dubi et al. (2008) have recently demonstrated that the androgen-insensitive PC-3 cell line exhibited two sublines that showed distinct receptor activation. The clonal background of HEK293 cells can differ markedly between laboratories. It is noteworthy, therefore, that GPR55 experiments were carried out by Ryberg et al. (2007) with a HEK293s cell line and by Johns et al. (2007) with a HEK293T cell line, and also, that these and other investigations into the ability of cannabinoid receptor ligands to target GPR55 (Oka et al., 2007; Lauckner et al., 2008; Henstridge et al., 2009; Kapur et al., 2009) were each performed in a different laboratory. It is noteworthy, too, that although HEK293 cells are referred to as "human embryonic kidney" cells, a study on the origin of this cell line suggests that these cells may in fact have been derived by adenoviral transformation of a neuronal precursor present in the HEK cell cultures from which the original HEK293 cell line was obtained (Shaw et al., 2002).

Many in vitro studies of GPR55 have used transfected cells overexpressing this receptor (Johns et al., 2007; Ryberg et al., 2007; Lauckner et al., 2008; Kapur et al., 2009). If overexpression of the receptor induces constitutive activity, this can lead to altered ligand behavior (Kenakin, 2001). Moreover, because of cell line and tissue heterogeneity, there may be accessory and other proteins in the various cell lines that modify the response of GPR55. The change in anandamide-induced $\mathrm{CB}_{1} / \mathrm{GPR} 55$ signaling that seems to occur in endothelial cells because of integrin clustering is one published example (Waldeck-Weiermair et al., 2008). The manner in which GPR55 responds to its ligands may also be dependent on cell culture conditions. Moreover, HEK293 and other cells can synthesize lipid mediators, and this may alter the measured response (Turu et al., 2009). The presence of endocannabinoids in serum has also been documented (Valk et al., 1997), and other growth factors are present as well.

15. Conclusions. Because of the large body of conflicting pharmacological data, no conclusive decision can yet be reached about whether GPR55 should be classified as a novel cannabinoid receptor. Particularly noteworthy are the mixed findings that have been obtained with the endocannabinoid anandamide. Thus, this compound has been found in GPR55 assays to stimulate $\left[{ }^{35} \mathrm{~S}\right] \mathrm{GTP} \gamma \mathrm{S}$ binding in the nanomolar range, to cause calcium mobilization in the micromolar range, but not to affect ERK1/2 phosphorylation or $\beta$-arrestin recruitment or to induce GPR55 internalization. These mixed findings may be the product of biased agonism at GPR55 or may have resulted simply from the use of different assay end points and cell systems. Therefore, although anandamide has been shown to be active at GPR55 in certain assays and cell types, the inconsistent manner with 
which it has been found to interact with this receptor prevents unequivocal designation of anandamide as a GPR55 ligand. Whether this inconsistency is the result of biased agonism or experimental variation remains to be determined; until it is, GPR55 cannot be considered an anandamide receptor.

The data for 2-AG are more consistent, albeit mainly negative. Thus, although it has been shown to display activity as a GPR55 agonist in a $\left[{ }^{35} \mathrm{~S}\right] \mathrm{GTP} \gamma \mathrm{S}$ binding assay, the majority of studies using calcium mobilization, ERK1/2 phosphorylation, or $\beta$-arrestin recruitment and receptor internalization have failed to demonstrate any effect of this endocannabinoid on GPR55. Consequently, there is no conclusive evidence at this time that this endocannabinoid is a ligand of GPR55. As for $\Delta^{9}$-THC, although it displays activity as a GPR55 agonist in $\left[{ }^{35} \mathrm{~S}\right] \mathrm{GTP} \gamma \mathrm{S}$ binding, calcium mobilization, and RhoA activation assays, it fails to stimulate ERK1/2 phosphorylation, $\beta$-arrestin recruitment, or GPR55 internalization. Whether this is a result of biased agonism by $\Delta^{9}$-THC or experimental variability remains to be determined.

A rare consensus among the articles published on GPR55 is that LPI is an agonist for this receptor. Another agreement among published reports is that the aminoalkylindole $R$-(+)-WIN55212, a potent $\mathrm{CB}_{1}$ and $\mathrm{CB}_{2}$ receptor agonist, does not target GPR55 as either an agonist or an antagonist. In contrast, both CP55940 and rimonabant have been found to behave as GPR55 agonists in some investigations but as GPR55 antagonists in others, possibly an indication that they possess low relative intrinsic activity as GPR55 agonists, although this remains to be established. Finally, the finding that 2-arachidonoyl lysophosphatidyl inositol is an endogenous agonist for GPR55 (section III.A.4) has revealed an interesting "parallel" between the chemical nature of GPR55 and $\mathrm{CB}_{1} / \mathrm{CB}_{2}$ receptor endogenous ligands.

\section{B. Other Deorphanized G Protein-Coupled Receptors}

1. GPR40, GPR41, GPR42, and GPR43. In 2003, it was discovered by three different research groups that the receptor GPR40 can be activated by long- and medium-chain fatty acids (C6-C22; Table 3) (Briscoe et al., 2003; Itoh et al.,
2003; Kotarsky et al., 2003). The receptor has been renamed $\mathrm{FFA}_{1}$ because it is now thought to be a fatty acid receptor that is involved in the regulation of insulin release (Stoddart et al., 2008). That GPR40 is indeed a fatty acid receptor has been confirmed in a recent investigation that used a new $\beta$-arrestin assay to deorphanize $\mathrm{G}$ protein-coupled receptors (Yin et al., 2009). $\mathrm{FFA}_{1}$ can be activated by glitazone drugs that are activators of PPAR $\gamma$ (Kotarsky et al., 2003; Gras et al., 2009; Smith et al., 2009), and a number of other small-molecule agonists/antagonists for $\mathrm{FFA}_{1}$ have also been discovered (Bharate et al., 2009; Hara et al., 2009; Hu et al., 2009). However, $\mathrm{FFA}_{1}$ has not been reported to be activated or inhibited by any known cannabinoid $\mathrm{CB}_{1}$ or $\mathrm{CB}_{2}$ receptor agonist or antagonist.

In the same year, two other orphan receptors, GPR41 and GPR43, were identified by three independent research groups as receptors for short-chain fatty acids (C1-C6; Table 3) (Brown et al., 2003; Le Poul et al., 2003; Nilsson et al., 2003) and these receptors have now been renamed $\mathrm{FFA}_{3}$ and $\mathrm{FFA}_{2}$, respectively (Stoddart et al., 2008). $\mathrm{FFA}_{2}$ is found in adipose tissue, where its activation may increase leptin production and, in white blood cells, where it may stimulate chemotaxis. $\mathrm{FFA}_{3}$ is found on immune cells, in the gastrointestinal tract, and in adipose tissue. $\mathrm{FFA}_{2}$ knockout mice do not respond to acetate-induced reductions in plasma free fatty acid levels, indicating a role for this receptor in the stimulation of lipolysis. A series of small molecule phenylacetamides have been found to be more potent $\mathrm{FFA}_{2}$ agonists, and these may also act as allosteric ligands at an allosteric binding site on $\mathrm{FFA}_{2}$ (Lee et al., 2008). $\mathrm{FFA}_{2}$ and $\mathrm{FFA}_{3}$ have not been reported to be activated or inhibited by any known agonists or antagonists for cannabinoid $\mathrm{CB}_{1}$ or $\mathrm{CB}_{2}$ receptors.

The GPR42 gene codes for a GPR42 receptor that is very similar to $\mathrm{FFA}_{3}$ but cannot be activated by shortchain fatty acids, prompting the suggestion that it is a pseudogene (Brown et al., 2003). However, recent findings suggest that GPR42 could potentially be a functional gene in a fraction of the human population because of a polymorphism resulting in the presence of arginine at amino acid 174 of the receptor (Liaw and

TABLE 3

Deorphanized $G$ protein-coupled receptors other than GPR55 that could possibly be activated by cannabinoid receptor ligands In all cases, it was not reported whether the receptor was targeted by cannabinoid receptor ligands. See Section III.B for references and further details.

\begin{tabular}{lll}
\hline \multicolumn{1}{c}{ Receptor } & \multicolumn{1}{c}{ Recognized Agonist(s) } & \multicolumn{1}{c}{ EC $_{50}$ Range } \\
\hline FFA $_{1}$ (GPR40 & Fatty acids (C6-C22) & Micromolar \\
FFA $_{2}$ (GPR43) & Fatty acids (C1-C6) & Micromolar to millimolar \\
FFA $_{3}$ (GPR41) & Fatty acids (C1-C6) & Micromolar to millimolar \\
GPR84 & Fatty acids (C9-C14) & Micromolar \\
GPR120 & Fatty acids (C14-C22) & Micromolar \\
GPR3 & Sphingosine-1-phosphate? & \\
GPR6 & Sphingosine-1-phosphate? & \\
GPR12 & Sphingosylphosphorylcholine? & Nanomolar to micromolar \\
& LPA & Nanomolar to micromolar \\
& Farnesyl pyrophosphate & Nanomolar to micromolar \\
GPR23 & NAGly & Low micromolar \\
\hline
\end{tabular}

OEA, oleoyl ethanolamide; OLDA, $N$-oleoyl dopamine. 
Connolly, 2009). If that is the case, it is likely that an active GPR42 will have nearly the same properties as the $\mathrm{FFA}_{3}$ receptor.

2. GPR84 and GPR120. The two orphan receptors, GPR84 and GPR120, seem to be receptors for mediumchain fatty acids (C9-C14; Table 3) (Wang et al., 2006a) and for long-chain fatty acids (C14-C22) (Hirasawa et al., 2005; Katsuma et al., 2005), respectively.

GPR84 is highly expressed in bone marrow, and in splenic T cells and B cells, and results from studies with GPR84 knockout mice suggest that GPR84 is involved in regulating early IL-4 gene expression in activated T cells (Venkataraman and Kuo, 2005) and that it is expressed in activated microglial cells and macrophages (Bouchard et al., 2007; Lattin et al., 2008). Mediumchain fatty acids activate GPR84 as can be seen from their ability to decrease intracellular cAMP and to stimulate $\left[{ }^{35} \mathrm{~S}\right] \mathrm{GTP} \gamma \mathrm{S}$ binding to membranes from $\mathrm{CHO}$ cells stably expressing GPR84 (Wang et al., 2006a). Shortand long-chain fatty acids were inactive, and GPR84 has not been reported to be activated or inhibited by any known agonists or antagonists for cannabinoid $\mathrm{CB}_{1}$ or $\mathrm{CB}_{2}$ receptors.

GPR120 is found mainly in the intestinal tract, although it is also expressed by a number of other tissues (e.g., adipocytes, taste buds, and lung) (Ichimura et al., 2009). More specifically, intestinal GPR120 is found in glucagon-like peptide-1 (GLP-1)-expressing endocrine cells in the large intestine (Hirasawa et al., 2005; Miyauchi et al., 2009) and in gastric inhibitory polypeptideexpressing $\mathrm{K}$ cells of the duodenum and jejunum (Parker et al., 2009). Dietary fatty acids may promote intestinal CCK and GLP-1 release via activation of intestinal GPR120 (Tanaka et al., 2008; Ichimura et al., 2009). Long-chain fatty acids (C14-C22; Table 3), especially unsaturated ones, activate GPR120 in cell lines stably expressing this receptor, as measured by an increase in intracellular $\mathrm{Ca}^{2+}$, whereas $\alpha$-linolenic acid methyl ester lacks activity (Hirasawa et al., 2005). It is noteworthy that some plant-derived compounds, grifolin derivatives that do not contain a carboxylic group, can also activate GPR120 (Hara et al., 2009). GPR120 has not been reported to be activated or inhibited by any known agonists or antagonists for cannabinoid $\mathrm{CB}_{1}$ or $\mathrm{CB}_{2}$ receptors.

3. GPR3, GPR6, and GPR12. GPR3, GPR6, and GPR12 are constitutively active proteins that signal through $\mathrm{G} \alpha_{\mathrm{s}}$ to increase cAMP levels in cells expressing these receptors (Tanaka et al., 2007). They are mainly expressed in the central nervous system, where they may contribute to the regulation of neuronal proliferation (Tanaka et al., 2009), monoamine neurotransmission (Valverde et al., 2009), reward learning processes (Lobo et al., 2007), and energy expenditure (Bjursell et al., 2006). They may also be involved in the regulation of meiosis in oocytes (Hinckley et al., 2005). Their closest phylogenetic GPCR relatives are cannabinoid receptors, lysophospholipid receptors, and melanocortin receptors (Uhlenbrock et al., 2002).

It has been suggested that GPR3, GPR6, and GPR12 (Table 3) are all activated by sphingosine-1-phosphate and/or sphingosylphosphorylcholine at nanomolar concentrations (Uhlenbrock et al., 2002; Ignatov et al., 2003a,b; Lobo et al., 2007). Results obtained in a recent investigation using $\beta$-arrestin recruitment instead of $\mathrm{G}$ protein activation as an assay for receptor agonism do, however, challenge this hypothesis as no sign of agonism was seen in response to sphingosine-1-phosphate or sphingosylphosphorylcholine at 8 and $42 \mu \mathrm{M}$, respectively (Yin et al., 2009). A large number of endogenous lipids, including endocannabinoids, were screened in this investigation and none of these were found to activate GPR3, GPR6, or GPR12 (Yin et al., 2009). However, anandamide and 2-AG did show weak agonist activity at the $\mathrm{S}_{1} \mathrm{P}_{1}$ receptor (edg1) at concentrations in the micromolar range (Yin et al., 2009).

4. GPR18 and GPR92. The chromosomal location of GPR18 has been determined as 13q32.3; it is a 331amino acid GPCR. GPR18 (Table 3) is highly expressed in spleen, thymus, and peripheral lymphocyte subsets (Gantz et al., 1997; Kohno et al., 2006). In GPR18-transfected cells, $N$-arachidonoyl glycine (NAGly) has been shown to induce intracellular $\mathrm{Ca}^{2+}$ mobilization at 10 $\mu \mathrm{M}$ (Kohno et al., 2006). Furthermore, the same study demonstrated inhibition of forskolin-stimulated cAMP production by NAGly with an $\mathrm{EC}_{50}$ of $20 \mathrm{nM}$; the effect was absent in untransfected cells and was pertussis toxin-sensitive, suggesting $\mathrm{G}_{\mathrm{i}}$-coupling. A more recent study used the $\beta$-arrestin PathHunter assay system to examine the pharmacological interactions of various lipids with a range of recently deorphanized GPCRs (Yin et al., 2009). In this study, NAGly did not activate GPR18 but elicited a weak activation of GPR92, at concentrations above $10 \mu \mathrm{M}$. GPR92 mRNA is highly expressed in dorsal root ganglia, suggesting a role in sensory neuron transmission. Oh et al. (2008) have also demonstrated that NAGly mobilizes intracellular $\mathrm{Ca}^{2+}$ and activates $\left[{ }^{35} \mathrm{~S}\right] \mathrm{GTP} \gamma \mathrm{S}$ binding in GPR92-expressing cells. However, the relative intrinsic activity of NAGly is significantly lower than that of the other putative endogenous GPR92 agonists, LPA and farnesyl pyrophosphate (Oh et al., 2008; Williams et al., 2009). In addition, farnesyl pyrophosphate and LPA activate both $\mathrm{G}_{\mathrm{q} / 11^{-}}$and $\mathrm{G}_{\mathrm{s}}$ mediated signaling, whereas NAGly activates only $\mathrm{G}_{\mathrm{q} / 11}$-mediated signaling. To date, there are no published data to indicate whether cannabinoid $\mathrm{CB}_{1}$ or $\mathrm{CB}_{2}$ receptor ligands can activate or block GPR18 or GPR92. It is noteworthy, however, that GPR18 may be a receptor for abnormal-cannabidiol (section III.H.2).

5. GPR23. The orphan receptor GPR23/p2y 9 is closely related to the purinergic $\mathrm{P} 2 \mathrm{Y}$ receptor and mRNA for this receptor in the mouse is mainly found in ovary, uterus, and placenta (Ishii et al., 2009). It has been found (Table 3 ) that GPR23 is activated by LPA in 
the nanomolar range as indicated by intracellular calcium mobilization and cAMP formation (Noguchi et al., 2003), probably through the activation of $\mathrm{G}_{\mathrm{q} / 11}$ and $\mathrm{G}_{\mathrm{s}}$ proteins (Ishii et al., 2009). Two other recent investigations have used $\beta$-arrestin recruitment to test the ability of LPA to activate GPR23. In one of these, activation was detected at $100 \mu \mathrm{M}$ (Wetter et al., 2009), whereas in the other, no activation was induced by concentrations of up to $100 \mu \mathrm{M}$ LPA (Yin et al., 2009). GPR23 has not been reported to be activated or inhibited by any known agonists or antagonists for cannabinoid $\mathrm{CB}_{1}$ or $\mathrm{CB}_{2}$ receptors.

6. GPR119. The human orphan receptor GPR119, identified by a basic local alignment search tool search of the genomic database, is an intronless GPCR belonging to the MECA (melanocortin, endothelial differentiation gene, cannabinoid, adenosine) cluster of receptors (Fredriksson et al., 2003a). It is preferentially expressed in pancreatic and intestinal cells, where it is involved in the control of glucose-dependent insulin release and GLP-1 release, respectively (Soga et al., 2005; Chu et al., 2007; Lauffer et al., 2008). Although GPR119 is phylogenetically related to cannabinoid receptors, only fatty acid amides interact with GPR119 (Table 3), the potency order of four of these being $N$-oleoyl dopamine $>$ oleoyl ethanolamide $>$ palmitoyl ethanolamide $>$ anandamide (Overton et al., 2006; Chu et al., 2010). Because only $\mathrm{N}$-oleoyl dopamine and oleoyl ethanolamide have reasonably high (low micromolar) affinity for GPR119, and because neither of these lipids interacts with $\mathrm{CB}_{1}$ or $\mathrm{CB}_{2}$ receptors, GPR119 cannot be viewed as a cannabinoid receptor. Oleoyl ethanolamide also activates TRPV1 channels and PPARs (sections III.E and III.G).

7. Conclusions. There is evidence that at least some cannabinoid receptor agonists do not activate GPR119, GPR3, GPR6, or GPR12 with significant potency (Table 3 and sections III.B3 and III.B.6). However, to our knowledge, cannabinoids have not been tested as ligands for most of the receptors mentioned in Table 3 or, in any case, no such data have been published. Clearly, therefore, there is a need for the receptors listed in
Table 3 to be tested for their responsiveness to a broad spectrum of potential ligands, including a carefully selected range of cannabinoids, to help clarify their pharmacological profiles and physiological roles and so provide a conclusive deorphanization of these receptors.

\section{Established G Protein-Coupled Receptors}

At concentrations in the low micromolar range, some cannabinoid receptor agonists (Table 4) or antagonists seem to target certain G protein-coupled "noncannabinoid" receptors, in some instances probably by targeting allosteric sites on these receptors. These G protein-coupled receptors include muscarinic acetylcholine receptors and $\alpha_{2^{-}}$and $\beta$-adrenoceptors and also opioid, adenosine, 5 -HT, angiotensin, prostanoid, dopamine, melatonin, and tachykinin receptors.

1. Opioid Receptors. There is evidence that certain phytocannabinoids or synthetic cannabinoids can act allosterically at concentrations in the low micromolar range to accelerate the dissociation of ligands from the orthosteric sites on $\mu$ - and/or $\delta$-opioid receptors. Thus, it has been found that the rate of dissociation of $\left[{ }^{3} \mathrm{H}\right]$ DAMGO $\left(\left[{ }^{3} \mathrm{H}\right]\left[\mathrm{D}-\mathrm{Ala}^{2}, N-\mathrm{Me}-\mathrm{Phe}^{4}, \mathrm{Gly}^{5}\right.\right.$-ol $]$-enkephalin), presumably from $\mu$-opioid receptors, and of $\left[{ }^{3} \mathrm{H}\right]$ naltrindol, presumably from $\delta$-opioid receptors, can be increased by $\Delta^{9}$-THC $\left(\mathrm{EC}_{50}=21.4\right.$ and $10 \mu \mathrm{M}$, respectively) (Kathmann et al., 2006). In contrast, rimonabant seems to displace $\left[{ }^{3} \mathrm{H}\right] \mathrm{DAMGO}$ in a competitive manner $\left(\mathrm{IC}_{50}=4.1 \mu \mathrm{M}\right)$. Results obtained from equilibrium binding experiments with rat whole-brain membranes also suggest that $\Delta^{9}$-THC is a noncompetitive inhibitor of ligand binding to $\mu$ - and $\delta$-opioid receptors $\left(\mathrm{IC}_{50}=7\right.$ and $16 \mu \mathrm{M}$, respectively), although not to $\kappa$-opioid receptors or $\sigma$ /phencyclidine receptors, and that inhibition of ligand binding to $\mu$-opioid receptors can be induced by certain other cannabinoids (Vaysse et al., 1987). In addition, it has been found by both Fong et al. (2009) and Cinar and Szücs (2009) that rimonabant can induce radioligand displacement from $\mu$-opioid receptors $\left(\mathrm{IC}_{50}=3\right.$ and $5.7 \mu \mathrm{M}$, respectively), and by Fong et al.

TABLE 4

Effects of cannabinoid $C B_{1}$ and/or $C B_{2}$ receptor agonists on noncannabinoid established $G$ protein-coupled receptors See Section III.C for references and further details.

\begin{tabular}{|c|c|c|c|c|}
\hline Receptor and Effect & Endocannabinoid(s)? & $\begin{array}{c}\text { Effective } \\
\text { Concentration Range }\end{array}$ & $\begin{array}{c}\text { Nonendogenous } \\
\text { Cannabinoid Agonist(s)? }\end{array}$ & $\begin{array}{c}\text { Effective } \\
\text { Concentration Range }\end{array}$ \\
\hline \multicolumn{5}{|l|}{ Radioligand binding $(\downarrow)$} \\
\hline Opioid $(\mu-$ and $\delta$-) & N.D. & N.D. & $\mathrm{Yes}^{a}$ & Micromolar \\
\hline Acetylcholine (muscarinic) & $\operatorname{Yes}^{a, b}$ & Micromolar & $\mathrm{Yes}^{a, c}$ & Micromolar \\
\hline $5-\mathrm{HT}_{1}$ or $5-\mathrm{HT}_{2 \mathrm{C}}$ & Yes $^{d}$ & Micromolar & Yes & Micromolar \\
\hline \multicolumn{5}{|l|}{ Radioligand binding $(\uparrow)$} \\
\hline Acetylcholine (muscarinic) & $\mathrm{Yes}^{a, b}$ & Micromolar & Yes $^{a, c}$ & Micromolar \\
\hline
\end{tabular}

N.D., no data.

${ }^{a}$ May target an allosteric site on this receptor.

${ }^{b}$ Also $R$-(+)-methanandamide.

${ }^{c}$ Only $R-(+)$-methanandamide.

${ }^{d}$ Also $5-\mathrm{HT}_{2 \mathrm{~A}}$ and $5-\mathrm{HT}_{2 \mathrm{~B}}$. 
(2009) that this $\mathrm{CB}_{1}$ receptor antagonist can induce radioligand displacement from $\kappa$-opioid receptors $\left(\mathrm{IC}_{50}=\right.$ $3.9 \mu \mathrm{M})$.

2. Muscarinic Acetylcholine Receptors. At concentrations in the micromolar range, both anandamide and $R$-(+)-methanandamide have been shown to modulate tritiated ligand binding to muscarinic acetylcholine receptors, probably by targeting allosteric sites on these receptors. Thus, Lagalwar et al. (1999) found that $\left[{ }^{3} \mathrm{H}\right] N$-methylscopolamine and $\left[{ }^{3} \mathrm{H}\right]$ quinuclidinyl benzilate could be displaced from binding sites on adult human frontal cerebrocortical membranes in a noncompetitive manner by both anandamide $\left(\mathrm{IC}_{50}=44\right.$ and 50 $\mu \mathrm{M}$, respectively) and $R$-(+)-methanandamide $\left(\mathrm{IC}_{50}=\right.$ 15 and $34 \mu \mathrm{M}$, respectively) but not $R$-(+)-WIN55212 (up to $5 \mu \mathrm{M}$ ). Both ethanolamides stimulated $\left[{ }^{3} \mathrm{H}\right] \mathrm{ox}-$ otremorine binding to these membranes at concentrations below 50 or $100 \mu \mathrm{M}$, although they did inhibit such binding at higher concentrations. It was concluded that these effects of anandamide did not require its conversion to arachidonic acid. It has also been found that anandamide and $R$-(+)-methanandamide but not $R-(+)$ WIN55212 can displace tritiated ligands from human $\mathrm{M}_{1}$ and $\mathrm{M}_{4}$ muscarinic acetylcholine receptors transfected into CHO cells (Christopoulos and Wilson, 2001). $\mathrm{IC}_{50}$ values for the displacement of $\left[{ }^{3} \mathrm{H}\right] N$-methylscopolamine and $\left[{ }^{3} \mathrm{H}\right]$ quinuclidinyl benzilate from $\mathrm{M}_{1}$ receptors were 2.8 and $13.5 \mu \mathrm{M}$, respectively, for anandamide and 1.45 and $6.5 \mu \mathrm{M}$, respectively, for $R-(+)$-methanandamide. Corresponding $\mathrm{IC}_{50}$ values for the displacement of these tritiated ligands from $\mathrm{M}_{4}$ receptors were 8.3 and $6.9 \mu \mathrm{M}$ for anandamide and 9.8 and $3.1 \mu \mathrm{M}$ for $R-(+)-$ methanandamide. The effect of anandamide on tritiated ligand binding seemed to be noncompetitive and hence possibly allosteric in nature. It is noteworthy, however, that anandamide $(10 \mu \mathrm{M})$ was subsequently found by the same research group not to affect the rate of dissociation of $\left[{ }^{3} \mathrm{H}\right] N$-methylscopolamine from $\mathrm{M}_{1}$ binding sites (Lanzafame et al., 2004).

3. Other Established G Protein-Coupled Receptors. It has been reported that at $10 \mu \mathrm{M}$, both rimonabant and AM251 can oppose the activation of adenosine $A_{1}$ receptors in rat cerebellar membranes and that these $\mathrm{CB}_{1}$ receptor antagonists can inhibit basal $\left[{ }^{35} \mathrm{~S}\right] \mathrm{GTP} \gamma \mathrm{S}$ binding to these membranes, probably by blocking $\mathrm{A}_{1}$ receptor activation by endogenously released adenosine (Savinainen et al., 2003). In addition, evidence has been obtained, first, that at $10 \mu \mathrm{M}$, both anandamide and 2-AG, but not AM251, $R$-(+)-WIN55212, or CP55940 can act as allosteric inhibitors at the human adenosine $\mathrm{A}_{3}$ receptor although not at the human adenosine $\mathrm{A}_{1}$ receptor (Lane et al., 2010), and second, that both rimonabant $\left(\mathrm{IC}_{50}=1.5 \mu \mathrm{M}\right)$ and taranabant $\left(\mathrm{IC}_{50}=3.4 \mu \mathrm{M}\right)$ can induce radiolabeled ligand displacement from adenosine $\mathrm{A}_{3}$ receptors (Fong et al., 2009). In contrast to taranabant $\left(\mathrm{IC}_{50}>10 \mu \mathrm{M}\right)$, rimonabant can also displace radiolabeled ligands from $\alpha_{2 \mathrm{~A}^{-}}$and $\alpha_{2 \mathrm{C}}$-adrenocep- tors, from $5-\mathrm{HT}_{6}$ and angiotensin $\mathrm{AT}_{1}$ receptors, and from prostanoid $\mathrm{EP}_{4}, \mathrm{FP}$, and IP receptors with $\mathrm{IC}_{50}$ values ranging from 2 to $7.2 \mu \mathrm{M}$ (Fong et al., 2009). Taranabant, however, has been found to displace radiolabeled ligands from dopamine $\mathrm{D}_{1}$ and $\mathrm{D}_{3}$ receptors $\left(K_{\mathrm{i}}=3.4\right.$ and $1.9 \mu \mathrm{M}$, respectively) and from melatonin $\mathrm{MT}_{1}$ receptors $\left(K_{\mathrm{i}}=5.4 \mu \mathrm{M}\right)$ (Fong et al., 2007). In addition, both rimonabant $\left(\mathrm{IC}_{50}=2 \mu \mathrm{M}\right)$ and taranabant $\left(\mathrm{IC}_{50}=0.5 \mu \mathrm{M}\right)$ can induce radiolabeled ligand displacement from tachykinin $\mathrm{NK}_{2}$ receptors (Fong et al., 2009).

There is also evidence that at 3 or $10 \mu \mathrm{M}$, but not higher or lower concentrations, both $\Delta^{9}$-THC and 11hydroxy- $\Delta^{9}$-THC increase the affinity of $\left[{ }^{3} \mathrm{H}\right]$ dihydroalprenolol for $\beta$-adrenoceptors in mouse cerebral cortical membranes (Hillard and Bloom, 1982). There is evidence too that $\left[{ }^{3} \mathrm{H}\right] 5-\mathrm{HT}$ binding to $5-\mathrm{HT}_{1 \mathrm{~A}}, 5-\mathrm{HT}_{1 \mathrm{~B}}$, $5-\mathrm{HT}_{1 \mathrm{D}}, 5-\mathrm{HT}_{1 \mathrm{E}}$, and/or $5-\mathrm{HT}_{2 \mathrm{C}}$ receptors in bovine cerebral cortical synaptic membranes can be reduced by 11-hydroxy- $\Delta^{8}$-THC and 11-oxo- $\Delta^{8}$-THC although not $\Delta^{8}$-THC at $10 \mu \mathrm{M}$, and by anandamide at 1 and $10 \mu \mathrm{M}$ (Kimura et al., 1996, 1998). The same concentrations of these cannabinoids did not decrease $\left[{ }^{3} \mathrm{H}\right]$ ketanserin binding to $5-\mathrm{HT}_{2 \mathrm{~A}}$ or $5-\mathrm{HT}_{2 \mathrm{~B}}$ receptors, although evidence was obtained that anandamide can reduce radioligand binding to $5-\mathrm{HT}_{1}$ and $5-\mathrm{HT}_{2}$ receptors at $100 \mu \mathrm{M}$. In addition, there has been a report that $\left[{ }^{3} \mathrm{H}\right]$ ketanserin binding to $5-\mathrm{HT}_{2}$ receptors in rat cerebral cortical membranes is enhanced by HU-210 at $500 \mathrm{nM}$ (Cheer et al., 1999).

4. Conclusions. There is evidence that at concentrations in the nanomolar or micromolar range, either or both of two $\mathrm{CB}_{1}$ receptor antagonists/inverse agonists, rimonabant and taranabant, can bind to some types of opioid, adrenergic, dopamine, 5-HT, adenosine, angiotensin, melatonin, tachykinin, and prostanoid receptors. There is also evidence that anandamide, 2-AG, and/or certain established nonendogenous $\mathrm{CB}_{1} / \mathrm{CB}_{2}$ receptor agonists can interact with at least some types of opioid, muscarinic acetylcholine, adrenergic, 5-HT, and adenosine receptors (Table 4). However, the potency with which these ligands target these receptors is significantly less than the potency with which they activate or block $\mathrm{CB}_{1}$ and/or $\mathrm{CB}_{2}$ receptors. Moreover, at least some of these interactions seem to be allosteric in nature. Consequently, no convincing case can be made for reclassifying any of the receptors mentioned in this section as a novel cannabinoid receptor.

\section{Ligand-Gated Ion Channels}

Several cannabinoid receptor agonists have been found to antagonize or enhance the activation of $5-\mathrm{HT}_{3}$, nicotinic acetylcholine, glycine, and/or ionotropic glutamate (NMDA) receptors (Table 5).

1. 5-HT $T_{3}$ Receptors. There has been one report that antagonism of the activation of $5-\mathrm{HT}_{3}$ receptors by $5-\mathrm{HT}$ can be induced by CP55940, $R$-(+)-WIN55212, and 
TABLE 5

Effects of cannabinoid $C B_{1}$ and/or $C B_{2}$ receptor agonists on ligand-gated ion channels See Section III.D for references and further details.

\begin{tabular}{|c|c|c|c|c|}
\hline Gated Channel and Effect & Endocannabinoid(s)? & $\begin{array}{l}\text { Effective Concentration } \\
\text { Range }\end{array}$ & $\begin{array}{c}\text { Nonendogenous } \\
\text { Cannabinoid Agonist(s)? }\end{array}$ & $\begin{array}{c}\text { Effective Concentration } \\
\text { Range }\end{array}$ \\
\hline \multicolumn{5}{|l|}{ Enhancement of activation } \\
\hline Glycine (native) & Yes & Nanomolar & Yes & Nanomolar \\
\hline Glycine $\alpha 1, \alpha 1 \beta 1$ & Yes & Nanomolar & Yes & Nanomolar \\
\hline Glycine $\alpha 1 \beta$ & Yes & Nanomolar & Yes & Micromolar \\
\hline NMDA & $\mathrm{Yes}^{a}$ & Nanomolar or micromolar & Yes $^{b}$ & Micromolar \\
\hline \multicolumn{5}{|l|}{ Inhibition of activation } \\
\hline $5-\mathrm{HT}_{3}$ & $\mathrm{Yes}^{c}$ & Nanomolar & $\mathrm{Yes}^{c}$ & Nanomolar \\
\hline Acetylcholine (nicotinic) & $\mathrm{Yes}^{c}$ & Nanomolar & $\mathrm{Yes}^{c}$ & Nanomolar or micromolar \\
\hline Glycine (native) & Yes & Nanomolar or micromolar & No & Nanomolar \\
\hline Glycine $\alpha 1, \alpha 1 \beta$ & No & Nanomolar & Yes & Micromolar \\
\hline Glycine $\alpha 2, \alpha 3$ & No & Micromolar & Yes & Nanomolar or micromolar \\
\hline \multicolumn{5}{|l|}{ Radioligand binding $(\downarrow)$} \\
\hline Benzodiazepine & No & Micromolar & Yes & Micromolar \\
\hline
\end{tabular}

${ }^{a}$ Also $R$-(+)-methanandamide.

${ }^{b}$ Only $R$-(+)-methanandamide.

${ }^{c}$ May target an allosteric site on this receptor.

anandamide with $\mathrm{IC}_{50}$ values of 94,310 , and $190 \mathrm{nM}$, respectively (Fan, 1995), and another report that these compounds induce antagonism of this kind with $\mathrm{IC}_{50}$ values of 648,104 , and $130 \mathrm{nM}$, respectively (Barann et al., 2002). The second of these research groups also found $5-\mathrm{HT}_{3}$ receptor activation to be potently antagonized by two other cannabinoid receptor agonists, $\Delta^{9}$ THC and JWH-015 ( $\mathrm{IC}_{50}=38$ and $147 \mathrm{nM}$, respectively) and by the $\mathrm{CB}_{1}$ receptor antagonist/inverse agonist LY320135 $\left(\mathrm{IC}_{50}=523 \mathrm{nM}\right)$, although not by rimonabant at $1 \mu \mathrm{M}$. In other investigations, anandamide has been found to antagonize $5-\mathrm{HT}_{3}$ receptor activation with $\mathrm{IC}_{50}$ values of $239 \mathrm{nM}$ (Xiong et al., 2008) or $3.7 \mu \mathrm{M}$ (Oz et al., 2002). There is evidence, at least for anandamide, CP55940, and $R$-(+)-WIN55212, that this antagonism is noncompetitive in nature and, indeed, that at least some of these cannabinoids may be targeting an allosteric site on the $5-\mathrm{HT}_{3}$ receptor (Fan, 1995; Barann et al., 2002; Oz et al., 2002; Xiong et al., 2008).

2. Nicotinic Acetylcholine Receptors. An allosteric mechanism may also underlie the antagonism of nicotinic acetylcholine receptors that is reportedly induced by anandamide, 2-AG, $R$-(+)-methanandamide, and $\mathrm{CP} 55940\left(\mathrm{IC}_{50}=230,168,183\right.$, and $3400 \mathrm{nM}$, respectively), although not by $\Delta^{9}$-THC or $R$-(+)-WIN55212 $(\mathrm{Oz}$ et al., 2003, 2004a, 2005). Evidence that anandamide can antagonize nicotinic acetylcholine receptors with significant potency has also been obtained by Spivak et al. (2007) $\left(\mathrm{IC}_{50} \sim 300 \mathrm{nM}\right)$ and Butt et al. (2008) $\left(\mathrm{IC}_{50}=\right.$ $900 \mathrm{nM}$ ). Anandamide behaved as a noncompetitive antagonist in the second of these investigations, in which further evidence that $\Delta^{9}$-THC $(30 \mu \mathrm{M})$ is not a nicotinic acetylcholine receptor antagonist was also obtained. Arachidonic acid, a metabolite of anandamide, has also been found to antagonize nicotinic acetylcholine receptors, although the ability of anandamide to inhibit this ligand-gated ion channel does not seem to depend on its conversion to this unsaturated fatty acid (Oz et al., 2003, 2004a).
3. Glycine Receptors. At least some cannabinoid receptor agonists have been found to modulate glycineinduced activation of subunits of glycine receptors with significant potency in a positive or negative manner. Thus, for example, results obtained from experiments with transfected cells (Hejazi et al., 2006; Yang et al., 2008) suggest the following:

- Activation of human $\alpha 1$ subunits is enhanced by anandamide $\left(\mathrm{IC}_{50}=38\right.$ or $\left.319 \mathrm{nM}\right), \Delta^{9}-\mathrm{THC}\left(\mathrm{IC}_{50}=\right.$ $86 \mathrm{nM})$, and HU-210 ( $\left.\mathrm{IC}_{50}=270 \mathrm{nM}\right)$ but weakly inhibited by HU-308 and unaffected by $R-(+)-$ WIN55212 at $30 \mu \mathrm{M}$.

- Activation of neither human $\alpha 2$ nor rat $\alpha 3$ subunits is affected by anandamide at up to $30 \mu \mathrm{M}$, whereas activation of both is inhibited by HU-210 $\left(\mathrm{IC}_{50}=90\right.$ and $50 \mathrm{nM}$, respectively), $R$-(+)-WIN55212 $\left(\mathrm{IC}_{50}=\right.$ 220 and $86 \mathrm{nM}$, respectively), and HU-308 $\left(\mathrm{IC}_{50}=\right.$ 1130 and $97 \mathrm{nM}$, respectively).

- Activation of human $\alpha 1 \beta 1$ dimers is enhanced by anandamide and $\Delta^{9}$-THC $\left(\mathrm{IC}_{50}=318\right.$ and $73 \mathrm{nM}$, respectively).

- Activation of human $\alpha 1 \beta$ subunits is enhanced by anandamide $\left(\mathrm{IC}_{50}=75 \mathrm{nM}\right)$ and HU-210 $(30 \mu \mathrm{M})$ but unaffected by $R$-(+)-WIN55212 and inhibited by HU-308 at $30 \mu \mathrm{M}$.

$\Delta^{9}$-THC $\left(\mathrm{IC}_{50}=115 \mathrm{nM}\right)$ and anandamide $\left(\mathrm{IC}_{50}=230\right.$ $\mathrm{nM}$ ) have also been found to enhance the activation of native glycine receptors in rat isolated ventral tegmental area neurons (Hejazi et al., 2006). There is evidence too, from experiments with rat isolated hippocampal pyramidal neurons, that at 0.2 to $2 \mu \mathrm{M}$, anandamide and 2-AG can antagonize glycine receptor activation, and that this effect of anandamide is not TRPV1 channelmediated (Lozovaya et al., 2005).

4. Other Ligand-Gated Ion Channels. Evidence has also been obtained that anandamide $(\geq 100 \mathrm{nM})$ and $R$-(+)-methanandamide $(1 \mu \mathrm{M})$ but not $\Delta^{9}$-THC $(\leq 10$ $\mu \mathrm{M})$ can enhance NMDA-induced activation of NMDA 
receptors (Hampson et al., 1998). In contrast, anandamide $(1-100 \mu \mathrm{M})$ has been found not to affect binding of $\left[{ }^{3} \mathrm{H}\right]$ muscimol to $\mathrm{GABA}_{\mathrm{A}}$ receptors in bovine cerebral cortical synaptic membranes or, indeed, binding of the benzodiazepine $\left[{ }^{3} \mathrm{H}\right]$ flunitrazepam to these membranes (Kimura et al., 1998). Binding of $\left[{ }^{3} \mathrm{H}\right]$ flunitrazepam to synaptic membranes, however, has been found to be decreased by 11 -hydroxy- $\Delta^{8}-\mathrm{THC}$ at $10 \mu \mathrm{M}$ (Yamamoto et al., 1992).

5. Conclusions. Some established endogenous and nonendogenous $\mathrm{CB}_{1} / \mathrm{CB}_{2}$ receptor agonists seem to block $5-\mathrm{HT}_{3}$ and nicotinic acetylcholine receptors or enhance the activation of glycine and NMDA receptors (Table 5), the relative potencies displayed by these cannabinoids as blockers or enhancers of ligand-gated ion channel activation differing from those they display as $\mathrm{CB}_{1}$ or $\mathrm{CB}_{2}$ receptor agonists. One $\mathrm{CB}_{1}$ receptor antagonist/ inverse agonist, LY320135, has also been found to block $5-\mathrm{HT}_{3}$ receptors. Many of these effects on ligand-gated ion channel activation are induced by cannabinoid concentrations in the low to mid-nanomolar range and hence with significant potency. Even so, no convincing case can be made for reclassifying glycine, NMDA, $5-\mathrm{HT}_{3}$, or nicotinic acetylcholine receptors as a novel cannabinoid receptor because 1) there is no evidence that glycine or NMDA receptors can be directly activated by any cannabinoid and 2) $5-\mathrm{HT}_{3}$ and nicotinic acetylcholine receptors are blocked rather than activated by cannabinoids; this blockade seems to be noncompetitive/allosteric in nature. There is also some evidence that benzodiazepine receptors do not behave as cannabinoid receptors. Thus, there have been reports that benzodiazepine receptors are not targeted by anandamide and that although these receptors can be targeted by 11-hydroxy- $\Delta^{8}$-THC, this occurs at the rather high ligand concentration of $10 \mu \mathrm{M}$.

\section{E. TRPV1 and other Transient Receptor Potential Channels}

1. Transient Receptor Potential Channels: A Brief Introduction. The transient receptor potential (TRP) superfamily of cation channels includes six subfamilies: "canonical," "vanilloid" (TRPV), "melastatin" (TRPM) "polycystin," "mucolipin," and "ankyrin" (TRPA). TRP channels are six-transmembrane (TM) domain integral membrane proteins with cytosolic $\mathrm{C}$ - and $\mathrm{N}$-terminal domains and a nonselective cation-permeable pore region between TMs 5 and 6 (Owsianik et al., 2006). The various subfamilies differ particularly in the number of ankyrin repeats present in the $\mathrm{N}$ termini, which is null in TRPM and very high in TRPA channels. More than 50 members of the TRP family have been characterized in yeast, worms, insects, and fish and 28 in mammals so far (Nilius and Voets, 2005). They are involved in the transduction of a remarkable range of stimuli, including temperature, mechanical and osmotic stimuli, electrical charge, light, olfactive and taste stimuli, hypotonic cell swelling, and effects of xenobiotic substances and endogenous lipids (Venkatachalam and
Montell, 2007). It is noteworthy that mutations in different TRPs have been linked to human diseases, and their expression in tissues affected by pathological conditions is often increased (Nilius et al., 2007). To date, five types of TRP channels belonging to three subfamilies have been suggested to interact with phytocannabinoids, synthetic $\mathrm{CB}_{1}$ and $\mathrm{CB}_{2}$ receptor ligands, or endocannabinoids: TRPV1, TRPV2, TRPV4, TRPM8, and TRPA1. Data on these interactions are increasing and, importantly, have prompted two different research groups to propose that at least some TRP channels could be "ionotropic cannabinoid receptors" (Di Marzo et al., 2002; Akopian et al., 2009).

2. TRPV1 Channels. TRPV1 (initially known as VR1) was the first TRP channel to be cloned as a receptor for capsaicin, the natural product responsible for the pungency of hot chilli peppers (Caterina et al., 1997). It is also activated by noxious stimuli, such as heat $\left(>43^{\circ} \mathrm{C}\right)$, protons $(\mathrm{pH}<6.9)$, and various other natural toxins. Consistent with the hypothesis that it is involved in pain, nociception, and temperature sensing (Caterina et al., 2000; Davis et al., 2000), TRPV1 is predominantly expressed in sensory neurons of unmyelinated axons (C fibers) and thin myelinated axons (A $\delta$ fibers) of dorsal root and trigeminal ganglia (Holzer, 1988; Caterina et al., 1997; Tominaga et al., 1998), where it can become upregulated during nerve injury-induced thermal hyperalgesia (Rashid et al., 2003b) and diabetic neuropathy (Rashid et al., 2003a). Evidence has accumulated for the presence of TRPV1 not only in sensory neurons but also in brain neurons and in non-neuronal cells, including epithelial, endothelial, glial, smooth muscle, mast and dendritic cells, lymphocytes, keratinocytes, osteoclasts, hepatocytes, myotubes, fibroblasts, and pancreatic $\beta$-cells (for review, see Starowicz et al., 2007). It is noteworthy that TRPV1 colocalizes with $\mathrm{CB}_{1}$ receptors in sensory (e.g., dorsal root ganglia and spinal cord) (Ahluwalia et al., 2003a; Price et al., 2004) and brain (Cristino et al., 2006) neurons and with $\mathrm{CB}_{2}$ receptors in sensory neurons (Anand et al., 2008) and osteoclasts (Rossi et al., 2009). This colocalization makes possible several types of intracellular cross-talk (for review, see Di Marzo and Cristino, 2008) and might have important functional consequences for those endogenous and synthetic ligands that activate both cannabinoid and TRPV1 receptors (Hermann et al., 2003; Fioravanti et al., 2008).

In fact, it is now well established from experimental work described in more than 300 articles that endocannabinoids, such as anandamide and $N$-arachidonoyl dopamine but not 2-AG, noladin ether, or virodhamine, bind to both human and rat TRPV1, upon which they act as full agonists (Zygmunt et al., 1999; for review, see Starowicz et al., 2007; Tóth et al., 2009). Although the affinity of these compounds in binding assays with the human recombinant channel is similar to, or only slightly lower than, that of capsaicin (Ross et al., 2001b; Di Marzo et al., 2002), their relative intrinsic activity and particularly their potency (Table 6) depends on the type of TRPV1 functional assay in which these pharmacological properties are assessed (i.e., enhancement of 
CANNABINOID RECEPTORS AND THEIR LIGANDS

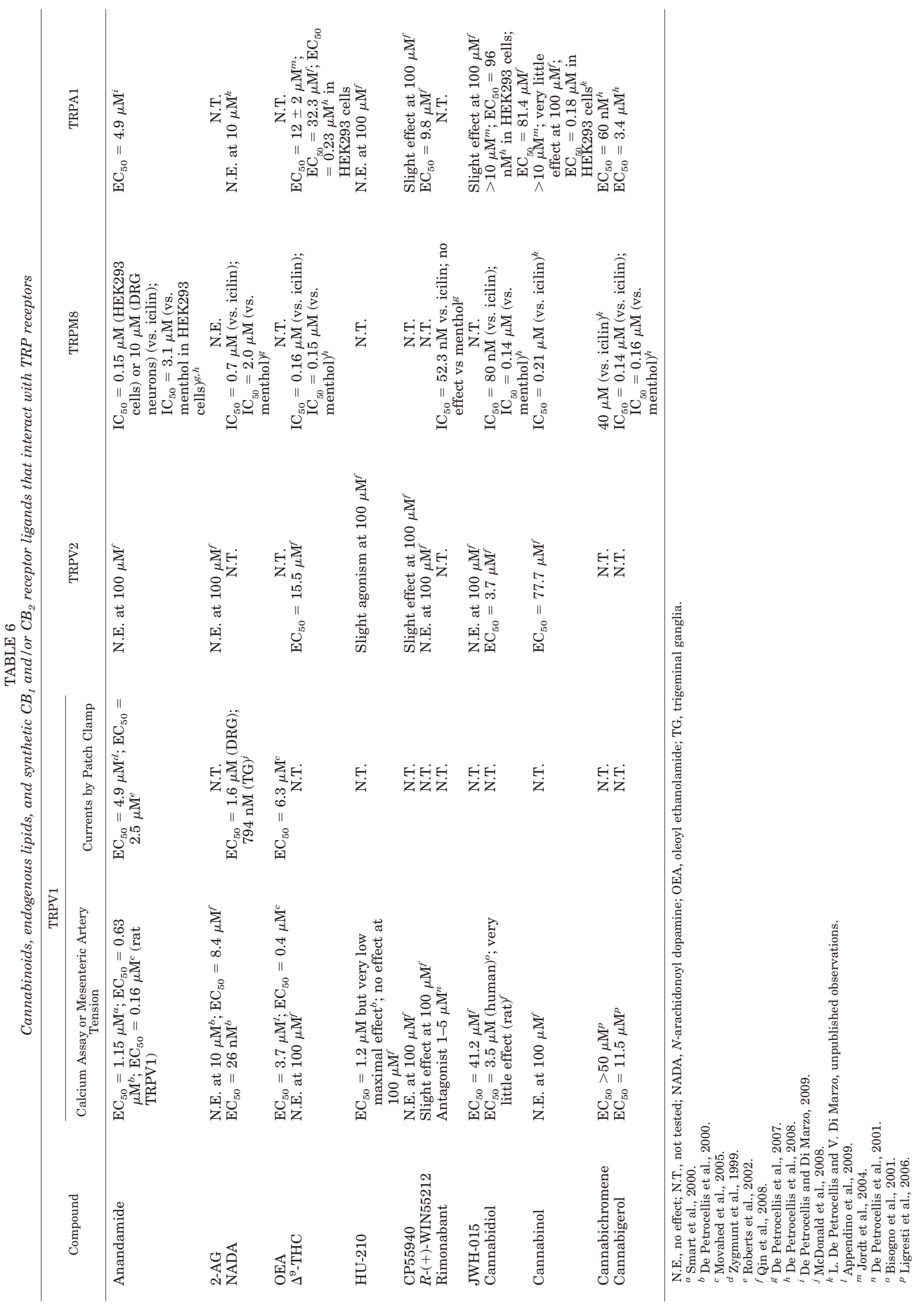


intracellular $\mathrm{Ca}^{2+}$ levels, induction of cation currents in neurons, or release of algogenic/vasodilatory peptides from sensory nervous tissue preparations) and on the experimental conditions used to carry out these assays. Furthermore, TRPV1 gating by its ligands can be markedly altered by several regulatory events and signals, including post-translational modifications (such as phosphorylation by several protein kinases), allosteric modulation by temperature, acid, membrane potential, membrane phospholipids (phosphatidylinositol bisphosphate in particular), metabotropic (including cannabinoid) receptor activation, neurotrophins, etc., all of which can be modulated by inflammatory and other pathological conditions. As a result, apparent anandamide-induced activation of TRPV1 has often been found to increase or decrease under such conditions. It has been proposed, for example, that endogenously released anandamide has higher efficacy and potency (Ahluwalia et al., 2003b). Although anandamide may be less potent as a TRPV1 agonist than as a $\mathrm{CB}_{1}$ receptor agonist, elevation of its endogenous levels with fatty acid amide hydrolase (FAAH) inhibitors [e.g., cyclohexylcarbamic acid 3'-carbamoyl-biphenyl-3-yl ester (URB597)] can lead to effects that are mediated by TRPV1 (Maione et al., 2006; Morgese et al., 2007; Rubino et al., 2008). This, together with data indicating that exogenous anandamide can exert effects at TRPV1 in a way sensitive to inhibitors of anandamide cellular uptake in HEK293 cells (De Petrocellis et al., 2001), trigeminal neurons (Price et al., 2005b), and, ex vivo, in mesenteric arteries (Andersson et al., 2002) represents strong indirect evidence that both endogenous and exogenous anandamide reaches its intracellular binding site on this molecular target.

It is noteworthy that anandamide and $N$-arachidonoyl dopamine seem to interact with TRPV1 at the same intracellular binding site as capsaicin. Jordt and Julius (2002) observed that the TM3/4 region of the mammalian TRPV1 receptor is responsible for its sensitivity to capsaicin and anandamide, whereas the avian receptor, which is activated only by heat or protons, lacks part of this region. The binding site is located on the inner face of the plasma membrane, thus opening up the possibility that when anandamide is biosynthesized by cells that express TRPV1, it will activate this receptor before being released, thereby regulating $\mathrm{Ca}^{2+}$ homeostasis as an intracellular messenger (van der Stelt et al., 2005). A crucial role for Tyr511 and Ser512, located at the transition between the second intracellular loop and TM3, has been demonstrated, and other critical residues seem to be in the TM4 segment (Jordt and Julius, 2002; Johnson et al., 2006). Tyr511 engages in a hydrophobic interaction with the hydrophobic tails of capsaicin, anandamide, and $N$-arachidonoyl dopamine, whereas the side-chain hydroxyl group of Thr550, as well as the aromatic region of Trp549, both present in the TM4 domain, might interact with the vanillyl, catecholamine, or ethanolamine moiety of TRPV1 ligands.

Synthetic $\mathrm{CB}_{1}$ and $\mathrm{CB}_{2}$ receptor ligands, such as $\mathrm{HU}-210$, $\mathrm{JWH}-015$, and rimonabant, have also been reported to interact with TRPV1, although usually with lower relative intrinsic activity and potency than anandamide, whereas $N$-arachidonoyl dopamine displays markedly greater potency than anandamide as a TRPV1 agonist (Table 6) (De Petrocellis et al., 2001; Qin et al., 2008). In contrast, phytocannabinoids that do not activate $\mathrm{CB}_{1}$ receptors, such as cannabidiol and cannabigerol (section II.C.5), were shown to act as full agonists at TRPV1 receptors (Bisogno et al., 2001; Ligresti et al., 2006). Cannabidiol, in particular, exhibits almost the same $K_{\mathrm{i}}$ as capsaicin at the human TRPV1 receptor (Bisogno et al., 2001), but seems to be significantly less potent at rat TRPV1 (Qin et al., 2008). It is noteworthy that anandamide and $\mathrm{N}$-arachidonoyldopamine congeners with little or no activity at $\mathrm{CB}_{1} / \mathrm{CB}_{2}$ receptors, such as oleoyl ethanolamide, linoleoyl ethanolamide, and $N$-oleoyl dopamine (section II.C.5), are also potent TRPV1 agonists (Movahed et al., 2005).

3. Other TRPV Channels. Apart from TRPV1, five other TRPV channels, all insensitive to capsaicin, have been identified and cloned to date. TRPV2, -3 , and -4 are involved in high-temperature sensing and nociception, whereas TRPV5 and -6 intervene in $\mathrm{Ca}^{2+}$ absorption/ reabsorption (for review, see Vennekens et al., 2008). TRPV2 was previously known as growth factor-regulated $\mathrm{Ca}^{2+}$ channel or vanilloid receptor-like 1 and is activated by higher temperatures than TRPV1, but not by protons (Qin et al., 2008). Strong evidence (albeit obtained so far in only one laboratory) exists for the interaction of cannabidiol, $\Delta^{9}$-THC, cannabinol, and, to a smaller extent, 11-hydroxy- $\Delta^{9}$-THC, nabilone, CP55940, and HU-210, with TRPV2. These effects were observed by measuring elevation of intracellular $\mathrm{Ca}^{2+}$ in HEK293 cells transfected with rat recombinant TRPV2 cDNA. Apart from cannabidiol, these compounds exhibited $\mathrm{EC}_{50}$ values much higher, or $E_{\max }$ values much lower, than those observed in functional assays that measure cannabinoid receptor-mediated responses (Table 6). It is noteworthy that cannabidiol has also been found to evoke TRPV2-mediated cation currents and release of calcitonin gene-related peptide in cultured dorsal root ganglion (DRG) neurons (Qin et al., 2008). Because TRPV2, like TRPV1, is immediately desensitized by its agonists, these findings might explain some of the anti-inflammatory and/or analgesic properties of cannabidiol.

TRPV4 is activated by a variety of physical and chemical stimuli, including heat and decreases in osmolarity (Everaerts et al., 2010). TRPV4 was originally reported to be activated by anandamide and 2-AG, probably via the formation of cytochrome P450 metabolites of arachidonic acid, such as epoxyeicosatrienoic acids (Watanabe et al., 2003). It is noteworthy that cytochrome P450 metabolites of anandamide activate cannabinoid recep- 
tors (Chen et al., 2008) but have never been tested on TRPV4.

4. Other TRP Channels: TRPM8 and TRPA1. TRPM8 and TRPA1 belong to two subfamilies different from that of the capsaicin (TRPV1) receptor but are still involved in thermosensation. Indeed, TRPM8 and TRPA1 were suggested to be activated by cold temperatures as well as by natural compounds (such as menthol in the case of TRPM8) and by various irritants [(mustard oil isothiocyanates, acrolein, etc.) in the case of TRPA1] (for review, see McKemy 2005). Recent evidence has emerged that both anandamide and $N$-arachidonoyl dopamine, but not 2-AG, can efficaciously antagonize the stimulatory effect of two TRPM8 agonists, menthol and the synthetic compound icilin, on intracellular $\mathrm{Ca}^{2+}$ elevation in HEK293 cells transfected with rat recombinant TRPM8 (De Petrocellis et al., 2007), as well as in DRG neurons (De Petrocellis et al., 2008). It is noteworthy that they did this in a cannabinoid receptor-independent manner. The concentrations at which anandamide exerted this effect ranged from submicromolar to $10 \mu \mathrm{M}$, depending on the type of TRPM8 agonist and cellular system used for the $\mathrm{Ca}^{2+}$ assay. It is noteworthy that several nonpsychotropic phytocannabinoids exert a similar action at TRPM8, and at significantly lower concentrations. Cannabidiol, cannabigerol, $\Delta^{9}-\mathrm{THC}$, and $\Delta^{9}$ THC-acid were almost equipotent $\left(\mathrm{IC}_{50}=70-160 \mathrm{nM}\right.$ in transfected HEK293 cells), whereas cannabidiolic acid was the least potent among the tested compounds $\left(\mathrm{IC}_{50}=0.9-1.6 \mu \mathrm{M}\right)$ (De Petrocellis et al., 2008).

Evidence that TRPA1 (ANKTM1) is activated by phytocannabinoid $\mathrm{CB}_{1} / \mathrm{CB}_{2}$ receptor agonists [i.e., $\Delta^{9}$-THC and cannabinol (sections II.C.1 and II.C.5)], was first described in the article reporting the cloning of this channel (Jordt et al., 2004). The authors of this article showed that concentrations of these two compounds $\geq 10$ $\mu \mathrm{M}$ were necessary to induce TRPA1-mediated effects, including endothelium- and $\mathrm{CB}_{1} / \mathrm{CB}_{2}$-independent vasodilation of rat mesenteric arteries. Later, Akopian et al. (2008) showed that micromolar concentrations of $R-(+)-$ WIN55212 as well as the CB $_{2}$-selective agonist AM1241 1) elicited TRPA1-mediated elevation of $\mathrm{Ca}^{2+}$ and currents in transfected $\mathrm{CHO}$ cells and trigeminal neurons; 2) desensitized TRPA1- and TRPV1-expressing cells to the action of capsaicin; 3) inhibited capsaicin-evoked nocifensive behavior in vivo in wild-type mice and much less so in TRPA1-null mutant mice (Akopian et al., 2008). Qin et al. (2008) recently confirmed that $\Delta^{9}$-THC and $R$-(+)-WIN55212 activate rat recombinant TRPA1 and also found that the cannabinoid receptor-inactive isomer of the latter compound, S-(-)-WIN55212, exerts a similar action, although at higher concentrations. Furthermore, the cannabinoid quinone $3 S, 4 R$-p-benzoquinone-3hydroxy-2-p-mentha-(1,8)-dien-3-yl-5-pentyl (HU-331) was also quite potent. Almost at the same time, De Petrocellis et al. (2008) found that in HEK293 cells transfected with rat TRPA1, $\Delta^{9}$-THC could be much more potent at eliciting TRPA1-mediated elevation of intracellular $\mathrm{Ca}^{2+}$ than previously suspected and that several nonpsychotropic phytocannabinoids were even more potent, cannabichromene $\left(\mathrm{EC}_{50}=60 \mathrm{nM}\right)$ being the most potent and cannabigerol and cannabidiolic acid $\left(\mathrm{EC}_{50}=3.4-\right.$ $12.0 \mu \mathrm{M})$ the least potent. Cannabichromene also activated mustard oil-sensitive (TRPA1-expressing) DRG neurons, although with lower potency $\left(\mathrm{EC}_{50}=34.3 \mu \mathrm{M}\right)$. It is noteworthy that anandamide was also recently reported to weakly but efficaciously stimulate TRPA1mediated elevation of intracellular $\mathrm{Ca}^{2+}$ in transfected HEK293 cells $\left(\mathrm{EC}_{50}=4.9 \mu \mathrm{M}\right)($ De Petrocellis and Di Marzo, 2009).

5. Conclusions. That some endocannabinoids, particularly anandamide, exert pharmacological effects in vivo by activating TRPV1 receptors has now been demonstrated in hundreds of investigations, including some in which supporting evidence was obtained from experiments with TRPV1-null mice. Furthermore, although $\Delta^{9}$-THC exerts only very weak effects at TRPV1, phytocannabinoids that do not activate $\mathrm{CB}_{1} / \mathrm{CB}_{2}$-receptors, on the one hand, and synthetic $\mathrm{CB}_{1} / \mathrm{CB}_{2}$ ligands, on the other hand, have been shown to interact with this protein with significant potency and/or relative intrinsic activity. Thus, a strong case can be made for classifying TRPV1 as an "ionotropic cannabinoid receptor," although this channel is clearly targeted less selectively than cannabinoid $\mathrm{CB}_{1}$ or $\mathrm{CB}_{2}$ receptors because its activity can be directly modulated by several endogenous or xenobiotic compounds that are not $\mathrm{CB}_{1}$ or $\mathrm{CB}_{2}$ receptor ligands. The capability of endocannabinoids and cannabidiol to inhibit TRPM8 functional responses might be a consequence, in part, of their agonist activity at TRPV1, because it has been observed that most of the regulatory events and mediators that affect this latter channel in one direction often affect the TRPM8 channel in the opposite direction (De Petrocellis et al., 2007). Further studies should be carried out to investigate fully the possibility that TRPA1 mediates some of the pharmacological effects of phytocannabinoids and/or synthetic $\Delta^{9}$-THC-mimetic compounds, although the fact that this TRP channel is also extremely promiscuous in its responsiveness to physiological and synthetic ligands should be kept in mind. Finally, too little evidence exists to date to allow any conclusions to be drawn about whether or not other TRP channels (e.g., TRPV2 and TRPV4) might be putative cannabinoid receptors.

\section{F. Other Ion Channels}

1. Calcium Channels. Certain cannabinoid receptor agonists (Table 7) and antagonists have been found to antagonize T-type voltage-gated calcium channels at concentrations in the mid-nanomolar or low micromolar range. Thus, for example, evidence has been obtained (Chemin et al., 2001, 2007; Ross et al., 2008, 2009) for $\mathrm{CB}_{1}$ receptor-independent inhibition of the following: 
TABLE 7

Apparent cannabinoid $C B_{1}$ receptor-independent effects of cannabinoid receptor agonists on ion channels other than TRP channels See Section III.F for references and further discussion.

\begin{tabular}{|c|c|c|c|c|}
\hline Ion Channel and Effect & Endocannabinoid(s)? & $\begin{array}{l}\text { Effective Concentration } \\
\text { Range }\end{array}$ & $\begin{array}{l}\text { Nonendogenous } \\
\text { Cannabinoid } \\
\text { Agonist(s)? }\end{array}$ & Effective Concentration Range \\
\hline \multicolumn{5}{|c|}{ Current enhancement/activation } \\
\hline $\mathrm{K}_{\mathrm{Ca}}(\mathrm{BK}) \mathrm{K}^{+}$ & $\operatorname{Yes}^{a}$ & Nanomolar or micromolar & $\operatorname{Yes}^{b}$ & Nanomolar or micromolar \\
\hline Voltage-gated $\mathrm{Na}^{+}$ & No & Micromolar & Yes & Nanomolar \\
\hline \multicolumn{5}{|l|}{ Inhibition } \\
\hline $\mathrm{Ca}^{2+}$ (native) & $\mathrm{Yes}^{c}$ & Nanomolar or micromolar & Yes $^{b}$ & Micromolar \\
\hline T-type $\mathrm{Ca}^{2+}\left(\mathrm{Ca}_{\mathrm{v}} 3.1\right)$ & $\mathrm{Yes}^{c}$ & Micromolar & Yes & Micromolar \\
\hline T-type $\mathrm{Ca}^{2+}\left(\mathrm{Ca}_{\mathrm{V}} 3.2\right)$ & Yes $^{a, c}$ & Nanomolar or micromolar & Yes & Micromolar \\
\hline T-type $\mathrm{Ca}^{2+}\left(\mathrm{Ca}_{\mathrm{V}} 3.3\right)$ & Yes $^{c}$ & Micromolar & Yes & Micromolar \\
\hline T-type $\mathrm{Ca}^{2+}$ (native) & N.D. & N.D. & Yes & Micromolar \\
\hline $\mathrm{N}-, \mathrm{P}-$, or $\mathrm{P} / \mathrm{Q}$-type $\mathrm{Ca}^{2+}$ & Yes $^{c}$ & Micromolar & Yes & Micromolar \\
\hline $\mathrm{K}_{\mathrm{ATP}} \mathrm{K}^{+}$ & $\mathrm{Yes}^{c, d}$ & Micromolar & Yes $^{b}$ & Micromolar \\
\hline TASK-1 $\mathrm{K}^{+}$ & Yes $^{a, c}$ & Nanomolar or micromolar & Yes & Nanomolar ${ }^{b}$ or micromolar \\
\hline TASK-3 $\mathrm{K}^{+}$ & Yes $^{c}$ & Micromolar & Yes $^{b}$ & Micromolar \\
\hline Voltage-gated $\mathrm{K}^{+}\left(\mathrm{K}_{\mathrm{V}}\right)$ & Yes $^{c}$ & Nanomolar or micromolar & Yes & Nanomolar ${ }^{b}$ or micromolar \\
\hline Voltage-gated $\mathrm{Na}^{+}$ & Yes & Micromolar & Yes & Micromolar $^{e}$ \\
\hline \multicolumn{5}{|l|}{ Radioligand binding $(\downarrow)$} \\
\hline L-type $\mathrm{Ca}^{2+}$ & $\mathrm{Yes}^{c, d}$ & Micromolar & $\operatorname{Yes}^{b}$ & Micromolar \\
\hline $\mathrm{K}_{\mathrm{ATP}} \mathrm{K}^{+}$ & Yes $^{c, d}$ & Micromolar & Yes $^{b}$ & Micromolar \\
\hline Voltage-gated $\mathrm{Na}^{+}$ & $\mathrm{Yes}^{d}$ & Micromolar & Yes $^{d}$ & Micromolar \\
\hline
\end{tabular}

N.D., no data.

${ }^{a}$ Anandamide but not 2-arachidonoyl glycerol.

${ }^{b}$ Only $R$-(+)-methanandamide.

${ }^{c}$ Also $R$-(+)-methanandamide.

${ }^{d}$ May target an allosteric site on this ion channel.

${ }^{e}$ Slight enhancement of sodium currents has also been detected in response to $10 \mathrm{nM} R$-(+)-WIN55212 (section III.G.3.).

- Cloned $\mathrm{Ca}_{\mathrm{V}} 3.1$ channels by anandamide $\left(\mathrm{IC}_{50}=4.2\right.$ $\mu \mathrm{M}), R$-(+)-methanandamide $(10 \mu \mathrm{M}), N$-arachidonoyl dopamine $\left(\mathrm{IC}_{50}=513 \mathrm{nM}\right)$, ACEA $(10 \mu \mathrm{M})$, and $\Delta^{9}$-THC $\left(\mathrm{IC}_{50}=1.6 \mu \mathrm{M}\right)$.

- Cloned $\mathrm{Ca}_{\mathrm{V}} 3.2$ channels by anandamide $\left(\mathrm{IC}_{50}=330\right.$ $\mathrm{nM}), N$-arachidonoyl dopamine $\left(\mathrm{IC}_{50}=1122 \mathrm{nM}\right)$, $R$-(+)-methanandamide $(1 \mu \mathrm{M})$, ACEA $(10 \mu \mathrm{M})$, $\Delta^{9}$-THC $\left(\mathrm{IC}_{50}=1.3 \mu \mathrm{M}\right), \mathrm{HU}-210(10$ but not $1 \mu \mathrm{M})$ and rimonabant (100 $\mathrm{nM}$ and $1 \mu \mathrm{M})$ but not by CP55940, $R$-(+)-WIN55212, or 2 -AG at $10 \mu \mathrm{M}$.

- Cloned $\mathrm{Ca}_{\mathrm{V}} 3.3$ channels by anandamide $\left(\mathrm{IC}_{50}=1.1\right.$ $\mu \mathrm{M})$ and $N$-arachidonoyl dopamine $\left(\mathrm{IC}_{50}=355\right.$ $\mathrm{nM})$, by $R$-(+)-methanandamide and ACEA at $10 \mu \mathrm{M}$, and by $\Delta^{9}$-THC $(4.3 \mu \mathrm{M})$.

- Native T-type calcium channels by $R$-(+)-methanandamide and $\Delta^{9}$-THC at $1 \mu \mathrm{M}$ and AM251 at $3 \mu \mathrm{M}$, but not by $R$-(+)-WIN55212 at $1 \mu \mathrm{M}$.

It is noteworthy that the phytocannabinoid cannabidiol has also been found to inhibit cloned $\mathrm{Ca}_{\mathrm{V}} 3.1$, $\mathrm{Ca}_{\mathrm{V}} 3.2$, and $\mathrm{Ca}_{\mathrm{V}} 3.3$ calcium channels, its reported $\mathrm{IC}_{50}$ values for this inhibition being 813, 776, and $3631 \mathrm{nM}$, respectively (Ross et al., 2008). In addition, a recent article reported that the endogenous lipo-amino acids, NAGly and $N$-arachidonoyl GABA, can potently inhibit $\mathrm{Ca}_{\mathrm{V}} 3.1, \mathrm{Ca}_{\mathrm{V}} 3.2$, and $\mathrm{Ca}_{\mathrm{V}} 3.3$ channels $\left(\mathrm{IC}_{50}<1.0 \mu \mathrm{M}\right)$ (Barbara et al., 2009).

In addition, there is evidence that anandamide, 2-AG, and $R$-(+)-methanandamide but not $\Delta^{9}$-THC, CP55940, or $R$-(+)WIN55212 can bind to L-type voltage-gated calcium channels, possibly in a noncompetitive/allosteric manner, their reported $\mathrm{IC}_{50}$ or apparent $K_{\mathrm{i}}$ values ranging from 3.2 to 40 $\mu \mathrm{M}$ (Johnson et al., 1993; Shimasue et al., 1996; Jarrahian and Hillard, 1997; Oz et al., 2000, 2004b). There have also been reports that 1$)$ displacement of $\left[n\right.$-methyl $\left.-{ }^{3} \mathrm{H}\right]$ diltiazem from L-type calcium channels can be induced by both rimon$\operatorname{abant}\left(\mathrm{IC}_{50}=6.1 \mu \mathrm{M}\right)$ and taranabant $\left(\mathrm{IC}_{50}=300 \mathrm{nM}\right)($ Fong et al., 2009); 2) that anandamide (100 nM) and rimonabant (1 $\mu \mathrm{M})$ can inhibit potassium-evoked $\mathrm{Ca}^{2+}$ influx into neonatal rat cultured DRG sensory neurons (Evans et al., 2004); and 3) that anandamide at $1 \mu \mathrm{M}$ and 2-AG and $R$-(+)-methanandamide, but not $\Delta^{9}$-THC, CP55940, or $R$-(+)-WIN55212 at 10 $\mu \mathrm{M}$, can inhibit depolarization-induced $\mathrm{Ca}^{2+}$ efflux in transverse tubule membrane vesicles ( $\mathrm{Oz}$ et al., 2000, 2004b). The data obtained in these investigations suggest that these effects of anandamide, 2-AG, and $R$-(+)-methanandamide on calcium flux were not $\mathrm{CB}_{1}$ receptor-mediated.

There is also evidence that at least some cannabinoids can antagonize N-, P-, and P/Q-type voltage-gated calcium channels. Thus, there have been reports that $\mathrm{N}$ - or $\mathrm{P} / \mathrm{Q}$-type channels can be antagonized at $10 \mu \mathrm{M}$ by $R$-(+)-WIN55212, $S$-(-)WIN55212, and anandamide, although not by 2-AG or noladin ether (Shen and Thayer, 1998; Guo and Ikeda, 2004), and that P-type channels can be antagonized by $R$-(+)WIN55212 $(10 \mu \mathrm{M})$, anandamide $\left(\mathrm{IC}_{50}=1.04 \mu \mathrm{M}\right), R$-(+)methanandamide $(2 \mu \mathrm{M})$, and $2-\mathrm{AG}(10 \mu \mathrm{M})$ (Fisyunov et al., 2006). These effects on N-, P- and P/Q-type channels seemed not to be $\mathrm{CB}_{1}$ receptor- or TRPV1 receptor-mediated. Arachidonic acid can also target T-, P-, and L-type channels, but it is unlikely that the ability of anandamide to antagonize these channels depends on its metabolic conversion to this acid (Shimasue et al., 1996; Jarrahian and Hillard, 1997; Oz et al., 2000; Chemin et al., 2001, 2007; Fisyunov et al., 2006).

2. Potassium Channels. Results obtained in a number of investigations suggest that several types of potassium 
channel can be targeted by certain cannabinoid receptor agonists (Table 7) and antagonists in a cannabinoid $\mathrm{CB}_{1}$ receptor-independent manner at concentrations in the nanomolar or low micromolar range. These are members of the 2TM domain family of channels ( $\mathrm{K}_{\mathrm{ATP}}$ channels), the 4TM domain family of leak or background channels (TASK and TREK), and the 6TM domain family of voltage-gated channels $\left(\mathrm{K}_{\mathrm{V}}\right.$ and calcium-activated $\mathrm{K}_{\mathrm{Ca}}$ channels).

Turning first to ATP-sensitive inward-rectifier $\left(\mathrm{K}_{\mathrm{ATP}}\right)$ channels, there is evidence that anandamide is a noncompetitive inhibitor of such channels $\left(\mathrm{IC}_{50}=8.1 \mu \mathrm{M}\right)$ and that this endocannabinoid also inhibits $\left[{ }^{3} \mathrm{H}\right]$ glibenclamide binding to $\mathrm{K}_{\text {АTP }}$ channels, again in a noncompetitive manner $\left(\mathrm{IC}_{50}=6.3 \mu \mathrm{M}\right)$. These channels can be inhibited by $R$-(+)-methanandamide at $10 \mu \mathrm{M}$ but not by rimonabant or SR144528 at $1 \mu \mathrm{M}$ (Oz et al., 2007).

Moving on to the 4TM domain family, it has been found that human or rat TASK-1 channels can be inhibited by $R$-(+)-methanandamide $\left(\mathrm{IC}_{50}=700 \mathrm{nM}\right)$, by anandamide at 3 and $10 \mu \mathrm{M}$, and by rimonabant (slight inhibition), CP55940, and $R$-(+)-WIN55212 but not $\Delta^{9}$-THC, HU-210, or 2-AG at $10 \mu \mathrm{M}$ (Maingret et al., 2001; Berg et al., 2004; Veale et al., 2007; Zhang et al., 2009). There have also been reports that human, rat, or mouse TASK-3 channels can be inhibited by $R$-(+)-methanandamide and anandamide at 1 to $10 \mu \mathrm{M}$ (Berg et al., 2004; Veale et al., 2007) and that bovine TREK-1 channels are inhibited by anandamide $\left(\mathrm{IC}_{50}=5.1 \mu \mathrm{M}\right)(\mathrm{Liu}$ et al., 2007).

As to $\mathrm{K}_{\mathrm{V}}$ channels, there is evidence for the following:

- $\mathrm{K}_{\mathrm{V}} 1.2$ channels are inhibited by anandamide $\left(\mathrm{IC}_{50}=\right.$ $2.7 \mu \mathrm{M})$, arachidonic acid $\left(\mathrm{IC}_{50}=6.6 \mu \mathrm{M}\right)$, and $\Delta^{9}$ THC $\left(\mathrm{IC}_{50}=2.4 \mu \mathrm{M}\right)$ (Poling et al., 1996).

- Human cardiac $\mathrm{K}_{\mathrm{V}} 1.5$ channels are inhibited by anandamide $\left(\mathrm{IC}_{50}=0.9 \mu \mathrm{M}\right), 2-\mathrm{AG}\left(\mathrm{IC}_{50}=2.5 \mu \mathrm{M}\right)$, and, with a similar potency, by both $R-(+)$-methanandamide and arachidonic acid (Barana et al., 2010).

- Human $\mathrm{K}_{\mathrm{V}} 1.5$ channels expressed on HEK293 cells are also blocked by anandamide, which displays significantly greater potency intracellularly $\left(\mathrm{IC}_{50}=213 \mathrm{nM}\right)$ than extracellularly $\left(\mathrm{IC}_{50}=2.1 \mu \mathrm{M}\right)$ (Moreno-Galindo et al., 2010).

- $\mathrm{K}_{\mathrm{V}} 3.1$ channels are inhibited by anandamide (0.1-3 $\mu \mathrm{M})$ and arachidonic acid (3 $\mu \mathrm{M})$ (Oliver et al., 2004) and cardiac $\mathrm{K}_{\mathrm{V}} 4.3$ channels are inhibited by anandamide $\left(\mathrm{IC}_{50}=400 \mathrm{nM}\right), R$-(+)-methanandamide $\left(\mathrm{IC}_{50}=\right.$ $600 \mathrm{nM}$ ), and 2-AG $\left(\mathrm{IC}_{50}=300 \mathrm{nM}\right.$ ) (Amorós et al., 2010).

In addition, there has been a report that $\mathrm{K}_{\mathrm{V}}$ channels can be inhibited not only by anandamide $\left(\mathrm{IC}_{50}=600 \mathrm{nM}\right)$ and $R$-(+)-methanandamide $(10 \mu \mathrm{M})$ but also by rimonabant $(10 \mu \mathrm{M})$ and $R$-(+)-WIN55212 $(20 \mu \mathrm{M})$, although not by arachidonic acid (Van den Bossche and Vanheel, 2000). It has been found too that both rimonabant $\left(\mathrm{IC}_{50}=2.5\right.$ $\mu \mathrm{M})$ and taranabant $\left(\mathrm{IC}_{50}=2.3 \mu \mathrm{M}\right)$ can induce radiolabeled ligand displacement from rapid delayed rectifier $\mathrm{K}_{\mathrm{V}}$ channels (Fong et al., 2009). Evidence has also recently been obtained that anandamide $(1 \mu \mathrm{M})$ can strongly inhibit $\mathrm{K}_{\mathrm{V}}$ channel-mediated delayed rectifier outward potassium current (Vignali et al., 2009). A similar degree of inhibition was induced by $R$-(+)-methanandamide $(1 \mu \mathrm{M})$. However, both $R$-(+)-WIN55212 and 2-AG induced less inhibition at $1 \mu \mathrm{M}$ than anandamide.

Finally, there is evidence that anandamide $\left(\mathrm{EC}_{50}=631\right.$ $\mathrm{nM}$ or $4.8 \mu \mathrm{M})$ and $R$-(+)-methanandamide $\left(\mathrm{EC}_{50}=7.9 \mu \mathrm{M}\right)$ but not 2-AG (up to $10 \mu \mathrm{M}$ ) can increase the activity of $\mathrm{K}_{\mathrm{Ca}}$ (BK) channels (White et al., 2001; Godlewski et al., 2009). Results obtained in experiments with rat isolated coronary arteries also suggest that such activation can be produced by both anandamide and $R$-(+)-methanandamide at concentrations of 0.3 to $3 \mu \mathrm{M}$, although not by JWH-133 at $1 \mu \mathrm{M}$ (Sade et al., 2006).

3. Sodium Channels. There is evidence that voltagegated sodium channels can be targeted by some cannabinoid receptor agonists at concentrations in the nanomolar or micromolar range (Table 7). Thus, for example, $R-(+)-$ WIN55212 has been found by Fu et al. (2008) to induce a slight enhancement (11.5\%) of voltage-gated sodium currents in rat cultured trigeminal ganglion neurons at $10 \mathrm{nM}$ but to inhibit these currents at higher concentrations $\left(\mathrm{IC}_{50}=17.8\right.$ $\mu \mathrm{M})$. In an earlier investigation, Nicholson et al. (2003) also found that $R$-(+)-WIN55212 can inhibit voltage-gated sodium channels. More specifically, they obtained evidence that this aminoalkylindole can act in a $\mathrm{CB}_{1}$ receptor-independent manner to inhibit 1) depolarization of mouse brain synaptoneurosomes induced by the sodium channel-selective activator veratridine $\left(\mathrm{IC}_{50}=21.1 \mu \mathrm{M}\right) ; 2$ ) veratridine-dependent release of L-glutamic acid $\left(\mathrm{IC}_{50}=12.2 \mu \mathrm{M}\right)$ and $\gamma$-aminobutyric acid $\left(\mathrm{IC}_{50}=14.4 \mu \mathrm{M}\right)$ from mouse purified whole-brain synaptosomes; and 3) the binding of the sodium channel site 2-selective ligand $\left[{ }^{3} \mathrm{H}\right]$ batrachotoxinin A 20 - $\alpha$-benzoate, to mouse brain synaptoneurosomal voltage-gated sodium channels $\left(\mathrm{IC}_{50}=19.5 \mu \mathrm{M}\right)$. Anandamide displayed similar inhibitory activity in these four bioassays $\left(\mathrm{IC}_{50}=21.8,5.1,16.5\right.$, and $23.4 \mu \mathrm{M}$, respectively) (Nicholson et al., 2003) as did $\mathrm{AM} 251\left(\mathrm{IC}_{50}=8.9,8.5,9.2\right.$, and $11.2 \mu \mathrm{M}$, respectively) (Liao et al., 2004). CP55940, $\mathrm{N}$-arachidonoyl dopamine, noladin ether, and 2-AG have also been found to displace $\left[{ }^{3} \mathrm{H}\right]$ batrachotoxinin A 20 - $\alpha$-benzoate from mouse brain synaptoneurosomal voltage-gated sodium channels $\left(\mathrm{IC}_{50}=22.3,20.7,51.2\right.$, and $90.4 \mu \mathrm{M}$, respectively) (Duan et al., 2008a,b). The mechanism underlying the inhibition of binding induced in this assay by these four compounds, and by AM251 and anandamide but not by $R$-(+)-WIN55212, could well be allosteric in nature (Nicholson et al., 2003; Liao et al., 2004; Duan et al., 2008a,b). It has been found too by Duan et al. (2008a) that the ability of $R$-(+)-WIN55212 and anandamide to inhibit veratridine-dependent depolarization of mouse synaptoneurosomes (Nicholson et al., 2003) extends to CP55940 $\left(\mathrm{IC}_{50}=3.2 \mu \mathrm{M}\right)$. This inhibition was produced by CP55940 in a noncompetitive manner. There have also been reports that voltage-gated sodium channels can be inhibited by anandamide in rat DRG sensory neurons (apparent $K_{\mathrm{d}}=5.4$ and 38.4 $\mu \mathrm{M}$ for tetrodotoxin-sensitive and tetrodotoxin-resistant so- 
dium currents, respectively) (Kim et al., 2005) and by $R$-(+)WIN55212 $(10 \mu \mathrm{M})$ and noladin ether $(50 \mu \mathrm{M})$ in frog parathyroid cells (Okada et al., 2005).

4. Conclusions. Several established endogenous and nonendogenous $\mathrm{CB}_{1} / \mathrm{CB}_{2}$ receptor agonists and some $\mathrm{CB}_{1}$ receptor antagonists can induce $\mathrm{CB}_{1}$ receptor-independent blockade of certain types of calcium, potassium, and sodium channels (Table 7), sometimes in an apparently noncompetitive/allosteric manner. Such blockade is induced by these agonists and antagonists at micromolar or nanomolar concentrations. There is also evidence that anandamide and $R$-(+)-methanandamide can activate $\mathrm{K}_{\mathrm{Ca}}(\mathrm{BK})$ channels and that a subinhibitory concentration of $R$-(+)-WIN55212 (10 $\mathrm{nM}$ ) can enhance voltage-gated sodium currents. Given the relatively high (nanomolar) potency with which $\mathrm{Ca}_{\mathrm{V}} 3.2$, $\mathrm{K}_{\mathrm{V}} 1.5$, and $\mathrm{K}_{\mathrm{Ca}}(\mathrm{BK})$ channels can apparently be targeted by anandamide, further research directed at seeking out $\mathrm{CB}_{1}$ receptor-independent physiological and/or pathological roles of these ion channels in the endocannabinoid system is clearly warranted.

\section{G. Peroxisome Proliferator-Activated Receptors}

Peroxisome proliferator-activated receptors (PPARs) are ligand-activated transcription factors that constitute part of the nuclear receptor family (Michalik et al., 2006). Activated PPARs form functional units as heterodimers with retinoid X receptors. Classical agonists at PPARs are fatty acids and their derivatives, ranging from oleic acid and arachidonic acid to leukotriene $\mathrm{B}_{4}$ and 15-deoxy- $\Delta^{12,14}$-prostaglandin $\mathrm{J}_{2}$. It is a widespread view that PPARs are not activated by a single endogenous ligand but are generalized lipid sensors, monitoring local changes in metabolism. There are three PPAR isoforms, PPAR $\alpha, \operatorname{PPAR} \beta$, and PPAR $\gamma$. PPAR $\alpha$ is the target of the clinically employed antihyperlipidemic fibrates, including gemfibrozil and fenofibrate. PPAR $\gamma$ is a therapeutic target in type 2 diabetes. Its ligands include pioglitazone, rosiglitazone, and troglitazone, which are known collectively as thiazolidinediones. $\operatorname{PPAR} \beta$ is also known as PPAR $\delta$ on the basis of differential naming of species orthologs and has yet to be targeted effectively in the clinic. All three isoforms are expressed in liver to some degree, although PPAR $\alpha$ predominates in skeletal muscle and PPAR $\gamma$ in adipose tissue. Because they are nuclear receptors, signal transduction at PPARs is primarily directed through alterations in gene transcription. A number of PPAR target genes have been identified, many of which are associated with lipid turnover, such as long-chain fatty acylCoA dehydrogenase and lipoprotein lipase; these are often used as markers of PPAR activation both in vitro and in vivo.

1. Direct Evidence for Peroxisome Proliferator-Activated Receptor Activation or Occupancy by Cannabinoids and Related Molecules. A number of cannabinoid $\mathrm{CB}_{1} / \mathrm{CB}_{2}$ agonists have also been reported to be PPAR agonists in in vitro experiments (Table 8). These include the
TABLE 8

Potency of cannabinoids and endocannabinoid-like molecules at peroxisome proliferator-activated receptors $\left(E C_{50}\right.$ or $I C_{50}$ values or effective concentrations)

\begin{tabular}{lccc}
\hline \multicolumn{1}{c}{$\begin{array}{c}\text { Cannabinoid or Related } \\
\text { Molecule }\end{array}$} & $\operatorname{PPAR} \alpha$ & $\operatorname{PPAR} \beta / \delta$ & $\operatorname{PPAR} \gamma$ \\
\hline \multicolumn{1}{c}{ Palmitoyl ethanolamide } & $3^{a}$ & $\mu M$ & \\
Stearoyl ethanolamide & $>30^{a}$ & N.D. & N.D. \\
Oleoyl ethanolamide & $0.12^{c} ; 0.12^{d}$ & $1^{c}$ & $>10^{c}$ \\
Anandamide & $10^{c} ; 10$ to $30^{e}$ & N.D. & $8^{b} ; 10^{f}$ \\
2-AG & N.D. & $>1^{g}$ & $10^{f} ; \sim 30^{h}$ \\
Noladin ether & 10 to $30^{e}$ & N.D. & $\sim 30^{h}$ \\
Virodhamine & 10 to $30^{e}$ & N.D. & N.D. \\
$R$-(+)-WIN55212 & $20^{e}$ & N.D. & N.D. \\
$\Delta^{9}$-THC & $>100^{e}$ & N.D. & $\sim 0.3^{i}$ \\
Cannabidiol & N.D. & N.D. & $5^{j}$ \\
Ajulemic acid & $>50^{j}$ & $>50^{j}$ & $0.6^{j} ; 13^{k}$ \\
Rimonabant & Activation & N.D. & $10^{l}$ \\
AM251 & Activation & N.D. & $10^{l}$ \\
\hline
\end{tabular}

N.D., no data.

${ }^{a} \mathrm{EC}_{50}$ reporter gene assay in HeLa cells expressing recombinant receptors (Lo Verme et al., 2005a).

${ }^{b} \mathrm{EC}_{50}$ reporter gene assay in $\mathrm{COS}$ cells expressing recombinant receptors (Bouaboula et al., 2005).

${ }^{c} \mathrm{EC}_{50}$ reporter gene assay in HeLa cells expressing recombinant receptors ( $\mathrm{Fu}$ et al., 2003).

${ }^{d} \mathrm{EC}_{50}$ reporter gene assay in MCF7 cells expressing recombinant receptors (Alvarado et al., 2008)

${ }^{e} \mathrm{IC}_{50}$ competition for fluorescent ligand occupancy of ligand binding domain (Sun et al., 2007a).

${ }^{f} \mathrm{IC}_{50}$ competition for fluorescent ligand occupancy of ligand binding domain (Bouaboula et al., 2005).

${ }^{g} \mathrm{EC}_{50}$ reporter gene assay in human umbilical vein endothelial cells in the presence of a COX-2 inhibitor (Ghosh et al., 2007).

${ }^{h} \mathrm{EC}_{50}$ reporter gene assay in $3 \mathrm{~T} 3-\mathrm{L} 1$ cells expressing recombinant receptors (Rockwell et al., 2006).

${ }^{i} \mathrm{EC}_{50}$ reporter gene assay in HEK293 cells expressing recombinant receptors (O’Sullivan et al., 2005).

${ }^{j} \mathrm{IC}_{50}$ competition for fluorescent ligand occupancy of ligand binding domain (O'Sullivan et al., 2009b).

${ }^{k} \mathrm{EC}_{50}$ reporter gene assay in HEK293 cells expressing recombinant receptors (Liu et al., 2003).

${ }^{l}$ Effective concentration in reporter gene assay in HEK293 cells expressing recombinant receptors; ligand concentration(s) for PPAR $\alpha$ activation not published (O'Sullivan et al., 2006; Sun et al., 2007b).

archetypal endocannabinoids anandamide and 2-AG as well as the phytocannabinoids $\Delta^{9}$-THC and cannabidiol and the synthetic cannabinoids $R$-(+)-WIN55212 and ajulemic acid (Table 8). The potency of the majority of these agents is approximately 2 orders of magnitude lower at PPARs than at the conventional cannabinoid GPCRs $\left(\mathrm{CB}_{1}\right.$ and $\left.\mathrm{CB}_{2}\right)$, although it is noteworthy that data from two investigations suggest that PPAR $\gamma$ can be activated by $\Delta^{9}$-THC (O'Sullivan et al., 2005) and $R$-(+)-WIN55212 (Giuliano et al., 2009) at $100 \mathrm{nM}$. There are also reports that rimonabant and AM251 can activate both PPAR $\gamma($ at $10 \mu \mathrm{M})$ and PPAR $\alpha$ (O'Sullivan et al., 2006; Sun et al., 2007b). However, it remains unclear whether this represents a direct or indirect phenomenon associated with high ligand concentrations. Two fatty acid ethanolamides (oleoyl ethanolamide and palmitoyl ethanolamide), which are essentially inactive at cannabinoid $\mathrm{CB}_{1}$ and $\mathrm{CB}_{2}$ receptors, are agonists with reasonable potency at PPAR $\alpha$ (Table 8). This receptor seems to display some preference for the medium-chain mono- or diunsaturated fatty acid ethanolamides, such as oleoyl ethanolamide and linoleoyl ethanolamide, compared with the long-chain polyunsaturated fatty acid ethanolamides, such as anandamide, $N$-eicosapentaenoyleth- 
anolamine and $N$-docosohexaenoylethanolamine (Artmann et al., 2008).

Oxidative metabolism of endocannabinoids generates agents that are also active at PPARs. Thus, 15lipoxygenase metabolism of 2-AG leads to the production of $15(S)$-hydroxyeicosatetraenoic acid-glyceryl ester (Kozak et al., 2002). This agent was identified as a preferential agonist at PPAR $\alpha$ in a reporter gene assay using NIH 3T3 cells as hosts, with an $\mathrm{EC}_{50}$ value of $\sim 3 \mu \mathrm{M}$, but was inactive up to $10 \mu \mathrm{M}$ at $\operatorname{PPAR} \beta$ or PPAR $\gamma$. It is noteworthy that the arachidonic acid metabolite 15(S)-hydroxyeicosatetraenoic acid at $10 \mu \mathrm{M}$ is a preferential PPAR $\gamma$ agonist (Kozak et al., 2002). 2-(14,15-Epoxyeicosatrienoyl)glycerol (a product of 2-AG metabolism by epoxygenase) but not 2-AG itself also appeared to be a PPAR $\alpha$ agonist (Fang et al., 2006). However, mass spectrometry analysis suggested that the active entity was 14,15-dihydroxyeicosatrienoic acid, produced through sequential hydrolysis of the glyceryl ester and epoxide bonds. One of the problems this study highlights is that the extended periods necessary for identification of agonist action at PPARs $(4 \mathrm{~h}$ or more) increases the potential for conversion of the added agent into an entity with altered activity at the receptor.

2. Indirect Evidence for Cannabinoid Activation of Peroxisome Proliferator-Activated Receptors. Indirect means of identifying an action of cannabinoid-related molecules at PPARs include 1) the use of reporter genes in model cells where PPARs are either endogenously expressed or overexpressed and 2) the use of pharmacological or genetic inhibition of PPARs.

3. Reporter Gene Assays and Metabolism of Endocannabinoids. COX-2-mediated metabolism of 2-AG, noladin ether, and anandamide led to greater activation of $\operatorname{PPAR} \beta$ compared with $\operatorname{PPAR} \gamma$, with no discernible $\operatorname{PPAR} \alpha$ activation, in human umbilical vein endothelial cells transfected with peroxisome proliferator-activated response element coupled to a reporter gene (Ghosh et al., 2007). COX-2 inhibition alone did not alter PPAR activation, suggesting that conversion of endogenous COX-2 substrates was not sufficient to activate PPARs. 2-AG itself, in the presence of a COX-2 inhibitor, was ineffective, indicating that COX-2 metabolism was an obligatory step in the production of a PPAR ligand. siRNA knockdown of prostacyclin synthase (CYP8A1) inhibited PPAR activation, demonstrating that prostaglandin $\mathrm{I}_{2}$-glyceride was probably the endogenous ligand, although attempts to identify endogenous levels of this agent using mass spectrometry were unsuccessful (Ghosh et al., 2007).

4. Antagonism. In mouse primary splenocytes in vitro, anandamide evoked a concentration-dependent inhibition of interleukin-2 secretion that was not blocked by rimonabant or SR144528 but was inhibited by 2-chloro-5-nitro- $N$-4-pyridinyl-benzamide (T0070907), indicating a role for PPAR $\gamma$ in these effects (Rockwell and Kaminski, 2004). Sequential metabolism in HeLa human cervical carcinoma cells by COX-2 and lipocalin type-prostaglandin $\mathrm{D}$ synthase led to activation of PPAR $\gamma$ by $R-(+)$-methanandamide, as evidenced by siRNA and 2-chloro-5-nitro- $N$-phenylbenzamide (GW9662) inhibition (Eichele et al., 2009). In vitro, the PPAR $\gamma$ antagonist GW9662 was able to block relaxations evoked by cannabidiol (O'Sullivan et al., 2009b), $\Delta^{9}$-THC (O'Sullivan et al., 2005), $\mathrm{N}$-arachidonoyl dopamine and anandamide (O'Sullivan et al., 2009a) in rat isolated aorta. $R$-(+)-WIN55212-evoked apoptosis of HepG2 human hepatoma cells was inhibited by GW9662 (Giuliano et al., 2009). Prolonged exposure of these cells to $R$-(+)-WIN55212 also induced increased expression of PPAR $\gamma$, a response associated with PPAR $\gamma$ activation. Likewise, HU-210 exposure over several days increased PPARy expression in 3T3-F442A mouse preadipocyte cells; however, this effect was blocked by rimonabant, indicating the involvement of cannabinoid $\mathrm{CB}_{1}$ receptors (Matias et al., 2006).

5. Genetic Disruption. An alternative method, although not without caveats, is to make use of animals in which the PPARs are genetically disrupted. These mice have been employed on a limited number of occasions in an attempt to study the effects of cannabinoid-related molecules, although, notably, not the archetypal endocannabinoids anandamide or 2-AG, or other ligands that are known to target $\mathrm{CB}_{1}$ or $\mathrm{CB}_{2}$ receptors. Thus, antinociceptive effects of palmitoyl ethanolamide, as well as the PPAR $\alpha$ agonist 2-[[4-[2-[[(cyclohexy]amino)carbonyl](4-cyclohexylbutyl)amino] ethyl]phenyl]thio]-2-methylpropanoic acid (GW7647), were lost in mice in which the ppara gene was disrupted (LoVerme et al., 2006; D'Agostino et al., 2007; Sasso et al., 2010). ppara gene disruption abrogated oleoyl ethanolamide-evoked feeding behaviors (Fu et al., 2003), oleoyl ethanolamide-evoked lipolysis (Guzmán et al., 2004) and oleoyl ethanolamide-mediated neuroprotection (Sun et al., 2007a), but not oleoyl ethanolamide effects on visceral pain (Suardíaz et al., 2007) or intestinal motility (Cluny et al., 2009). Genetic disruption of PPAR $\gamma$ in a homozygous manner results in embryonic lethality, so heterozygous mice have been generated and studied (Kishida et al., 2001), as have mice with conditional disruption of the pparg gene (Akiyama et al., 2002). However, the use of these mice or those in which PPAR $\beta$ is genetically disrupted (Peters et al., 2000) has not been reported in investigations of endocannabinoids and their analogs.

6. Amplification of Endocannabinoid Levels and Peroxisome Proliferator-Activated Receptors. Nicotine-induced elevation of firing of ventral tegmental area neurons in anesthetized rats was inhibited by prior administration (60-120 $\mathrm{min}$ ) of URB597, an inhibitor of the anandamide-metabolizing enzyme FAAH (Melis et al., 2008). Rimonabant failed to alter the effects of URB597, whereas 1-[(4-chlorophenyl) methyl]-3-[(1,1-dimethylethyl)thio]- $\alpha, \alpha$-dimethyl-5-(1-methylethyl)- $1 H$-indole-2-propanoic acid (MK886) was able to prevent the effects of URB597. The effects of URB597 were mimicked in vitro by administration of oleoyl ethanolamide, palmitoyl ethanolamide, or the PPAR $\alpha$ agonist WY14643 in a manner sensitive to MK886 (Melis et al., 2008). 
Palmitoylallylamide, described as a low-potency inhibitor of FAAH (Vandevoorde et al., 2003), evoked an inhibition of nociceptive behaviors in rat models of neuropathic pain 40 to $100 \mathrm{~min}$ after administration (Wallace et al., 2007). These effects were reduced after administration of rimonabant, SR144528, or MK886, dependent on the paradigm under study. In a passive avoidance paradigm, URB597 administration to rats 40 min before testing enhanced memory acquisition (Mazzola et al., 2009), whereas $\Delta^{9}$-THC administration impaired memory. The URB597 enhancement was reduced by either rimonabant or MK886. Intraplantar administration of a low, but not high, dose of URB597 reduced pain behaviors in the carrageenan model of inflammatory pain (Jhaveri et al., 2008) up to $210 \mathrm{~min}$ after injection. At this time, levels of anandamide and 2-AG, but not oleoyl ethanolamide or palmitoyl ethanolamide, were elevated in URB597 and carrageenan-treated paws compared with tissue from animals treated with carrageenan alone. The antinociceptive effects of URB597 were prevented by coadministration of the PPAR $\alpha$-selective antagonist [(2S)-2-[[(1Z)-1-methyl-3-oxo3-[4-(trifluoromethyl)phenyl)-1-propenyl]amino]-3-[4-[2-(5methyl-2-phenyl-4-oxazolyl)ethoxyphenylpropyl]-carbamic acid ethyl ester (GW6471) but not the PPAR $\gamma$-selective antagonist GW9662, indicating a role for PPAR $\alpha$ in these responses.

Blockade of endocannabinoid uptake by $(5 Z, 8 Z$, $11 Z, 14 Z$ )- $N$-(3-furanylmethyl)-5,8,11,14-eicosatetraenamide (UCM707) evoked neuroprotective effects in mouse mixed astrocytic neuronal cultures by activation of $\mathrm{CB}_{1}, \mathrm{CB}_{2}$, and PPAR $\gamma$ receptors (Loría et al., 2010). Application of $\mathrm{CB}_{1}$ and $\mathrm{CB}_{2}$ receptor antagonists, but not the PPAR $\gamma$ antagonist GW9662, led to an exacerbation of the excitotoxic effects of $\alpha$-amino3-hydroxy-5-methyl-4-isoxazolepropionic acid application. Administration of $N$-(4-hydroxyphenyl)- $5 Z, 8 Z$, $11 Z, 14 Z$-eicosatetraenamide (AM404), a mixed inhibitor of FAAH and endocannabinoid uptake, enhanced bacterial lipopolysaccharide-evoked tumor necrosis factor- $\alpha$ levels in rat plasma. Antagonists of $\mathrm{CB}_{1}, \mathrm{CB}_{2}$, and TRPV1 receptors attenuated elevations of tumor necrosis factor- $\alpha$ levels in response to LPS and the combination of LPS and AM404, whereas PPAR $\gamma$ antagonism interfered only with the AM404-evoked elevation (Roche et al., 2008). Collectively, these data might be taken to indicate that PPARs are only activated significantly in vivo by endocannabinoids when endocannabinoid levels are pharmacologically amplified.

7. Regulation by Peroxisome Proliferator-Activated Receptors and Peroxisome Proliferator-Activated Receptor Ligands of the Endocannabinoid System. There is some evidence that the functioning of the endocannabinoid system can be affected by PPARs and PPAR ligands. This has come primarily from experiments with adipocytes. For example, $24 \mathrm{~h}$ of activation of PPAR $\gamma$ by ciglitazone decreased levels of $2-A G$, but not anandamide, in immature, but not mature, 3T3
F442A mouse adipocytes (Matias et al., 2006). It remains to be determined whether this effect is due to a direct action on endocannabinoid synthesizing and/or metabolizing enzymes, or a consequence of cellular differentiation; interestingly, however, Pagano et al. (2007) have found that the PPAR $\gamma$ agonist rosiglitazone upregulates FAAH in human adipocytes. In 3T3 L1 mouse preadipocyte cells, a related cell type, ppard gene silencing increased $\mathrm{CB}_{1}$ receptor gene expression (Yan et al., 2007). Treatment of human adipocytes in vitro with the PPAR $\gamma$ agonist rosiglitazone markedly down-regulated $\mathrm{CB}_{1}$ receptor gene expression, whereas $R$-(+)-WIN55212 up-regulated PPAR $\gamma$ (Pagano et al., 2007). Treatment of human adipocytes in vitro with a different PPAR $\gamma$ agonist, ciglitazone, failed to alter endocannabinoids levels (Gonthier et al., 2007).

In a distinct series of investigations, a number of PPAR $\gamma$ agonists, including ciglitazone, pioglitazone, rosiglitazone, and troglitazone, were shown to inhibit FAAH activity in rat brain membranes, as well as in intact C6 rat glioma and RBL-2H3 rat basophilic leukemia cells (Lenman and Fowler, 2007). The low potency with which these inhibitions were induced $\left(\mathrm{IC}_{50}\right.$ values $\left.\sim 100 \mu \mathrm{M}\right)$ suggests that this is an unlikely mechanism for influencing endocannabinoid levels.

8. Conclusions. Although there has yet to be a systematic investigation of the activity of all the putative endocannabinoids at all three PPAR isoforms, anandamide and 2-AG have each already been reported to activate two PPAR receptors (Table 8): PPAR $\gamma$ and $\operatorname{PPAR} \alpha$ (anandamide) and PPAR $\gamma$ and PPAR $\beta / \delta(2-$ $A G)$. Overall, the potencies of endocannabinoids and their metabolites as PPAR agonists or antagonists are relatively low compared with their potencies as agonists of canonical cannabinoid $\mathrm{CB}_{1} / \mathrm{CB}_{2}$ receptors. This might be taken as evidence that endocannabinoids are poor candidates as PPAR ligands in vivo. However, this fails to take into account background levels of established endogenous PPAR agonists. One estimate puts intracellular levels of long-chain fatty acids at $20 \mu \mathrm{M}$ (Forman et al., 1997), which is a level sufficient to occupy PPARs in cell-free systems. Although this background level may vary depending on the cell type and the active state of the cell, fluctuations in intracellular endocannabinoid levels may well prove sufficient to activate PPARs in vivo.

The best current evidence that endocannabinoids are endogenous agonists at PPARs in vivo derives from the use of a model of inflammatory pain. More specifically, local administration of a FAAH inhibitor has been found to induce local accumulation of both anandamide and 2-AG (but not oleoyl ethanolamide or palmitoyl ethanolamide) at a time when behavioral responses to the FAAH inhibitor could be blocked by local administration of a PPAR $\alpha$ antagonist but not a PPAR $\gamma$ antagonist (Jhaveri et al., 2008). 


\section{H. Some Putative Receptors}

1. Imidazoline-Like Receptors. There is evidence that at least some cannabinoid receptor agonists and antagonists can interact with a non- $\mathrm{I}_{1}$, non- $\mathrm{I}_{2}$ subtype of the putative imidazoline receptor that may belong to a family of G protein-coupled sphingosine-1-phosphate/LPA receptors originally known as endothelial differentiation gene receptors. These putative receptors have been reported to be activated by CP55940 (300 $\mathrm{nM})$ and $R$-(+)-WIN55212 (10 and $100 \mu \mathrm{M})$ but not by anandamide $(1 \mu \mathrm{M})$ and to be blocked by rimonabant $(1 \mu \mathrm{M})$ and LY320135 (0.1 to 10 $\mu \mathrm{M})$ (Molderings et al., 1999, 2002).

2. The Putative Abnormal-Cannabidiol Receptor. Since its original description as a receptor mediating the $\mathrm{CB}_{1} /$ $\mathrm{CB}_{2}$-independent, endothelium-dependent vasodilator effect of anandamide and some atypical cannabinoids (Járai et al., 1999), the putative abn-CBD receptor, also called the endothelial anandamide receptor (Mukhopadhyay et al., 2002), has eluded molecular identification. The emergence of GPR55 as the first GPCR other than $\mathrm{CB}_{1}$ or $\mathrm{CB}_{2}$ receptors with high affinity for certain cannabinoid ligands has raised the question of its possible identity with the putative abn-CBD receptor.

There are a number of important parallels between the pharmacology of GPR55 and the putative abn-CBD receptor (see also section III.A.6). Thus, as summarized recently (Ross, 2009), it has been shown that in at least some GPR55 and putative abn-CBD receptor bioassays, 1) the endocannabinoid, anandamide, is active; 2 ) the synthetic cannabinoid receptor agonist $R$-(+)-WIN55212 is inactive (in all GPR55 and abn-CBD bioassays); 3) abn-CBD and the compound O-1602 (section II.C.5 and Fig. 5) (Járai et al., 1999) act as agonists, whereas their parent compound, cannabidiol, acts as an antagonist; 4) the $\mathrm{CB}_{1}$ antagonist rimonabant, but not its close structural analog AM251, can inhibit both apparent GPR55- and apparent abn-CBD receptor-mediated responses, although with lower potency than it displays as a $\mathrm{CB}_{1}$ receptor antagonist; 5) the endogenous lipid $N$-arachidonoyl serine causes pertussis toxin- and 1,3-dimethoxy-5-methyl-2-[(1R,6R)3-methyl-6-(1-methylethenyl)-2-cyclohexen-1-yl]benzene (O-1918)-sensitive, endothelium-dependent mesenteric vasodilation and thus may be an agonist of the abn-CBD-sensitive receptor (Milman et al., 2006). It has also been reported recently that nanomolar concentrations of $\mathrm{N}$-arachidonoyl serine promote angiogenesis and endothelial wound healing in human dermal microvascular endothelial cells and that these effects could be partly inhibited by siRNA-mediated knockdown of GPR55 and could also be antagonized by O-1918 but not by AM251 (Zhang et al., 2010).

On the other hand, there are some key differences: 1) vasodilator effects attributed to abn-CBD receptor activation are moderately sensitive to pertussis toxin, suggestive of $\mathrm{G}_{\mathrm{i} / \mathrm{o}}$ protein involvement, whereas GPR55 signals through $\mathrm{G} \alpha_{12}, \mathrm{G} \alpha_{13}$, or $\mathrm{G} \alpha_{\mathrm{q}}$; 2) lysophosphatidyl inositol is a potent agonist of GPR55, but not of the putative abnCBD receptor; and 3) the hypotensive/vasodilator actions of abn-CBD and its antagonism by the synthetic cannabinoid, O-1918 (Offertáler et al., 2003), persist in GPR55 knockout mice (Johns et al., 2007). However, the possibility exists that GPR55 and $\mathrm{CB}_{1}$ receptors may form heterodimers with pharmacological properties distinct from those of either one of the monomeric receptors, which may account for some or all of the above differences. Future experiments could address this question by exploring the presence of such heterodimers in various tissues under native conditions and/or by analyzing the pharmacology of cannabinoid-induced responses after the individual or joint transgenic expression of these two receptors in cells devoid of both.

Evidence has recently emerged that the putative abnCBD receptor has features similar to those of GPR18 (McHugh et al., 2010). In BV-2 microglia and in GPR18transfected HEK293 cells, but not in the parent HEK293 cells, abn-CBD and O-1602 potently stimulated cell migration and proliferation. Furthermore, the pertussis toxin-sensitive potent pro-migratory effect of NAGly, the putative endogenous ligand of GPR18 (section III.B.4), was inhibited by O-1918 or by the low-efficacy agonists $\mathrm{N}$-arachidonoyl serine and cannabidiol. Although vascular effects were not tested in this study, it is noteworthy that in earlier experiments with human umbilical vein endothelial cells, abn-CBD-induced cell migration was found to be susceptible to inhibition by O-1918 or pertussis toxin (Mo et al., 2004). These two compounds, O-1918 and pertussis toxin, have also been reported to inhibit NAGly-induced endothelium-dependent vasorelaxation of rat mesenteric artery segments (Parmar and Ho, 2010). However, the parallel between the putative abn-CBD receptor and GPR18 is not perfect. Rimonabant, which is a low-affinity antagonist of the vascular putative abn-CBD receptor (for review, see Pertwee 2005a; Ross, 2009), had no effect on GPR18-mediated microglial migration at concentrations up to $1 \mu \mathrm{M}$ (McHugh et al., 2010). Clearly, the exciting possibility that the putative abn-CBD receptor is GPR18 should be followed up.

In conclusion, there is evidence to support the contention that both GPR55 and GPR18 have at least some of the features associated with the abn-CBD-sensitive receptor. This will need to be validated by further studies.

3. A Putative Receptor for Anandamide and R-(+)WIN55212. Investigations with $\mathrm{C} 57 \mathrm{BL} / 6 \mathrm{CB}_{1}(-/-)$ mice revealed that antinociception, locomotor hypoactivity, and catalepsy (immobility) responses could be elicited in these animals by anandamide but not $\Delta^{9}$-THC, leading Di Marzo et al. (2000) to postulate the existence of a non- $\mathrm{CB}_{1}$ receptor for this endocannabinoid agonist. Using $\mathrm{CB}_{1}(-/-)$ brain membranes, they demonstrated that anandamide and $R$-(+)-WIN55212, but not $\Delta^{9}$-THC, CP55940, or HU210 , stimulated $\left[{ }^{35} \mathrm{~S}\right] \mathrm{GTP} \gamma \mathrm{S}$ binding, supporting the existence of a novel non- $\mathrm{CB}_{1}, \mathrm{G}_{\mathrm{i} / \mathrm{o}}$-coupled receptor (Di Marzo 
et al., 2000; Breivogel et al., 2001). The potencies for anandamide $\left(\mathrm{EC}_{50}=3.6 \mu \mathrm{M}\right)$ and $R$-(+)-WIN55212 $\left(\mathrm{EC}_{50}=1.8\right.$ $\mu \mathrm{M}$ ) were low compared with the $\mathrm{CB}_{1}$ receptor (Breivogel and Childers, 2000), and although rimonabant antagonized both these ligands, it did so in a manner that may not have been competitive in nature because it occurred only at concentrations $\left(\mathrm{IC}_{50}>1 \mu \mathrm{M}\right)$ high enough to reduce basal $\left[{ }^{35} \mathrm{~S}\right]$ GTP $\gamma \mathrm{S}$ binding (Breivogel et al., 2001). The anandamide/ $R$-(+)-WIN55212-stimulated $\left.{ }^{35} \mathrm{~S}\right] \mathrm{GTP} \gamma \mathrm{S}$ binding was found in brain regions that were not abundant in $\mathrm{CB}_{1}$ receptors, such as the brain stem, midbrain, and spinal cord, as well as in some areas that are well populated with the $\mathrm{CB}_{1}$ receptor, such as the cerebral cortex and hippocampus (Breivogel et al., 2001). The occurrence of non$\mathrm{CB}_{1}$-mediated anandamide/ $R$-(+)-WIN55212-stimulated $\left[{ }^{35} \mathrm{~S}\right] \mathrm{GTP} \gamma \mathrm{S}$ binding was later confirmed in another study carried out with $\mathrm{CB}_{1}(-/-)$ mouse brain membranes (Monory et al., 2002). A similar pharmacological profile is apparent in pertussis toxin-sensitive inhibition of cAMP accumulation in cultured mouse striatal astrocytes, which has been found to respond to anandamide and WIN55212, but poorly to CP55940, and to be resistant to antagonism by rimonabant (Sagan et al., 1999). In contrast to neurons, the mouse striatal astrocytes did not express immunoreactive $\mathrm{CB}_{1}$ receptors and did not exhibit $\left[{ }^{3} \mathrm{H}\right] \mathrm{SR} 141716 \mathrm{~A}-$ binding activity (Sagan et al., 1999).

In conclusion, the current evidence that this target, and indeed the targets described in sections III.H.1 and III.H.2, are non- $\mathrm{CB}_{1}$, non- $\mathrm{CB}_{2}$ cannabinoid receptors is based upon pharmacological profiling only, with the additional caveats that only a limited number of agents were assessed and the two identified agonists also exhibit broad $\mathrm{CB}_{1} / \mathrm{CB}_{2}$ pharmacological activity. Moreover, the possibility that anandamide, or anandamide metabolic products, trigger responses via other bona fide targets is an equally plausible alternative potential mechanism that remains to be investigated. A radioligand binding assay for this putative receptor based upon $\left[{ }^{3} \mathrm{H}\right] R$-(+)-WIN55212 would be plagued by the abundance of brain $\mathrm{CB}_{1}$ receptors, so a more selective radioligand probe would have to be developed to define the receptor binding profile. Thus, in the absence of a more comprehensive pharmacological profile and of a unique, identified protein, the naming of this pharmacological target as a definitive cannabinoid receptor cannot be justified.

4. The Putative CBsc Receptor for R-(+)-WIN55212. A non-CB ${ }_{1}, \quad R$-(+)-WIN55212-sensitive receptor has been proposed to be present in the CA1 region of the hippocampus (Hájos et al., 2001; Hájos and Freund, 2002a). This putative cannabinoid receptor has been provisionally named CBsc because of its apparent location on hippocampal Schaffer collateral/commissural axon terminals (Hoffman et al., 2005). Pharmacological evidence for the CBsc receptor is that $1 \mu \mathrm{M}$ $R$-(+)-WIN55212 reduced amplitudes of evoked excitatory postsynaptic potentials in hippocampal slice preparations from $\mathrm{CB}_{1}(-/-)$ (and wild-type) CD1 mice (Hájos et al., 2001). Although this response was ob- served in Wistar and Sprague-Dawley rats, the response to $R$-(+)-WIN55212 was absent in young/adult $\mathrm{C} 56 \mathrm{Bl} / 6 \mathrm{CB}_{1}(-/-)$ and wild-type $\mathrm{C} 57 \mathrm{BL} / 6$ mice (Hoffman et al., 2005). It was detectable, however, in neonatal and juvenile wild-type C57BL/6 mice (OhnoShosaku et al., 2002). Additional supporting evidence was the failure to identify immunoreactive $\mathrm{CB}_{1}$ receptors at glutamatergic presynaptic terminals (Hájos et al., 2000). However, such immunoreactivity has since been detected using more sensitive antibodies/methods (Katona et al., 2006; Kawamura et al., 2006). In some experiments, the log concentration-response curve for $R$-(+)-WIN55212 exhibited an apparent $\mathrm{EC}_{50}$ of $2 \mu \mathrm{M}$ but failed to develop an asymptotic maximum even at a concentration of $30 \mu \mathrm{M}$ (Hájos and Freund, 2002b; Németh et al., 2008). At such a high concentration, nonstereoselective $R-(+) / S-(-)$ WIN55212 effects on $N$-type voltage-gated $\mathrm{Ca}^{2+}$ channels could be responsible for the decrement in presynaptic neurotransmission (Shen and Thayer, 1998; Németh et al., 2008). In CA1 pyramidal cells and dentate gyrus granule cells, $R$-(+)-WIN55212 or CP55940 influenced glutamate release via a capsazepine-sensitive mechanism (Hájos and Freund, 2002b; Benninger et al., 2008). It is unlikely, however, that TRPV1 channels were responsible for this effect, because there is evidence that both capsaicin and capsazepine can reduce hippocampal glutamatergic neurotransmission in TRPV1 $(-/-)$ mice as well as in wild-type animals (Benninger et al., 2008). The putative CBsc receptor may be a TRPV1-like receptor. It is noteworthy that it is also unlikely that the proposed CBsc receptor is the same as the putative $R-(+)-$ WIN55212 receptor first identified by Breivogel et al. (2001), because evidence for the existence of this latter receptor came from experiments with C57BL/6 mouse tissue (section III.H.3).

In the absence of a more complete pharmacological characterization of the putative CBsc receptor, it remains possible that those effects on glutamate release that are induced in $\mathrm{CB}_{1}$-expressing Schaffer collaterals by cannabinoids with significant potency and that are sensitive to antagonism by either rimonabant or AM251, at least in rat and CD1 mouse tissue (Hájos and Freund, 2002b; Hoffman et al., 2005), are in fact mediated by the $\mathrm{CB}_{1}$ receptor. Moreover, those effects on glutamate release that are induced by cannabinoids with low potency, and in a nonstereoselective, and $\mathrm{CB}_{1}$ antagonist-insensitive manner, could result from perturbations of ion channel functions.

In conclusion, given the positive results obtained with $R$-(+)-WIN55212 in $\mathrm{CB}_{1}(-/-)$ CD1 mouse tissue and some negative results obtained with this cannabinoid in wildtype C57BL/6 mouse tissue, further experiments directed at establishing whether the proposed CBsc receptor truly is a novel cannabinoid receptor are clearly warranted. 


\section{Phylogenetic Relationships}

The sequence similarity (44\% amino acid sequence identity) that the CX5 receptor $\left(\mathrm{CB}_{2}\right)$ shares with the SKR6 receptor $\left(\mathrm{CB}_{1}\right)$ provided crucial evidence that $\mathrm{CX} 5$ might be a cannabinoid receptor (Munro et al., 1993). Thus, the identification of the cannabinoid $\mathrm{CB}_{2}$ receptor heralded a new approach to the discovery of putative cannabinoid receptors: homology-based searching of gene sequence databases. Furthermore, sequencing of the human genome (Lander et al., 2001) enabled genome-wide searches for receptors structurally and/or functionally related to $\mathrm{CB}_{1}$ and $\mathrm{CB}_{2}$.

An analysis of human gene/genome sequence data carried out in 2003 revealed more than 800 genes encoding GPCRs, which were grouped on the basis of sequence relationships, into five main families named after a prototypical receptor: 1) glutamate (G), 2) rhodopsin (R), 3) adhesion (A), 4) frizzled/ taste2 (F), and 5) secretin (S), with the rhodopsin family further subdivided into groups $\alpha, \beta, \gamma$, and $\delta$ (Fredriksson et al., 2003b). This "GRAFS" classification system provides a useful framework both for analysis of relationships between $\mathrm{CB}_{1} / \mathrm{CB}_{2}$-type cannabinoid receptors and other $\mathrm{G}$ proteincoupled receptors and for investigation of the occurrence of putative non- $\mathrm{CB}_{1} / \mathrm{CB}_{2} \mathrm{G}$ protein-coupled cannabinoid receptors in humans and other mammals.

\section{A. $C B_{1}, C B_{2}$, and Other Rhodopsin $\alpha$ Group-Type $G$ Protein-Coupled Receptors}

Cannabinoid $\mathrm{CB}_{1}$ and $\mathrm{CB}_{2}$ receptors belong to the $\alpha$ group of rhodopsin-type GPCRs, which is composed largely of receptors for amine-type neurotransmitters and neuromodulators (e.g., serotonin, adrenaline, dopamine) (Fredriksson et al., 2003b). Thus, $\mathrm{CB}_{1}$ and $\mathrm{CB}_{2}$ receptors are atypical of the $\alpha$ group in that they are activated endogenously by the lipid-type signaling molecules anandamide and 2-AG. $\mathrm{CB}_{1}$ and $\mathrm{CB}_{2}$ receptors are not, however, the only receptors in the $\alpha$ group that are activated by lipid ligands. The receptors in the $\alpha$ group that share the highest level of sequence similarity with $\mathrm{CB}_{1}$ and $\mathrm{CB}_{2}$ are a group of eight receptors that are activated by lysophospholipids. These include the sphingosine-1-phosphate $(\mathrm{S} 1 \mathrm{P})$ receptors $\left(\mathrm{S}_{1} \mathrm{P}_{1}\right.$, $\mathrm{S}_{1} \mathrm{P}_{2}, \mathrm{~S}_{1} \mathrm{P}_{3}, \mathrm{~S}_{1} \mathrm{P}_{4}, \mathrm{~S}_{1} \mathrm{P}_{5}$ ) and the LPA receptors $\mathrm{LPA}_{1}$, $\mathrm{LPA}_{2}$, and $\mathrm{LPA}_{3}$ (Chun et al., 2002). It is noteworthy that $\mathrm{S} 1 \mathrm{P}$ exerts $\mathrm{CB}_{1}$-independent cannabinoid-like effects, including thermal antinociception, hypothermia, catalepsy, and hypolocomotion (Sim-Selley et al., 2009), whereas sphingosine and the sphingosine analog 2-amino-2-(2-[4-octylphenyl]ethyl)-1,3-propanediol (FTY720) inhibit binding of cannabinoid ligands to $\mathrm{CB}_{1}$ receptors in vitro (Paugh et al., 2006). Thus, there are some striking similarities in the pharmacological properties of the $\mathrm{CB}_{1}$ receptor and $\mathrm{S} 1 \mathrm{P}$ receptors.

Cannabinoid $\mathrm{CB}_{1} / \mathrm{CB}_{2}$ receptors and the related lysophospholipid receptors belong to a distinct branch of $\alpha$-type receptors (Fig. 6) that also includes receptors for melanocortin peptides $\left(\mathrm{MC}_{1}-\mathrm{MC}_{5}\right)$, adenosine re- ceptors $\left(\mathrm{A}_{1}, \mathrm{~A}_{2 \mathrm{~A}}, \mathrm{~A}_{2 \mathrm{~B}}, \mathrm{~A}_{3}\right)$, and the orphan receptors GPR3, GPR6, and GPR12 (Elphick and Egertová, 2001; Fredriksson et al., 2003b; Elphick, 2007). Thus, on the basis of analysis of human genome sequence data, it can be speculated that, as a consequence of multiple gene duplication events, an ancestral $\alpha$-type GPCR gave rise to receptors that are activated by endocannabinoids, lysophospholipids, melanocortin peptides, and adenosine. Furthermore, comparative analysis of genome sequence data reveals that adenosine receptors have a wider phylogenetic distribution than $\mathrm{CB}_{1} / \mathrm{CB}_{2}$-type cannabinoid receptors, lysophospholipid receptors, melanocortin receptors, and GPR3, GPR6, and GPR12 (Elphick and Egertová, 2001; Dolezelova et al., 2007). Therefore, the common ancestor of this group of GPCRs may in fact have been an adenosine receptor. Furthermore, orthologs of the $\mathrm{CB}_{1} / \mathrm{CB}_{2}$-type cannabinoid receptors have only been found in the phylum Chordata (vertebrates, urochordates, and cephalochordates) (Elphick, 2002, 2007; Elphick et al., 2003; Elphick and Egertová, 2005). Therefore, the duplication of a putative adenosine receptor gene that may have ultimately given rise to $\mathrm{CB}_{1} / \mathrm{CB}_{2}$-receptors probably occurred in a common ancestor of extant chordates.

As highlighted above, among the receptors that are closely related (on the basis of sequence similarity) to $\mathrm{CB}_{1}$ and $\mathrm{CB}_{2}$ are three receptors known as GPR3, GPR6 and GPR12 (section III.B.3). It has been reported that these "orphan" receptors are activated in vitro by the lysophospholipid S1P (Uhlenbrock et al., 2002). However, a more recent screen using the $\beta$-arrestin PathHunter assay found that these receptors were not activated by S1P, even at concentrations as high as $8 \mu \mathrm{M}$ (Yin et al., 2009). Furthermore, GPR3, GPR6, and GPR12 are not activated by the endocannabinoids anandamide and 2-AG in this assay, suggesting that they may not be cannabinoid receptors. It is noteworthy, however, that the lysophospholipid receptor $\mathrm{S}_{1} \mathrm{P}_{1}$, was activated by anandamide and 2-AG, albeit only at concentrations in the micromolar range (Yin et al., 2009).

Another rhodopsin $\alpha$ group-type GPCR that is of interest with respect to cannabinoid receptors is GPR119 (section III.B.6). This receptor is activated by oleoyl ethanolamide, an $\mathrm{N}$-acylethanolamine with molecular properties similar to those of the endocannabinoid anandamide (Overton et al., 2006). There is evidence that oleoyl ethanolamide has an important physiological role as a peripherally acting agent that reduces food intake (Lo Verme et al., 2005b) and this effect of oleoyl ethanolamide may be mediated, at least in part, by GPR119 (Overton et al., 2006). Analysis of the sequence of GPR119 reveals that it shares structural similarity with adenosine receptors and amine receptors such as the $5-\mathrm{HT}_{4}$ and $5-\mathrm{HT}_{6}$ receptors, $\beta_{1^{-}}$and $\beta_{2}$-adrenoceptors, and $\mathrm{D}_{1}$-type dopamine receptors. Furthermore, in a neighbor joining tree (Fig. 6) based on multiple sequence 


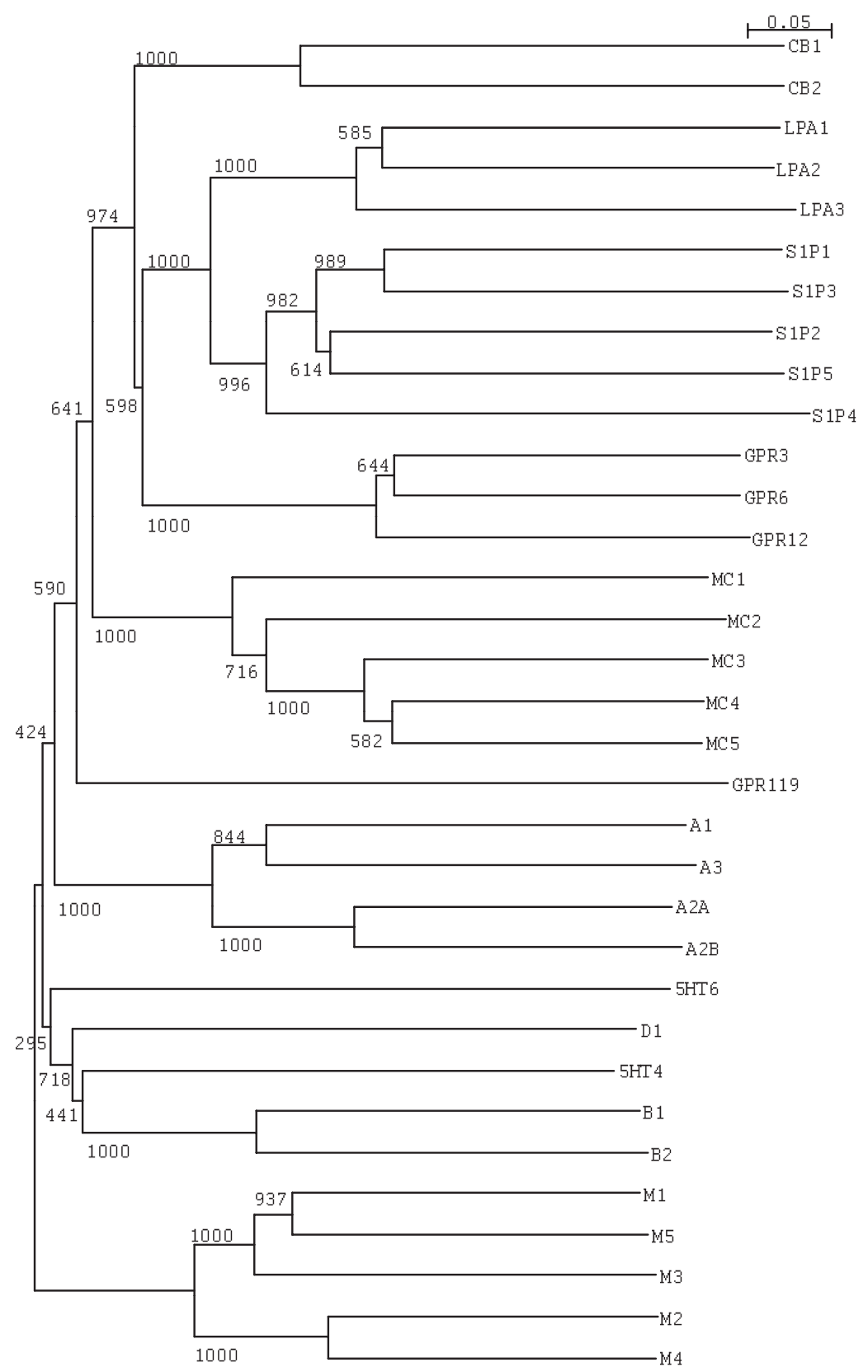

FIG. 6. Neighbor joining tree showing relationships between the human cannabinoid $\mathrm{CB}_{1}$ and $\mathrm{CB}_{2}$ receptors and other human rhodopsin $\alpha$-group type $\mathrm{G}$ protein-coupled receptors. The tree was generated using the multiple sequence alignment program ClustalX, with bootstrapping (1000 bootstrap trials), and viewed using NJ plot. The tree shows receptors that are discussed in section IV.A of this review; the muscarinic acetylcholine receptors $\mathrm{M}_{1}-\mathrm{M}_{5}$ are included as an outgroup.

alignment, GPR119 is positioned within the branch of rhodopsin $\alpha$ group-type GPCRs that include cannabinoid $\mathrm{CB}_{1} /$ $\mathrm{CB}_{2}$ receptors, lysophospholipid receptors, melanocortin receptors, and GPR3, GPR6, GPR12, and adenosine receptors. Thus, it seems that receptors for two different $N$ acylethanolamines, anandamide $\left(\mathrm{CB}_{1}\right.$ and $\left.\mathrm{CB}_{2}\right)$ and oleoyl ethanolamide (GPR119), originated within this branch of GPCRs. This suggests that structural features characteristic of this branch of GPCRs may, perhaps, confer on them a propensity for ligand-binding associations with the $N$ acylethanolamine class of signaling molecules.

\section{B. GPR55 and Other Rhodopsin $\delta$ Group-Type $G$ Protein-Coupled Receptors}

As discussed elsewhere in this review (section III.A), the concept that GPR55 is a "cannabinoid receptor" is controversial, and GPR55 may in fact be activated physiologically by lysophosphatidyl inositol (Oka et al., 2007), which has been reported not to be a $\mathrm{CB}_{1}$ or $\mathrm{CB}_{2}$ receptor ligand (section II.C.5). The pharmacological properties of GPR55 will not be revisited here, but we will use this receptor as the starting point for a phylogenetic survey of "potential" 
cannabinoid receptors based on sequence similarity with GPR55. First, it is important to emphasize that GPR55 does not belong to the same group of rhodopsin-type GPCRs as $\mathrm{CB}_{1}$ and $\mathrm{CB}_{2}$; GPR55 falls within the $\delta$ group, whereas $\mathrm{CB}_{1}$ and $\mathrm{CB}_{2}$ receptors are in the $\alpha$ group, as discussed above. Therefore, if GPR55 is activated by endocannabinoids physiologically, then it must have acquired this property independently of the $\mathrm{CB}_{1} / \mathrm{CB}_{2}$-type cannabinoid receptors. The $\delta$ group of rhodopsin-type GPCRs comprises a heterogeneous collection of receptors, including MAS oncogene-related receptors, glycoprotein hormone receptors, purine receptors, and $\sim 460$ odorant receptors (Fredriksson et al., 2003b).

One of the receptors that shares a high level of sequence similarity with GPR55 is GPR35. However, there is no evidence that cannabinoids or other lipid signaling molecules activate this receptor. In fact it has been found that kynurenic acid, a product of tryptophan metabolism, acts as a GPR35 agonist (Wang et al., 2006b), although the physiological relevance of this finding remains unknown. It is noteworthy that among other receptors that share high levels of sequence similarity with GPR55 are receptors that have recently been identified as lysophospholipid receptors (Fig. 7). These include GPR23 and GPR92 (sections III.B.4 and III.B.5), which are activated by LPA and are now designated $\mathrm{LPA}_{4}$ (Lee et al., 2007) and $\mathrm{LPA}_{5}$ (Lee et al., 2006), respectively, to distinguish them from the $\mathrm{CB}_{1} / \mathrm{CB}_{2}$-like $\mathrm{LPA}_{1}-\mathrm{LPA}_{3}$ receptors belonging to the $\alpha$ group of rhodopsin-type GPCRs. Thus, it seems that LPA receptors have evolved independently in both the $\alpha$ and $\delta$ branches of the rhodopsin family of GPCRs. GPR55, $\mathrm{LPA}_{4}$ (GPR23), and $\mathrm{LPA}_{5}$ (GPR92) belong to a group of closely related receptors that include $\mathrm{P} 2$-type purine receptors (e.g., $\mathrm{P}_{2} \mathrm{Y}_{1}$ and $\mathrm{P}_{2} \mathrm{Y}_{2}$ ) and a putative $\mathrm{P} 2$-like receptor originally designated $\mathrm{P}_{2} \mathrm{Y}_{5}$, which is in fact also activated by LPA and therefore has recently been designated as $\mathrm{LPA}_{6}$ (Yanagida et al., 2009). Furthermore, the P2-like receptor originally designated $\mathrm{P} 2 \mathrm{Y}_{10}$ has been identified as a lysophospholipid receptor that is activated by both S1P and LPA (Murakami et al., 2008). Another receptor that is closely related to $\mathrm{P}_{2} \mathrm{Y}_{1}$ is GPR174 (Fig. 7), but the ligand(s) that activate this receptor are not yet known.

It is interesting that GPR55 and the lysophospholipid receptors $\mathrm{LPA}_{4}, \mathrm{LPA}_{5}$, and $\mathrm{LPA}_{6}$ are closely related to $\mathrm{P} 2$-type purine receptors because, as discussed above, $\mathrm{CB}_{1} / \mathrm{CB}_{2}$-type cannabinoid receptors and $\mathrm{LPA}_{1-3}$ receptors are closely related to P1-type (adenosine) purine receptors. Thus, in different branches of the rhodopsin family of GPCRs ( $\alpha$ and $\delta$ ), lipid receptors that are activated by lysophospholipids or cannabinoids may have evolved independently from receptors that are activated by purines.

Other receptors in the $\delta$ group of rhodopsin-type GPCRs that are quite closely related to GPR55 and $\mathrm{LPA}_{4-6}$ are
GPR17, GPR18 (section III.B.4), and GPR34 (Fig. 7). GPR17 is a P2Y-like receptor that is activated by both uracil nucleotides (e.g., UDP-glucose) and cysteinyl-leukotrienes (Ciana et al., 2006). GPR18, however, is of particular interest with respect to the endocannabinoid anandamide because it is activated by NAGly (Kohno et al., 2006), a lipoamino acid that also activates GPR92 (LPA $)$ (Oh et al., 2008). Furthermore, GPR34 is activated by a different lipoamino acid: lysophosphatidyl-L-serine (Sugo et al., 2006). Finally, with lipid ligands as a recurring theme, there are GPR41 and GPR43 (section III.B.1 and Fig. 7), which are activated by short-chain fatty acids. Thus, within the branch of the $\delta$ group of rhodopsin-type GPCRs that include GPR55, there are a variety of related receptors that are activated by endocannabinoid/lysophospholipid-like molecules. However, it remains to be determined whether any of these receptors have pharmacological properties of the kind that could justify their classification as a "cannabinoid receptor."

\section{Conclusions}

$\mathrm{CB}_{1} / \mathrm{CB}_{2}$-type cannabinoid receptors are phylogenetically restricted to the chordate branch of the animal kingdom. The lysophospholipid receptors $\mathrm{S}_{1} \mathrm{P}_{1}, \mathrm{~S}_{1} \mathrm{P}_{2}$, $\mathrm{S}_{1} \mathrm{P}_{3}, \mathrm{~S}_{1} \mathrm{P}_{4}, \mathrm{~S}_{1} \mathrm{P}_{5}, \mathrm{LPA}_{1}, \mathrm{LPA}_{2}$, and $\mathrm{LPA}_{3}$ are the GPCRs that are most closely related to $\mathrm{CB}_{1} / \mathrm{CB}_{2}$-type receptors. Receptors for endocannabinoid/lysophospholipid-like molecules have evolved independently in different branches of the GPCR superfamily, but $\mathrm{CB}_{1}$ and $\mathrm{CB}_{2}$ are the only bona fide "cannabinoid receptors" that have been identified thus far.

\section{Cannabinoid Receptor Nomenclature: CB or Not CB? That Is the Question}

The terms "cannabinoid $\mathrm{CB}_{1}$ " and "cannabinoid $\mathrm{CB}_{2}$ " have been used throughout this review because this is the nomenclature that is currently recommended by the International Union of Basic and Clinical Pharmacology Committee on Receptor Nomenclature and Drug Classification and by its Subcommittee on Cannabinoid Receptors. It is noteworthy, however, that the adjective "cannabinoid" predates the discovery of cannabinoid receptors by many years and was originally coined to describe compounds, none of which is a structural analog of any known endocannabinoid. As a result, this term is widely used to describe not only all ligands that target $\mathrm{CB}_{1}$ or $\mathrm{CB}_{2}$ receptors but also other compounds with structures similar to the phytocannabinoid $\Delta^{9}$-THC, irrespective of whether they are or are not cannabinoid receptor agonists or antagonists. These additional cannabinoids include a number of nonpsychoactive compounds that are found in cannabis. The question arises, therefore, as to whether cannabinoid receptors should be renamed.

One possibility would be to rename these receptors after one of their endogenous agonists as is generally done for other receptors. However, selecting the most 


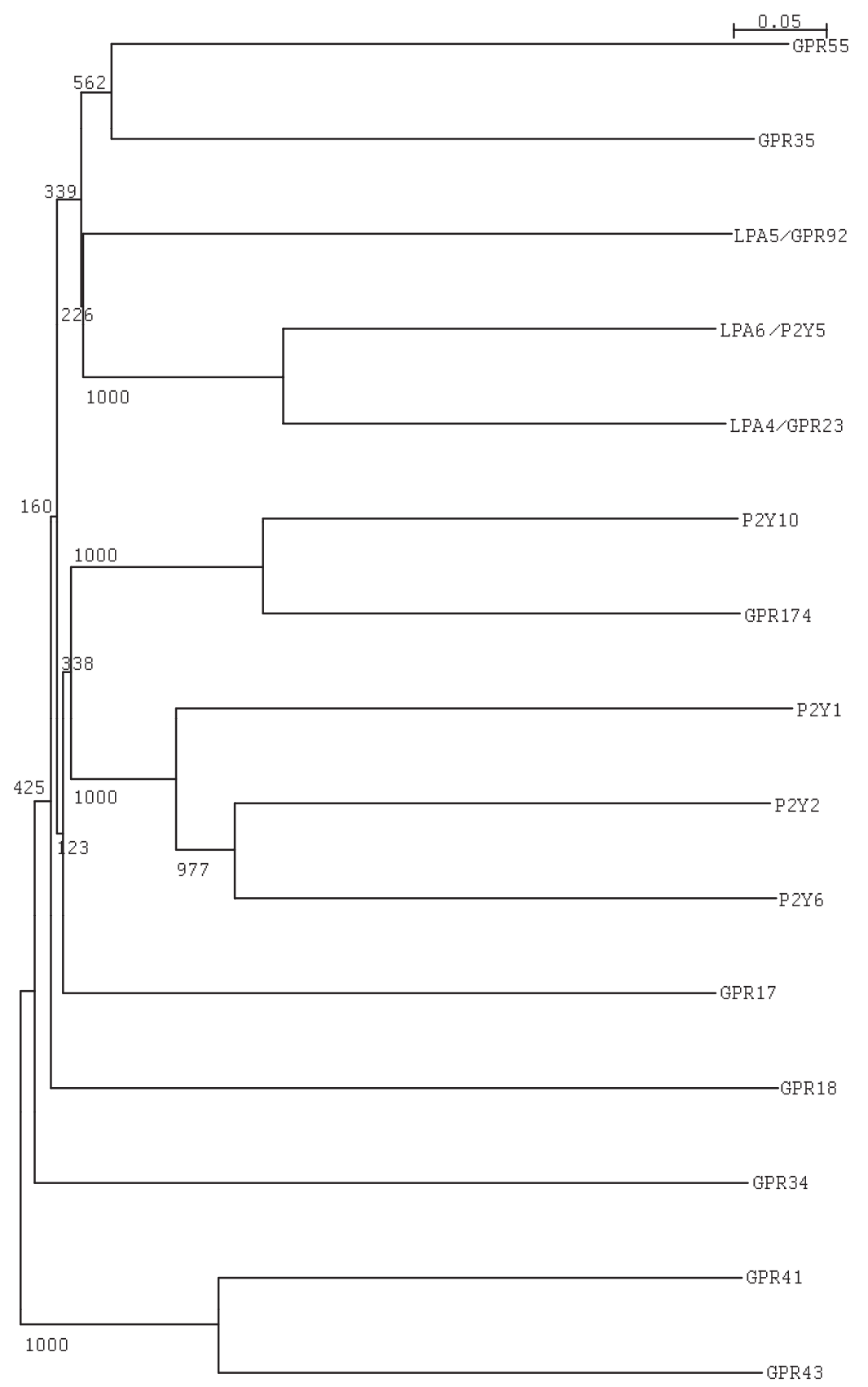

FIG. 7. Neighbor joining tree showing relationships between human GPR55 and other human rhodopsin $\delta$-group type G protein-coupled receptors. The tree was generated using the multiple sequence alignment program ClustalX, with bootstrapping (1000 bootstrap trials), and viewed using NJ plot. The tree shows receptors that are discussed in section IV.B of this review.

appropriate endocannabinoid for this purpose presents a formidable challenge. Thus, it is currently unclear whether anandamide, 2-AG, or some other established endocannabinoid should be selected for this purpose. Moreover, another as-yet-undiscovered endocannabinoid may emerge in the future as the most appropriate candidate for renaming cannabinoid receptors. Hence, for the present at least, this is probably not a sensible or viable option.

Another possibility would be to rename these receptors "endocannabinoid" receptors (for example, endocannabinoid $\mathrm{CB}_{1}$ and endocannabinoid $\mathrm{CB}_{2}$ receptors). Such no- menclature is of course tautologous, because all receptors are expected to have endogenous ligands. Nonetheless, it would remove the current confusion created by the term "cannabinoid" and yet, by retaining the terms " $\mathrm{CB}_{1}$ " and " $\mathrm{CB}_{2}$," would most likely not be the cause of any significant new confusion.

These and other options will be regularly considered by the International Union of Basic and Clinical Pharmacology Committee on Receptor Nomenclature and Drug Classification Subcommittee on Cannabinoid Receptors. In the meantime, it would be prudent to retain the present nomenclature for these receptors. 


\section{Overall Conclusions and Future Directions}

In conclusion, the endocannabinoid system seems to interact in a significant manner with several other endogenous systems. Thus, there is good evidence that $\mathrm{CB}_{1}$ receptors form heteromers with certain other GPCRs and that this heteromerization affects the manner in which the $\mathrm{CB}_{1}$ receptor responds to agonists (section II.D). In addition, it is generally accepted that at least some endocannabinoids, as well as $\Delta^{9}$-THC and several synthetic $\mathrm{CB}_{1} / \mathrm{CB}_{2}$ receptor agonists and antagonists, can interact with a number of established non- $\mathrm{CB}_{1}$, non$\mathrm{CB}_{2}$ GPCRs, ligand-gated ion channels, ion channels, and nuclear receptors (PPARs) (section III). Of particular interest are channels or non- $\mathrm{CB}_{1}$, non- $\mathrm{CB}_{2}$ receptors that seem to be activated or blocked by some $\mathrm{CB}_{1} / \mathrm{CB}_{2}$ receptor ligands with potencies that differ little from those with which they target $\mathrm{CB}_{1}$ and/or $\mathrm{CB}_{2}$ receptors as agonists or antagonists. Examples include 1) enhancement of the activation of glycine receptors by anandamide, $\Delta^{9}$-THC, HU-210, and $R$-(+)-WIN55212 (section III.D.3); 2) the enhancement of NMDA-induced activation of NMDA receptors by anandamide (section III.D.4); 3) the inhibition of T-type voltage-gated calcium channels by anandamide and rimonabant (section III.F.1); and 4) the inhibition of voltage-gated $\mathrm{K}_{\mathrm{V}} 3.1$ and $\mathrm{K}_{\mathrm{V}} 4.3$ potassium channels and the activation of calciumactivated potassium (BK) channels by anandamide, 2-AG, and/or $R$-(+)-methanandamide (section III.F.2). Some channels may be targeted by $\mathrm{CB}_{1} / \mathrm{CB}_{2}$ receptor ligands allosterically. These are $5-\mathrm{HT}_{3}$ and nicotinic acetylcholine receptors that can be potently activated by anandamide and certain other $\mathrm{CB}_{1} / \mathrm{CB}_{2}$ receptor ligands (sections III.D.1 and III.D.2). For some GPCRs (section III.C.3) and ligand-gated ion channels (section III.D), evidence that they can interact with $\mathrm{CB}_{1} / \mathrm{CB}_{2}$ receptor ligands has come solely from data obtained in radiolabeled ligand displacement experiments, prompting a need for further research directed at establishing whether such binding leads to receptor/channel activation or blockade. It should be noted, however, that $\mathrm{CB}_{1} /$ $\mathrm{CB}_{2}$ receptor ligands such as anandamide, $\Delta^{9}$-THC, HU210, 11-hydroxy- $\Delta^{8}$-THC, rimonabant, and taranabant did not display particularly high potency in these displacement experiments.

There seems to be no correlation between the ability of compounds to activate or block $\mathrm{CB}_{1}$ and/or $\mathrm{CB}_{2}$ receptors and their ability to target other receptors or channels. Moreover, some receptors and channels have been found to be activated by $\mathrm{CB}_{1} / \mathrm{CB}_{2}$ receptor antagonists or antagonized or inhibited by $\mathrm{CB}_{1} / \mathrm{CB}_{2}$ receptor agonists in a $\mathrm{CB}_{1} /$ $\mathrm{CB}_{2}$ receptor independent manner. Examples include the antagonism of GPR55 and inhibition of $5-\mathrm{HT}_{3}$ receptors and certain ion channels that has been observed in some experiments in response to $\mathrm{CB}_{1} / \mathrm{CB}_{2}$ receptor agonists (sections III.A.9., III.D.1, and III.F) and the activation of GPR55 and PPAR $\gamma$ (sections III.A.11., III.A.12 and III.G.1) that can apparently be induced by certain $\mathrm{CB}_{1}$ receptor antagonists in some bioassay systems. It should be borne in mind, therefore, that 1 ) some ligands that interact similarly with $\mathrm{CB}_{1}$ or $\mathrm{CB}_{2}$ receptors are likely to display significantly different pharmacological profiles in both some in vitro and in vivo bioassay systems and in the clinic and 2) a cannabinoid receptor antagonist might modulate the actions of a cannabinoid receptor agonist not only directly, through competitive antagonism or by inducing an inverse agonist effect at the cannabinoid receptor (sections II.C.3 and II.C.4), but also indirectly, by producing one or more $\mathrm{CB}_{1} / \mathrm{CB}_{2}$ receptor-independent effects. Clearly, therefore, a number of $\mathrm{CB}_{1} / \mathrm{CB}_{2}$ receptor agonists and antagonists together constitute a library of compounds, each with its own distinct "pharmacological fingerprint." It is noteworthy, too, that the terms " $\mathrm{CB}_{1}$-selective" and " $\mathrm{CB}_{2}$-selective" are often used to indicate that a particular ligand activates or blocks one of these two receptors more potently than the other. However, because at least some ligands that can be described in this way interact no more potently with a $\mathrm{CB}_{1}$ or $\mathrm{CB}_{2}$ receptor than with one or more other type of receptor or channel (section III), any use of these terms should be accompanied by an appropriate definition or caveat (section I). It is also worth noting that anandamide seems to be the first endogenous molecule to have been found capable of activating certain GPCRs, ligand-gated ion channels, ion channels, and nuclear receptors and hence members of superfamilies that display negligible structural homology.

An important question to arise from the data presented in this review is whether any known mammalian channel or non- $\mathrm{CB}_{1} / \mathrm{CB}_{2}$ receptor should be classified as a novel cannabinoid " $\mathrm{CB}_{3}$ " receptor or channel. We propose that any such receptor or channel should meet at least some of the following criteria:

1. It should be activated at its orthosteric site and with significant potency by an established $\mathrm{CB}_{1} / \mathrm{CB}_{2}$ receptor ligand.

2. It should be activated by at least one established endogenous $\mathrm{CB}_{1} / \mathrm{CB}_{2}$ receptor agonist at "physiologically relevant" concentrations.

3. If it is a GPCR, it should display significant amino acid sequence similarity with the $\mathrm{CB}_{1}$ or the $\mathrm{CB}_{2}$ receptor, which are members of the $\alpha$ group of rhodopsin-type GPCRs.

4. It should not be a "well established" non- $\mathrm{CB}_{1} / \mathrm{CB}_{2}$ receptor or channel, especially if there is already strong evidence that 1 ) this is activated endogenously by a non- $\mathrm{CB}_{1} / \mathrm{CB}_{2}$ receptor ligand with appropriate potency and relative intrinsic activity and 2) this is not activated endogenously by any endocannabinoid with appropriate potency and relative intrinsic activity.

5. It should be expressed by mammalian cells that are known to be exposed to concentrations of endog- 
enously released endocannabinoid molecules capable of eliciting a response.

Criterion 1 is not met by any receptors or channels that seem only to be potently targeted by $\mathrm{CB}_{1} / \mathrm{CB}_{2}$ receptor ligands in an allosteric manner. These probably include $5-\mathrm{HT}_{3}$ and nicotinic acetylcholine receptors (section III.D). Criteria 1 and 2 are not met by established GPCRs or deorphanized GPCRs other than GPR55, because there is, at least currently, no evidence that an endogenous or synthetic $\mathrm{CB}_{1} / \mathrm{CB}_{2}$ receptor agonist activates any of these with significant potency (sections III.B.7 and III.C). In addition, criterion 2 does not seem to be met by PPARs, although it should be borne in mind that intracellular levels of established endogenous PPAR agonists can be very high (section III.G.8).

Criterion 3 is not met by GPR55 but is met by GPR3, GPR6, GPR12, and other non- $\mathrm{CB}_{1} / \mathrm{CB}_{2}$ members of the $\alpha$ group of rhodopsin-type GPCRs (section IV). However, there is no pharmacological evidence that any of these non-GPR55, deorphanized receptors behaves as a cannabinoid receptor (sections III.B.3 and IV.A). Moreover, many $\alpha$ group rhodopsin-type GPCRs (for example, $\alpha_{1^{-}}$, $\alpha_{2^{-}}$, and $\beta$-adrenoceptors and established 5-HT, dopamine, adenosine, melanocortin, sphingosine 1-phosphate, and lysophosphatidic acid receptors) are each excluded by criterion 4 from being a novel cannabinoid receptor. The case for considering GPR55 as a non-CB $\mathrm{CB}_{1}$ $\mathrm{CB}_{2}$ cannabinoid receptor is further weakened 1) by the finding that it can be potently activated by an endogenous, non- $\mathrm{CB}_{1} / \mathrm{CB}_{2}$ receptor agonist, $\mathrm{LPI}$, and 2 ) by the inconsistent nature of much of the pharmacological data that have been generated to-date in GPR55 experiments with $\mathrm{CB}_{1} / \mathrm{CB}_{2}$ receptor ligands (section III.A). Criterion 4 is also not met by calcium, potassium, or sodium channels, ligand-gated ion channels, or nuclear receptors that are targeted by $\mathrm{CB}_{1} / \mathrm{CB}_{2}$ receptor ligands (sections III.D., III.F., and III.G). As to criterion 5, this is not met, at least at the present time, by the putative receptors discussed in section III.H. It is also noteworthy that at least some of these putative receptors seem to be activated by endogenous or synthetic $\mathrm{CB}_{1}$ or $\mathrm{CB}_{2}$ receptor agonists with rather low potency.

It is concluded that according to the five criteria listed in this section, no channel, non- $\mathrm{CB}_{1} / \mathrm{CB}_{2}$ established receptor or deorphanized receptor should currently be classified or reclassified as a novel cannabinoid receptor. It is noteworthy, however, that the TRPV1 channel does seem to meet criteria 1,4 , and 5, at least in part. Thus, 1 ) it is activated by anandamide at the capsaicin binding site, albeit with lower potency than the $\mathrm{CB}_{1}$ receptor, and also by $N$-arachidonoyl dopamine; 2 ) it is colocalized in some neurons with $\mathrm{CB}_{1}$ receptors and hence presumably exposed to endogenously produced endocannabinoids; and 3) anandamide was the first TRPV1 endogenous agonist to be identified (section III.E.2). It is also noteworthy that there is already evidence that TRPV1 channels are activated by endogenously released anandamide, at least in the presence of a FAAH inhibitor (section III.E.2). Clearly, there is a need for further research directed at exploring the possibility that the TRPV1 channel should be regarded as being either an "ionotropic cannabinoid $\mathrm{CB}_{3}$ receptor" or a dual TRPV1/ $\mathrm{CB}_{3}$ channels. Such research should also investigate the hypothesis that the extent to which endogenously released anandamide activates TRPV1 channels increases under certain pathological conditions (section III.E.2). Increased activation of this kind might mean that the TRPV1 channel would also meet criterion 2 in disease if not in health. Thus, it might well be considered acceptable for the term "physiologically relevant" in criterion 2 to encompass concentrations of an endogenously released established endocannabinoid that activate a putative cannabinoid $\mathrm{CB}_{3}$ receptor only under pathological conditions. An alternative possibility (that anandamide should be classified as a dual endocannabinoid/endovanilloid) also merits further investigation. So too does the question of whether any other non- $\mathrm{CB}_{1} / \mathrm{CB}_{2}$ receptor/ channel that displays significant sensitivity to an endocannabinoid is ever exposed to active concentrations of this endocannabinoid when it is released endogenously in the absence or presence of drugs that inhibit its metabolism or enhance its biosynthesis. Such research should perhaps focus initially on endocannabinoid-sensitive receptors or channels that are colocalized with $\mathrm{CB}_{1}$ or $\mathrm{CB}_{2}$ receptors. It will also be important to explore both the pharmacology of GPR55 more fully and the ability of $\mathrm{CB}_{1} / \mathrm{CB}_{2}$ receptor ligands to target other deorphanized receptors. The search for a cannabinoid $\mathrm{CB}_{3}$ receptor should and will continue.

Acknowledgments. This work was supported in part by the Intramural Research Program of the National Institutes of Health National Institute on Alcohol Abuse and Alcoholism (to G.K.); by the National Institutes of Health National Institute on Drug Abuse [Grants DA009789 (to R.G.P., V.D., R.A.R., R.M.), DA021696 (to K.M.), DA023204 (to M.E.A.), DA03672 (to R.G.P., R.A.R.), DA03690 (to A.C.H.), DA03934 (to R.G.P., R.A.R.), DA05274 (to M.E.A.)]; and by funding from the UNIK program "Food, Fitness and Pharma" (to H.S.H.).

\section{REFERENCES}

Abadji V, Lin S, Taha G, Griffin G, Stevenson LA, Pertwee RG, and Makriyannis A $(1994)(R)$-methanandamide: a chiral novel anandamide possessing higher potency and metabolic stability. J Med Chem 37:1889-1893.

Adam L, Salois D, Rihakova L, Lapointe S, St-Onge S, Labrecque J, and Payza K (2007) Positive allosteric modulators of CB1 receptors, in 17th Annual Symposium of the Cannabinoids; 2007 Jun 26-Jul 1; St-Sauveur, Canada. p. 86. International Cannabinoid Research Society, Burlington, Vermont.

Ahluwalia J, Urban L, Bevan S, and Nagy I (2003a) Anandamide regulates neuropeptide release from capsaicin-sensitive primary sensory neurons by activating both the cannabinoid 1 receptor and the vanilloid receptor 1 in vitro. Eur J Neurosci 17:2611-2618.

Ahluwalia J, Yaqoob M, Urban L, Bevan S, and Nagy I (2003b) Activation of capsaicin-sensitive primary sensory neurones induces anandamide production and release. $J$ Neurochem 84:585-591.

Akiyama TE, Sakai S, Lambert G, Nicol CJ, Matsusue K, Pimprale S, Lee YH, Ricote M, Glass CK, Brewer HB Jr, et al. (2002) Conditional disruption of the peroxisome proliferator-activated receptor gamma gene in mice results in lowered expression of ABCA1, ABCG1, and apoE in macrophages and reduced cholesterol efflux. Mol Cell Biol 22:2607-2619.

Akopian AN, Ruparel NB, Jeske NA, Patwardhan A, and Hargreaves KM (2009) Role of ionotropic cannabinoid receptors in peripheral antinociception and antihyperalgesia. Trends Pharmacol Sci 30:79-84. 
Akopian AN, Ruparel NB, Patwardhan A, and Hargreaves KM (2008) Cannabinoids desensitize capsaicin and mustard oil responses in sensory neurons via TRPA1 activation. $J$ Neurosci 28:1064-1075.

Alexander SP, Mathie A, and Peters JA (2009) Guide to Receptors and Channels (GRAC), 4th Edition. Br J Pharmacol 158 (Suppl 1):S1-S254.

Alvarado M, Goya P, Macías-González M, Pavón FJ, Serrano A, Jagerovic N, Elguero J, Gutiérrez-Rodríguez A, García-Granda S, Suardíaz M, et al. (2008) Antiobesity designed multiple ligands: synthesis of pyrazole fatty acid amides and evaluation as hypophagic agents. Bioorg Med Chem 16:10098-10105.

Amorós I, Barana A, Caballero R, Gómez R, Osuna L, Lillo MP, Tamargo J, and Delpón E (2010) Endocannabinoids and cannabinoid analogues block human cardiac $\mathrm{K}_{\mathrm{V}} 4.3$ channels in a receptor-independent manner. J Mol Cell Cardiol 48: 201-210.

Anand U, Otto WR, Sanchez-Herrera D, Facer P, Yiangou Y, Korchev Y, Birch R Benham C, Bountra C, Chessell IP, et al. (2008) Cannabinoid receptor CB2 localisation and agonist-mediated inhibition of capsaicin responses in human sensory neurons. Pain 138:667-680.

Andersson DA, Adner M, Högestätt ED, and Zygmunt PM (2002) Mechanisms underlying tissue selectivity of anandamide and other vanilloid receptor agonists. Mol Pharmacol 62:705-713.

Andersson M, Usiello A, Borgkvist A, Pozzi L, Dominguez C, Fienberg AA, Svenningsson P, Fredholm BB, Borrelli E, Greengard P, et al. (2005) Cannabinoid action depends on phosphorylation of dopamine- and cAMP-regulated phosphoprotein of $32 \mathrm{kDa}$ at the protein kinase A site in striatal projection neurons. J Neurosci 25:8432-8438.

Appendino G, Ligresti A, Minassi A, Cascio MG, Allarà M, Taglialatela-Scafati O Pertwee RG, De Petrocellis L, and Di Marzo V (2009) Conformationally constrained fatty acid ethanolamides as cannabinoid and vanilloid receptor probes. $J$ Med Chem 52:3001-3009.

Artmann A, Petersen G, Hellgren LI, Boberg J, Skonberg C, Nellemann C, Hansen $\mathrm{SH}$, and Hansen HS (2008) Influence of dietary fatty acids on endocannabinoid and $N$-acylethanolamine levels in rat brain, liver and small intestine. Biochim Biophys Acta 1781:200-212.

Bab I, Zimmer A, and Melamed E (2009) Cannabinoids and the skeleton: from marijuana to reversal of bone loss. Ann Med 41:560-567.

Baek JH, Zheng Y, Darlington CL, and Smith PF (2008) Cannabinoid $\mathrm{CB}_{2}$ receptor expression in the rat brainstem cochlear and vestibular nuclei. Acta Otolaryngo 128:961-967.

Barana A, Amorós I, Caballero R, Gómez R, Osuna L, Lillo MP, Blázquez C, Guzmán M, Delpón E, and Tamargo J (2010) Endocannabinoids and cannabinoid analogues block cardiac $\mathrm{hK}_{\mathrm{V}} 1.5$ channels in a cannabinoid receptor-independent manner. Cardiovasc Res 85:56-67.

Barann M, Molderings G, Brüss M, Bönisch H, Urban BW, and Göthert M (2002) Direct inhibition by cannabinoids of human $5-\mathrm{HT}_{3 \mathrm{~A}}$ receptors: probable involvement of an allosteric modulatory site. Br J Pharmacol 137:589-596.

Barbara G, Alloui A, Nargeot J, Lory P, Eschalier A, Bourinet E, and Chemin J (2009) T-type calcium channel inhibition underlies the analgesic effects of the endogenous lipoamino acids. $J$ Neurosci 29:13106-13114.

Beltramo M, Bernardini N, Bertorelli R, Campanella M, Nicolussi E, Fredduzzi S, and Reggiani A (2006) CB2 receptor-mediated antihyperalgesia: possible direct involvement of neural mechanisms. Eur J Neurosci 23:1530-1538.

Benninger F, Freund TF, and Hájos N (2008) Control of excitatory synaptic transmission by capsaicin is unaltered in TRPV1 vanilloid receptor knockout mice. Neurochem Int 52:89-94.

Berg AP, Talley EM, Manger JP, and Bayliss DA (2004) Motoneurons express heteromeric TWIK-related acid-sensitive $\mathrm{K}^{+}$(TASK) channels containing TASK-1 (KCNK3) and TASK-3 (KCNK9) subunits. J Neurosci 24:6693-6702.

Bharate SB, Nemmani KV, and Vishwakarma RA (2009) Progress in the discovery and development of small-molecule modulators of G-protein-coupled receptor 40 (GPR40/FFA1/FFAR1): an emerging target for type 2 diabetes. Expert Opin Ther Pat 19:237-264.

Bidaut-Russell M and Howlett AC (1991) Cannabinoid receptor-regulated cyclic AMP accumulation in the rat striatum. J Neurochem 57:1769-1773.

Bisogno T, Hanus L, De Petrocellis L, Tchilibon S, Ponde DE, Brandi I, Moriello AS, Davis JB, Mechoulam R and Di Marzo V (2001) Molecular targets for cannabidio and its synthetic analogues: effect on vanilloid VR1 receptors and on the cellular uptake and enzymatic hydrolysis of anandamide. Br J Pharmacol 134:845-852.

Bisogno T, Melck D, Bobrov MYu, Gretskaya NM, Bezuglov VV, De Petrocellis L, and Di Marzo V (2000) $N$-Acyl-dopamines: novel synthetic $\mathrm{CB}_{1}$ cannabinoid-recepto ligands and inhibitors of anandamide inactivation with cannabimimetic activity in vitro and in vivo. Biochem $J$ 351:817-824.

Bjursell M, Gerdin AK, Jönsson M, Surve VV, Svensson L, Huang XF, Törnell J, and Bohlooly-Y M (2006) G protein-coupled receptor 12 deficiency results in dyslipidemia and obesity in mice. Biochem Biophys Res Commun 348:359-366.

Borgkvist A, Marcellino D, Fuxe K, Greengard P, and Fisone G (2008) Regulation of DARPP-32 phosphorylation by $\Delta^{9}$-tetrahydrocannabinol. Neuropharmacology $\mathbf{5 4}$ $31-35$.

Bouaboula M, Hilairet S, Marchand J, Fajas L, Le Fur G, and Casellas P (2005) Anandamide induced PPAR $\gamma$ transcriptional activation and 3T3-L1 preadipocyte differentiation. Eur J Pharmacol 517:174-181.

Bouchard C, Pagé J, Bédard A, Tremblay P, and Vallières L (2007) G protein-coupled receptor 84, a microglia-associated protein expressed in neuroinflammatory conditions. Glia 55:790-800.

Bradshaw HB and Walker JM (2005) The expanding field of cannabimimetic and related lipid mediators. Br J Pharmacol 144:459-465.

Breivogel CS and Childers SR (2000) Cannabinoid agonist signal transduction in rat brain: comparison of cannabinoid agonists in receptor binding, G-protein activation, and adenylyl cyclase inhibition. J Pharmacol Exp Ther 295:328-336.

Breivogel CS, Griffin G, Di Marzo V, and Martin BR (2001) Evidence for a new G protein-coupled cannabinoid receptor in mouse brain. Mol Pharmacol 60:155-163.

Briscoe CP, Tadayyon M, Andrews JL, Benson WG, Chambers JK, Eilert MM, Ellis
C, Elshourbagy NA, Goetz AS, Minnick DT, et al. (2003) The orphan G proteincoupled receptor GPR40 is activated by medium and long chain fatty acids. J Biol Chem 278:11303-11311.

Brown AJ, Goldsworthy SM, Barnes AA, Eilert MM, Tcheang L, Daniels D, Muir AI, Wigglesworth MJ, Kinghorn I, Fraser NJ, et al. (2003) The orphan G protein coupled receptors GPR41 and GPR43 are activated by propionate and other short chain carboxylic acids. J Biol Chem 278:11312-11319.

Butt C, Alptekin A, Shippenberg T, and Oz M (2008) Endogenous cannabinoid anandamide inhibits nicotinic acetylcholine receptor function in mouse thalamic synaptosomes. J Neurochem 105:1235-1243.

Cabral GA and Staab A (2005) Effects on the immune system. Handb Exp Pharmaco 168:385-423.

Calandra B, Portier M, Kernéis A, Delpech M, Carillon C, Le Fur G, Ferrara P, and Shire D (1999) Dual intracellular signaling pathways mediated by the human cannabinoid $\mathrm{CB}_{1}$ receptor. Eur J Pharmacol 374:445-455.

Canals M and Milligan G (2008) Constitutive activity of the cannabinoid CB1 receptor regulates the function of co-expressed mu opioid receptors. $J$ Biol Chem 283:11424-11434

Carriba P, Navarro G, Ciruela F, Ferré S, Casadó V, Agnati L, Cortés A, Mallol J, Fuxe K, Canela EI, et al. (2008) Detection of heteromerization of more than two proteins by sequential BRET-FRET. Nat Methods 5:727-733.

Carriba P, Ortiz O, Patkar K, Justinova Z, Stroik J, Themann A, Müller C, Woods AS, Hope BT, Ciruela F, et al. (2007) Striatal adenosine $A_{2 A}$ and cannabinoid CB receptors form functional heteromeric complexes that mediate the motor effects of cannabinoids. Neuropsychopharmacology 32:2249-2259.

Cascio MG, Gauson LA, Stevenson LA, Ross RA, and Pertwee RG (2010) Evidence that the plant cannabinoid cannabigerol is a highly potent $\alpha_{2}$-adrenoceptor agonis and moderately potent $5 \mathrm{HT}_{1 \mathrm{~A}}$ receptor antagonist. $\mathrm{Br} J$ Pharmacol 159:129-141.

Caterina MJ, Leffler A, Malmberg AB, Martin WJ, Trafton J, Petersen-Zeitz KR, Koltzenburg M, Basbaum AI, and Julius D (2000) Impaired nociception and pain sensation in mice lacking the capsaicin receptor. Science 288:306-313

Caterina MJ, Schumacher MA, Tominaga M, Rosen TA, Levine JD, and Julius D (1997) The capsaicin receptor: a heat-activated ion channel in the pain pathway. Nature 389:816-824.

Cheer JF, Cadogan AK, Marsden CA, Fone KC, and Kendall DA (1999) Modification of $5-\mathrm{HT}_{2}$ receptor mediated behaviour in the rat by oleamide and the role of cannabinoid receptors. Neuropharmacology 38:533-541.

Chemin J, Monteil A, Perez-Reyes E, Nargeot J, and Lory P (2001) Direct inhibition of T-type calcium channels by the endogenous cannabinoid anandamide. EMBO $J$ 20:7033-7040

Chemin J, Nargeot J, and Lory P (2007) Chemical determinants involved in anandamide-induced inhibition of T-type calcium channels. J Biol Chem 282:23142323.

Chen JK, Chen J, Imig JD, Wei S, Hachey DL, Guthi JS, Falck JR, Capdevila JH, and Harris RC (2008) Identification of novel endogenous cytochrome p450 arachidonate metabolites with high affinity for cannabinoid receptors. $J$ Biol Chem 283:24514-24524

Childers SR, Pacheco MA, Bennett BA, Edwards TA, Hampson RE, Mu J, and Deadwyler SA (1993) Cannabinoid receptors: G-protein-mediated signal transduction mechanisms. Biochem Soc Symp 59:27-50.

Christopoulos A and Wilson $\mathrm{K}$ (2001) Interaction of anandamide with the $\mathrm{M}_{1}$ and $\mathrm{M}_{4}$ muscarinic acetylcholine receptors. Brain Res 915:70-78.

Chu ZL, Carroll C, Chen R, Alfonso J, Gutierrez V, He H, Lucman A, Xing C, Sebring $\mathrm{K}$, Zhou J, et al. (2010) $N$-oleoyldopamine enhances glucose homeostasis through the activation of GPR119. Mol Endocrinol 24:161-170.

Chu ZL, Jones RM, He H, Carroll C, Gutierrez V, Lucman A, Moloney M, Gao H, Mondala H, Bagnol D, et al. (2007) A role for beta-cell-expressed G protein-coupled receptor 119 in glycemic control by enhancing glucose-dependent insulin release. Endocrinology 148:2601-2609.

Chun J, Goetzl EJ, Hla T, Igarashi Y, Lynch KR, Moolenaar W, Pyne S, and Tigyi G (2002) International Union of Pharmacology. XXXIV. Lysophospholipid receptor nomenclature. Pharmacol Rev 54:265-269.

Ciana P, Fumagalli M, Trincavelli ML, Verderio C, Rosa P, Lecca D, Ferrario S, Parravicini C, Capra V, Gelosa P, et al. (2006) The orphan receptor GPR17 identified as a new dual uracil nucleotides/cysteinyl-leukotrienes receptor. $E M B O$ 25:4615-4627.

Cinar R, Freund TF, Katona I, Mackie K, and Szucs M (2008) Reciprocal inhibition of G-protein signaling is induced by $\mathrm{CB}_{1}$ cannabinoid and $\mathrm{GABA}_{\mathrm{B}}$ receptor interactions in rat hippocampal membranes. Neurochem Int 52:1402-1409.

Cinar R and Szücs M (2009) $\mathrm{CB}_{1}$ receptor-independent actions of SR141716 on G-protein signaling: coapplication with the $\mu$-opioid agonist Tyr-D-AlaGly (NMe)Phe-Gly-ol unmasks novel, pertussis toxin-insensitive opioid signaling in $\mu$-opioid receptor-Chinese hamster ovary cells. J Pharmacol Exp Ther 330:567574

Cluny NL, Keenan CM, Lutz B, Piomelli D, and Sharkey KA (2009) The identification of peroxisome proliferator-activated receptor alpha-independent effects of oleoylethanolamide on intestinal transit in mice. Neurogastroenterol Motil 21 $420-429$.

Cristino L, de Petrocellis L, Pryce G, Baker D, Guglielmotti V, and Di Marzo V (2006) Immunohistochemical localization of cannabinoid type 1 and vanilloid transien receptor potential vanilloid type 1 receptors in the mouse brain. Neuroscience 139:1405-1415.

D’Agostino G, La Rana G, Russo R, Sasso O, Iacono A, Esposito E, Raso GM, Cuzzocrea S, Lo Verme J, Piomelli D, et al. (2007) Acute intracerebroventricula administration of palmitoylethanolamide, an endogenous PPAR- $\alpha$ agonist, modu lates carrageenan-Induced paw edema in mice. J Pharmacol Exp Ther 322:11371143

Davis JB, Gray J, Gunthorpe MJ, Hatcher JP, Davey PT, Overend P, Harries MH Latcham J, Clapham C, Atkinson K, et al. (2000) Vanilloid receptor-1 is essential for inflammatory thermal hyperalgesia. Nature 405:183-187.

De Jesús ML, Sallés J, Meana JJ, and Callado LF (2006) Characterization of CB1 
cannabinoid receptor immunoreactivity in postmortem human brain homogenates. Neuroscience 140:635-643.

De Petrocellis L, Bisogno T, Davis JB, Pertwee RG, and Di Marzo V (2000) Overlap between the ligand recognition properties of the anandamide transporter and the VR1 vanilloid receptor: inhibitors of anandamide uptake with negligible capsaicinlike activity. FEBS Lett 483:52-56.

De Petrocellis L, Bisogno T, Maccarrone M, Davis JB, Finazzi-Agro A, and Di Marzo $\mathrm{V}(2001)$ The activity of anandamide at vanilloid VR1 receptors requires facilitated transport across the cell membrane and is limited by intracellular metabolism. J Biol Chem 276:12856-12863.

De Petrocellis L and Di Marzo V (2009) Role of endocannabinoids and endovanilloids in $\mathrm{Ca}^{2+}$ signalling. Cell Calcium 45:611-624.

De Petrocellis L, Starowicz K, Moriello AS, Vivese M, Orlando P, and Di Marzo V (2007) Regulation of transient receptor potential channels of melastatin type 8 (TRPM8): effect of cAMP, cannabinoid $\mathrm{CB}_{1}$ receptors and endovanilloids. Exp Cell Res 313:1911-1920.

De Petrocellis L, Vellani V, Schiano-Moriello A, Marini P, Magherini PC, Orlando P, and Di Marzo V (2008) Plant-derived cannabinoids modulate the activity of transient receptor potential channels of ankyrin type-1 and melastatin type-8. J Pharmacol Exp Ther 325:1007-1015.

Devane WA, Hanus L, Breuer A, Pertwee RG, Stevenson LA, Griffin G, Gibson D, Mandelbaum A, Etinger A, and Mechoulam R (1992) Isolation and structure of a brain constituent that binds to the cannabinoid receptor. Science 258:1946-1949.

Di Marzo V, Breivogel CS, Tao Q, Bridgen DT, Razdan RK, Zimmer AM, Zimmer A, and Martin BR (2000) Levels, metabolism, and pharmacological activity of anandamide in $\mathrm{CB}_{1}$ cannabinoid receptor knockout mice: evidence for non- $\mathrm{CB}_{1}$, non$\mathrm{CB}_{2}$ receptor-mediated actions of anandamide in mouse brain. J Neurochem 75: $2434-2444$.

Di Marzo V and Cristino L (2008) Why endocannabinoids are not all alike. Nat Neurosci 11:124-126.

Di Marzo V, De Petrocellis L, and Bisogno T (2005) The biosynthesis, fate and pharmacological properties of endocannabinoids. Handb Exp Pharmacol 168:147185.

Di Marzo V, De Petrocellis L, Fezza F, Ligresti A, and Bisogno T (2002) Anandamide receptors. Prostaglandins Leukot Essent Fatty Acids 66:377-391.

Dolezelova E, Nothacker HP, Civelli O, Bryant PJ, and Zurovec M (2007) A Drosophila adenosine receptor activates cAMP and calcium signaling. Insect Biochem Mol Biol 37:318-329.

Duan Y, Liao C, Jain S, and Nicholson RA (2008a) The cannabinoid receptor agonist CP-55,940 and ethyl arachidonate interfere with $\left[{ }^{3} \mathrm{H}\right]$ batrachotoxinin A $20 \alpha$-benzoate binding to sodium channels and inhibit sodium channel function. Comp Biochem Physiol C Toxicol Pharmacol 148:244-249.

Duan Y, Zheng J, and Nicholson RA (2008b) Inhibition of $\left[{ }^{3} \mathrm{H}\right]$ batrachotoxinin A-20 $\alpha$-benzoate binding to sodium channels and sodium channel function by endocannabinoids. Neurochem Int 52:438-446.

Dubi N, Gheber L, Fishman D, Sekler I, and Hershfinkel M (2008) Extracellular zinc and zinc-citrate, acting through a putative zinc-sensing receptor, regulate growth and survival of prostate cancer cells. Carcinogenesis 29:1692-1700.

Dyson A, Peacock M, Chen A, Courade JP, Yaqoob M, Groarke A, Brain C, Loong Y, and Fox A (2005) Antihyperalgesic properties of the cannabinoid CT-3 in chronic neuropathic and inflammatory pain states in the rat. Pain 116:129-137.

Eichele K, Ramer R, and Hinz B (2009) $R(+)$-Methanandamide-induced apoptosis of human cervical carcinoma cells involves a cyclooxygenase-2-dependent pathway. Pharm Res 26:346-355.

Ellis J, Pediani JD, Canals M, Milasta S, and Milligan G (2006) Orexin-1 receptorcannabinoid CB1 receptor heterodimerization results in both ligand-dependent and -independent coordinated alterations of receptor localization and function. J Biol Chem 281:38812-38824.

Elphick MR (2002) Evolution of cannabinoid receptors in vertebrates: identification of a $\mathrm{CB}_{2}$ gene in the puffer fish Fugu rubripes. Biol Bull 202:104-107.

Elphick MR (2007) BfCBR: a cannabinoid receptor ortholog in the cephalochordate Branchiostoma floridae (Amphioxus). Gene 399:65-71.

Elphick MR and Egertová M (2001) The neurobiology and evolution of cannabinoid signalling. Philos Trans R Soc Lond B Biol Sci 356:381-408.

Elphick MR and Egertová M (2005) The phylogenetic distribution and evolutionary origins of endocannabinoid signalling. Handb Exp Pharmacol 168:283-297.

Elphick MR, Satou Y, and Satoh N (2003) The invertebrate ancestry of endocannabinoid signalling: an orthologue of vertebrate cannabinoid receptors in the urochordate Ciona intestinalis. Gene 302:95-101.

Evans RM, Scott RH, and Ross RA (2004) Multiple actions of anandamide on neonatal rat cultured sensory neurones. Br J Pharmacol 141:1223-1233.

Everaerts W, Nilius B, and Owsianik G (2010) The vanilloid transient receptor potential channel TRPV4: from structure to disease. Prog Biophys Mol Biol 103: $2-17$.

Facci L, Dal Toso R, Romanello S, Buriani A, Skaper SD, and Leon A (1995) Mast cells express a peripheral cannabinoid receptor with differential sensitivity to anandamide and palmitoylethanolamide. Proc Natl Acad Sci USA 92:3376-3380.

Fan $\mathrm{P}$ (1995) Cannabinoid agonists inhibit the activation of $5-\mathrm{HT}_{3}$ receptors in rat nodose ganglion neurons. J Neurophysiol 73:907-910.

Fang X, Hu S, Xu B, Snyder GD, Harmon S, Yao J, Liu Y, Sangras B, Falck JR, Weintraub NL, et al. (2006) 4,15-Dihydroxyeicosatrienoic acid activates peroxisome proliferator-activated receptor- $\alpha$. Am J Physiol Heart Circ Physiol 290:H55H63.

Ferré S, Baler R, Bouvier M, Caron MG, Devi LA, Durroux T, Fuxe K, George SR, Javitch JA, Lohse MJ, et al. (2009a) Building a new conceptual framework for receptor heteromers. Nat Chem Biol 5:131-134.

Ferré S, Goldberg SR, Lluis C, and Franco R (2009b) Looking for the role of cannabinoid receptor heteromers in striatal function. Neuropharmacology $\mathbf{5 6}$ (Suppl 1):226-234.

Fioravanti B, De Felice M, Stucky CL, Medler KA, Luo MC, Gardell LR, Ibrahim M, Malan TP Jr, Yamamura HI, Ossipov MH, et al. (2008) Constitutive activity at the cannabinoid $\mathrm{CB} 1$ receptor is required for behavioral response to noxious chemical stimulation of TRPV1: antinociceptive actions of CB1 inverse agonists. $J$ Neurosci 28:11593-11602.

Fisyunov A, Tsintsadze V, Min R, Burnashev N, and Lozovaya N (2006) Cannabinoids modulate the P-type high-voltage-activated calcium currents in Purkinje neurons. J Neurophysiol 96:1267-1277.

Fong TM, Guan XM, Marsh DJ, Shen CP, Stribling DS, Rosko KM, Lao J, Yu H, Feng Y, Xiao JC, et al. (2007) Antiobesity efficacy of a novel cannabinoid-1 receptor inverse agonist, $N$-[(1S,2S)-3-(4-chlorophenyl)-2-(3-cyanophenyl)-1-methylpropyl]2-methyl-2-\{[5-(trifluoromethyl)pyridin-2-yl]oxy\}propanamide (MK-0364), in rodents. J Pharmacol Exp Ther 321:1013-1022.

Fong TM, Shearman LP, Stribling DS, Shu J, Lao J, Huang CR, Xiao JC, Shen CP, Tyszkiewicz J, Strack AM, et al. (2009) Pharmacological efficacy and safety profile of taranabant in preclinical species. Drug Dev Res 70:349-362.

Forman BM, Chen J, and Evans RM (1997) Hypolipidemic drugs, polyunsaturated fatty acids, and eicosanoids are ligands for peroxisome proliferator-activated receptors $\alpha$ and $\delta$. Proc Natl Acad Sci USA 94:4312-4317.

Fredriksson R, Höglund PJ, Gloriam DE, Lagerström MC, and Schiöth HB (2003a) Seven evolutionarily conserved human rhodopsin G protein-coupled receptors lacking close relatives. FEBS Lett 554:381-388.

Fredriksson R, Lagerström MC, Lundin LG, and Schiöth HB (2003b) The G-proteincoupled receptors in the human genome form five main families. Phylogenetic analysis, paralogon groups, and fingerprints. Mol Pharmacol 63:1256-1272.

Fu H, Xiao JM, Cao XH, Ming ZY, and Liu LJ (2008) Effects of WIN55,212-2 on voltage-gated sodium channels in trigeminal ganglion neurons of rats. Neurol Res 30:85-91.

Fu J, Gaetani S, Oveisi F, Lo Verme J, Serrano A, Rodríguez De Fonseca F, Rosengarth A, Luecke H, Di Giacomo B, Tarzia G, et al. (2003) Oleylethanolamide regulates feeding and body weight through activation of the nuclear receptor PPAR- $\alpha$. Nature 425:90-93.

Fuxe K, Marcellino D, Rivera A, Diaz-Cabiale Z, Filip M, Gago B, Roberts DC, Langel U, Genedani S, Ferraro L, et al. (2008) Receptor-receptor interactions within receptor mosaics. Impact on neuropsychopharmacology. Brain Res Rev 58:415452.

Gantz I, Muraoka A, Yang YK, Samuelson LC, Zimmerman EM, Cook H, and Yamada T (1997) Cloning and chromosomal localization of a gene (GPR18) encoding a novel seven transmembrane receptor highly expressed in spleen and testis. Genomics 42:462-466.

Ghosh M, Wang H, Ai Y, Romeo E, Luyendyk JP, Peters JM, Mackman N, Dey SK, and Hla T (2007) COX-2 suppresses tissue factor expression via endocannabinoiddirected PPAR $\delta$ activation. J Exp Med 204:2053-2061.

Giuliano M, Pellerito O, Portanova P, Calvaruso G, Santulli A, De Blasio A, Vento R, and Tesoriere G (2009) Apoptosis induced in HepG2 cells by the synthetic cannabinoid WIN: involvement of the transcription factor PPAR $\gamma$. Biochimie 91:457465 .

Glass M and Felder CC (1997) Concurrent stimulation of cannabinoid CB1 and dopamine D2 receptors augments cAMP accumulation in striatal neurons: evidence for a $G_{\mathrm{s}}$ linkage to the CB1 receptor. J Neurosci 17:5327-5333.

Godlewski G, Offertáler L, Osei-Hyiaman D, Mo FM, Harvey-White J, Liu J, Davis MI, Zhang L, Razdan RK, Milman G, et al. (2009) The endogenous brain constituent $N$-arachidonoyl L-serine is an activator of large conductance $\mathrm{Ca}^{2+}$-activated $\mathrm{K}^{+}$channels. J Pharmacol Exp Ther 328:351-361.

Gong JP, Onaivi ES, Ishiguro H, Liu QR, Tagliaferro PA, Brusco A, and Uhl GR (2006) Cannabinoid $\mathrm{CB}_{2}$ receptors: immunohistochemical localization in rat brain. Brain Res 1071:10-23.

Gonthier MP, Hoareau L, Festy F, Matias I, Valenti M, Bès-Houtmann S, Rouch C, Robert-Da Silva C, Chesne S, Lefebvre d'Hellencourt C, et al. (2007) Identification of endocannabinoids and related compounds in human fat cells. Obesity 15:837845 .

Gras D, Chanez P, Urbach V, Vachier I, Godard P, and Bonnans C (2009) Thiazolidinediones induce proliferation of human bronchial epithelial cells through the GPR40 receptor. Am J Physiol Lung Cell Mol Physiol 296:L970-L978.

Griffin G, Tao Q, and Abood ME (2000) Cloning and pharmacological characterization of the rat $\mathrm{CB}_{2}$ cannabinoid receptor. J Pharmacol Exp Ther 292:886-894.

Guo J and Ikeda SR (2004) Endocannabinoids modulate N-type calcium channels and G-protein-coupled inwardly rectifying potassium channels via CB1 cannabinoid receptors heterologously expressed in mammalian neurons. Mol Pharmacol 65:665-674.

Guzmán M, Lo Verme J, Fu J, Oveisi F, Blázquez C, and Piomelli D (2004) Oleoylethanolamide stimulates lipolysis by activating the nuclear receptor peroxisome proliferator-activated receptor $\alpha$ (PPAR- $\alpha$ ). J Biol Chem 279:27849-27854.

Hájos N and Freund TF (2002a) Distinct cannabinoid sensitive receptors regulate hippocampal excitation and inhibition. Chem Phys Lipids 121:73-82.

Hájos N and Freund TF (2002b) Pharmacological separation of cannabinoid sensitive receptors on hippocampal excitatory and inhibitory fibers. Neuropharmacology 43:503-510.

Hájos N, Katona I, Naiem SS, MacKie K, Ledent C, Mody I, and Freund TF (2000) Cannabinoids inhibit hippocampal GABAergic transmission and network oscillations. Eur J Neurosci 12:3239-3249.

Hájos N, Ledent C, and Freund TF (2001) Novel cannabinoid-sensitive receptor mediates inhibition of glutamatergic synaptic transmission in the hippocampus. Neuroscience 106:1-4.

Hampson AJ, Bornheim LM, Scanziani M, Yost CS, Gray AT, Hansen BM, Leonoudakis DJ, and Bickler PE (1998) Dual effects of anandamide on NMDA receptor-mediated responses and neurotransmission. J Neurochem 70:671-676.

Hanus L, Abu-Lafi S, Fride E, Breuer A, Vogel Z, Shalev DE, Kustanovich I, and Mechoulam R (2001) 2-Arachidonyl glyceryl ether, an endogenous agonist of the cannabinoid $\mathrm{CB}_{1}$ receptor. Proc Natl Acad Sci USA 98:3662-3665.

Hara T, Hirasawa A, Sun Q, Sadakane K, Itsubo C, Iga T, Adachi T, Koshimizu TA, Hashimoto T, Asakawa Y, et al. (2009) Novel selective ligands for free fatty acid 
receptors GPR120 and GPR40. Naunyn Schmiedebergs Arch Pharmacol 380:247255 .

Hejazi N, Zhou C, Oz M, Sun H, Ye JH, and Zhang L (2006) $\Delta^{9}$-Tetrahydrocannabinol and endogenous cannabinoid anandamide directly potentiate the function of glycine receptors. Mol Pharmacol 69:991-997.

Henquet C, Di Forti M, Morrison P, Kuepper R, and Murray RM (2008) Geneenvironment interplay between cannabis and psychosis. Schizophr Bull 34:11111121.

Henstridge CM, Balenga NA, Ford LA, Ross RA, Waldhoer M, and Irving AJ (2009) The GPR55 ligand L- $\alpha$-lysophosphatidylinositol promotes RhoA-dependent $\mathrm{Ca}^{2+}$ signaling and NFAT activation. FASEB J 23:183-193.

Henstridge CM, Balenga NA, Schröder R, Kargl JK, Platzer W, Martini L, Arthur S, Penman J, Whistler JL, Kostenis E, et al. (2010) GPR55 ligands promote receptor coupling to multiple signalling pathways. Br J Pharmacol 160:604-614.

Hermann H, De Petrocellis L, Bisogno T, Schiano Moriello A, Lutz B, and Di Marzo $\mathrm{V}$ (2003) Dual effect of cannabinoid $\mathrm{CB}_{1}$ receptor stimulation on a vanilloid VR1 receptor-mediated response. Cell Mol Life Sci 60:607-616.

Hermann H, Marsicano G, and Lutz B (2002) Coexpression of the cannabinoid receptor type 1 with dopamine and serotonin receptors in distinct neuronal subpopulations of the adult mouse forebrain. Neuroscience 109:451-460.

Hilairet S, Bouaboula M, Carrière D, Le Fur G, and Casellas P (2003) Hypersensitization of the orexin 1 receptor by the CB1 receptor: evidence for cross-talk blocked by the specific CB1 antagonist, SR141716. J Biol Chem 278:23731-23737.

Hillard CJ and Bloom AS (1982) $\Delta^{9}$-Tetrahydrocannabinol-induced changes in $\beta$-adrenergic receptor binding in mouse cerebral cortex. Brain Res 235:370-377.

Hillard CJ, Manna S, Greenberg MJ, DiCamelli R, Ross RA, Stevenson LA, Murphy V, Pertwee RG, and Campbell WB (1999) Synthesis and characterization of poten and selective agonists of the neuronal cannabinoid receptor (CB1). J Pharmacol Exp Ther 289:1427-1433.

Hinckley M, Vaccari S, Horner K, Chen R, and Conti M (2005) The G-protein-coupled receptors GPR3 and GPR12 are involved in cAMP signaling and maintenance of meiotic arrest in rodent oocytes. Dev Biol 287:249-261.

Hirasawa A, Tsumaya K, Awaji T, Katsuma S, Adachi T, Yamada M, Sugimoto Y Miyazaki S, and Tsujimoto G (2005) Free fatty acids regulate gut incretin glucagon-like peptide-1 secretion through GPR120. Nature Med 11:90-94.

Hoffman AF, Macgill AM, Smith D, Oz M, and Lupica CR (2005) Species and strain differences in the expression of a novel glutamate-modulating cannabinoid receptor in the rodent hippocampus. Eur $J$ Neurosci 22:2387-2391.

Holzer P (1988) Local effector functions of capsaicin-sensitive sensory nerve endings: involvement of tachykinins, calcitonin gene-related peptide and other neuropeptides. Neuroscience 24:739-768.

Horswill JG, Bali U, Shaaban S, Keily JF, Jeevaratnam P, Babbs AJ, Reynet C, and Wong Kai In P (2007) PSNCBAM-1, a novel allosteric antagonist at cannabinoid $\mathrm{CB}_{1}$ receptors with hypophagic effects in rats. Br J Pharmacol 152:805-814.

Howlett AC (1987) Cannabinoid inhibition of adenylate cyclase: relative activity of constituents and metabolites of marihuana. Neuropharmacology 26:507-512.

Howlett AC (2005) Cannabinoid receptor signaling. Handb Exp Pharmacol 168:5379

Howlett AC, Barth F, Bonner TI, Cabral G, Casellas P, Devane WA, Felder CC, Herkenham M, Mackie K, Martin BR, et al. (2002) International Union of Phar macology. XXVII. Classification of cannabinoid receptors. Pharmacol Rev 54:161202.

Hu H, He LY, Gong Z, Li N, Lu YN, Zhai QW, Liu H, Jiang HL, Zhu WL, and Wang HY (2009) A novel class of antagonists for the FFAs receptor GPR40. Biochem Biophys Res Commun 390:557-563.

Ichimura A, Hirasawa A, Hara T, and Tsujimoto G (2009) Free fatty acid receptors act as nutrient sensors to regulate energy homeostasis. Prostaglandins Other Lipid Mediat 89:82-88.

Ignatov A, Lintzel J, Hermans-Borgmeyer I, Kreienkamp HJ, Joost P, Thomsen S, Methner A, and Schaller HC (2003a) Role of the G-protein-coupled receptor GPR12 as high-affinity receptor for sphingosylphosphorylcholine and its expression and function in brain development. J Neurosci 23:907-914.

Ignatov A, Lintzel J, Kreienkamp HJ, and Schaller HC (2003b) Sphingosine-1phosphate is a high-affinity ligand for the $\mathrm{G}$ protein-coupled receptor GPR6 from mouse and induces intracellular $\mathrm{Ca}^{2+}$ release by activating the sphingosine-kinase pathway. Biochem Biophys Res Commun 311:329-336.

Ishii S, Noguchi K, and Yanagida K (2009) Non-Edg family lysophosphatidic acid (LPA) receptors. Prostaglandins Other Lipid Mediat 89:57-65.

Itoh Y, Kawamata Y, Harada M, Kobayashi M, Fujii R, Fukusumi S, Ogi K, Hosoya M, Tanaka Y, Uejima H, et al. (2003) Free fatty acids regulate insulin secretion from pancreatic $\beta$ cells through GPR40. Nature 422:173-176.

Iwamura H, Suzuki H, Ueda Y, Kaya T, and Inaba T (2001) In vitro and in vivo pharmacological characterization of JTE-907, a novel selective ligand for cannabinoid $\mathrm{CB}_{2}$ receptor. J Pharmacol Exp Ther 296:420-425.

Jaggar SI, Hasnie FS, Sellaturay S, and Rice AS (1998) The anti-hyperalgesic actions of the cannabinoid anandamide and the putative CB2 receptor agonist palmitoylethanolamide in visceral and somatic inflammatory pain. Pain 76:189-199.

Járai Z, Wagner JA, Varga K, Lake KD, Compton DR, Martin BR, Zimmer AM, Bonner TI, Buckley NE, Mezey E, et al. (1999) Cannabinoid-induced mesenteric vasodilation through an endothelial site distinct from CB1 or CB2 receptors. Proc Natl Acad Sci USA 96:14136-14141.

Jarrahian A and Hillard CJ (1997) Arachidonylethanolamide (anandamide) binds with low affinity to dihydropyridine binding sites in brain membranes. Prostaglandins Leukot Essent Fatty Acids 57:551-554.

Jarrahian A, Watts VJ, and Barker EL (2004) $\mathrm{D}_{2}$ dopamine receptors modulate $\mathrm{G} \alpha$-subunit coupling of the $\mathrm{CB}_{1}$ cannabinoid receptor. J Pharmacol Exp Ther 308:880-886.

Jhaveri MD, Richardson D, Robinson I, Garle MJ, Patel A, Sun Y, Sagar DR, Bennett AJ, Alexander SP, Kendall DA, et al. (2008) Inhibition of fatty acid amide hydrolase and cyclooxygenase-2 increases levels of endocannabinoid related molecules and produces analgesia via peroxisome proliferator-activated receptor-alpha in a model of inflammatory pain. Neuropharmacology 55:85-93.

Johns DG, Behm D.J, Walker DJ, Ao Z, Shapland EM, Daniels DA, Riddick M, Dowell S, Staton PC, Green P, et al. (2007) The novel endocannabinoid receptor GPR55 is activated by atypical cannabinoids but does not mediate their vasodilator effects. Br J Pharmacol 152:825-831.

Johnson DE, Heald SL, Dally RD, and Janis RA (1993) Isolation identification and synthesis of an endogenous arachidonic amide that inhibits calcium channel antagonist 1,4-dihydropyridine binding. Prostaglandins Leukot Essent Fatty Acids 48:429-437.

Johnson DM, Garrett EM, Rutter R, Bonnert TP, Gao YD, Middleton RE, and Sutton KG (2006) Functional mapping of the transient receptor potential vanilloid 1 intracellular binding site. Mol Pharmacol 70:1005-1012.

Jordt SE, Bautista DM, Chuang HH, McKemy DD, Zygmunt PM, Högestätt ED, Meng ID, and Julius D (2004) Mustard oils and cannabinoids excite sensory nerve fibres through the TRP channel ANKTM1. Nature 427:260-265.

Jordt SE and Julius D (2002) Molecular basis for species-specific sensitivity to "hot" chili peppers. Cell 108:421-430.

Kapur A, Zhao P, Sharir H, Bai Y, Caron MG, Barak LS, and Abood ME (2009) Atypical responsiveness of the orphan receptor GPR55 to cannabinoid ligands. $J$ Biol Chem 284:29817-29827.

Kathmann M, Flau K, Redmer A, Tränkle C, and Schlicker E (2006) Cannabidiol is an allosteric modulator at mu- and delta-opioid receptors. Naunyn-Schmiedebergs Arch Pharmacol 372:354-361.

Katona I, Urbán GM, Wallace M, Ledent C, Jung KM, Piomelli D, Mackie K, and Freund TF (2006) Molecular composition of the endocannabinoid system at glutamatergic synapses. J Neurosci 26:5628-5637.

Katsuma S, Hatae N, Yano T, Ruike Y, Kimura M, Hirasawa A, and Tsujimoto G (2005) Free fatty acids inhibit serum deprivation-induced apoptosis through GPR120 in a murine enteroendocrine cell line STC-1. J Biol Chem 280:1950719515

Kawamura Y, Fukaya M, Maejima T, Yoshida T, Miura E, Watanabe M, OhnoShosaku T, and Kano M (2006) The CB1 cannabinoid receptor is the major cannabinoid receptor at excitatory presynaptic sites in the hippocampus and cerebellum. J Neurosci 26:2991-3001.

Kearn CS, Blake-Palmer K, Daniel E, Mackie K, and Glass M (2005) Concurrent stimulation of cannabinoid CB1 and dopamine D2 receptors enhances heterodimer formation: a mechanism for receptor cross-talk? Mol Pharmacol 67:1697-1704.

Kenakin TP (2001) Quantitation in receptor pharmacology. Receptors Channels 7:371-385

Kim HI, Kim TH, Shin YK, Lee CS, Park M, and Song JH (2005) Anandamide suppression of $\mathrm{Na}^{+}$currents in rat dorsal root ganglion neurons. Brain Res 1062:39-47.

Kimura T, Ohta T, Watanabe K, Yoshimura H, and Yamamoto I (1998) Anandamide, an endogenous cannabinoid receptor ligand, also interacts with 5-hydroxytryptamine (5-HT) receptor. Biol Pharm Bull 21:224-226.

Kimura T, Yamamoto I, Ohta T, Yoshida H, Watanabe K, Ho IK, and Yoshimura H (1996) Changes in 5-HT receptor binding induced by tetrahydrocannabinol metabolites in bovine cerebral cortex. Res Commun Alcohol Subst Abuse 17:57-69.

Kishida K, Shimomura I, Nishizawa H, Maeda N, Kuriyama H, Kondo H, Matsuda M, Nagaretani H, Ouchi N, Hotta K, et al. (2001) Enhancement of the aquaporin adipose gene expression by a peroxisome proliferator-activated receptor gamma. $J$ Biol Chem 276:48572-48579.

Kohno M, Hasegawa H, Inoue A, Muraoka M, Miyazaki T, Oka K, and Yasukawa M (2006) Identification of $N$-arachidonylglycine as the endogenous ligand for orphan G-protein-coupled receptor GPR18. Biochem Biophys Res Commun 347:827-832.

Kotarsky K, Boketoft A, Bristulf J, Nilsson NE, Norberg A, Hansson S, Owman C, Sillard R, Leeb-Lundberg LM, and Olde B (2006) Lysophosphatidic acid binds to and activates GPR92, a G protein-coupled receptor highly expressed in gastrointestinal lymphocytes. J Pharmacol Exp Ther 318:619-628.

Kotarsky K, Nilsson NE, Flodgren E, Owman C, and Olde B (2003) A human cell surface receptor activated by free fatty acids and thiazolidinedione drugs. Biochem Biophys Res Commun 301:406-410.

Kozak KR, Gupta RA, Moody JS, Ji C, Boeglin WE, DuBois RN, Brash AR, and Marnett LJ (2002) 15-Lipoxygenase metabolism of 2-arachidonylglycerol: generation of a peroxisome proliferator-activated receptor $\alpha$ agonist. J Biol Chem 277: $23278-23286$

Lagalwar S, Bordayo EZ, Hoffmann KL, Fawcett JR, and Frey WH 2nd (1999) Anandamides inhibit binding to the muscarinic acetylcholine receptor. $J \mathrm{Mol}$ Neurosci 13:55-61.

Lander ES, Linton LM, Birren B, Nusbaum C, Zody MC, Baldwin J, Devon K, Dewar K, Doyle M, FitzHugh W, et al. (2001) Initial sequencing and analysis of the human genome. Nature 409:860-921.

Lane JR, Beukers MW, Mulder-Krieger T, and Ijzerman AP (2010) The endocan nabinoid 2-arachidonylglycerol is a negative allosteric modulator of the human $\mathrm{A}_{3}$ adenosine receptor. Biochem Pharmacol 79:48-56.

Lanzafame AA, Guida E, and Christopoulos A (2004) Effects of anandamide on the binding and signaling properties of $\mathrm{M}_{1}$ muscarinic acetylcholine receptors. Biochem Pharmacol 68:2207-2219.

Lattin JE, Schroder K, Su AI, Walker JR, Zhang J, Wiltshire T, Saijo K, Glass CK, Hume DA, Kellie S, et al. (2008) Expression analysis of G protein-coupled receptors in mouse macrophages. Immunome Res 4:5.

Lauckner JE, Jensen JB, Chen HY, Lu HC, Hille B, and Mackie K (2008) GPR55 is a cannabinoid receptor that increases intracellular calcium and inhibits M current. Proc Natl Acad Sci USA 105:2699-2704

Lauffer L, Iakoubov R, and Brubaker PL (2008) GPR119: “double-dipping” for better glycemic control. Endocrinology 149:2035-2037.

Le Poul E, Loison C, Struyf S, Springael JY, Lannoy V, Decobecq ME, Brezillon S, Dupriez V, Vassart G, Van Damme J, et al. (2003) Functional characterization of human receptors for short chain fatty acids and their role in polymorphonuclear cell activation. J Biol Chem 278:25481-25489. 
Lee CW, Rivera R, Dubin AE, and Chun J (2007) $\mathrm{LPA}_{4} / \mathrm{GPR} 23$ is a lysophosphatidic acid (LPA) receptor utilizing $\mathrm{G}_{\mathrm{s}^{-}}, \mathrm{G}_{\mathrm{q}} / \mathrm{G}_{\mathrm{i}}$-mediated calcium signaling and $\mathrm{G}_{12 / 13^{-}}$ mediated Rho activation. J Biol Chem 282:4310-4317.

Lee CW, Rivera R, Gardell S, Dubin AE, and Chun J (2006) GPR92 as a new $\mathrm{G}_{12 / 13^{-}}$

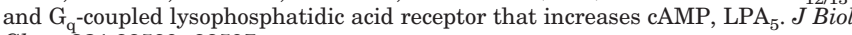
Chem 281:23589-23597.

Lee T, Schwandner R, Swaminath G, Weiszmann J, Cardozo M, Greenberg J, Jaeckel P, Ge H, Wang Y, Jiao X, et al. (2008) Identification and functional characterization of allosteric agonists for the G protein-coupled receptor FFA2. Mol Pharmacol 74:1599-1609.

Lenman A and Fowler CJ (2007) Interaction of ligands for the peroxisome proliferator-activated receptor $\gamma$ with the endocannabinoid system. $\mathrm{Br} J$ Pharmacol 151: $1343-1351$.

Liao C, Zheng J, David LS, and Nicholson RA (2004) Inhibition of voltage-sensitive sodium channels by the cannabinoid 1 receptor antagonist AM 251 in mammalian brain. Basic Clin Pharmacol Toxicol 94:73-78.

Liaw CW and Connolly DT (2009) Sequence polymorphisms provide a common consensus sequence for GPR41 and GPR42. DNA Cell Biol 28:555-560.

Ligresti A, Moriello AS, Starowicz K, Matias I, Pisanti S, De Petrocellis L, Laezza C, Portella G, Bifulco M, and Di Marzo V (2006) Antitumor activity of plant cannabinoids with emphasis on the effect of cannabidiol on human breast carcinoma. J Pharmacol Exp Ther 318:1375-1387.

Lin S, Khanolkar AD, Fan P, Goutopoulos A, Qin C, Papahadjis D, and Makriyannis A (1998) Novel analogues of arachidonylethanolamide (anandamide): affinities for the CB1 and CB2 cannabinoid receptors and metabolic stability. $J$ Med Chem 41:5353-5361.

Liu H, Enyeart JA, and Enyeart JJ (2007) Potent inhibition of native TREK-1 K channels by selected dihydropyridine $\mathrm{Ca}^{2+}$ channel antagonists. J Pharmacol Exp Ther 323:39-48.

Liu J, Li H, Burstein SH, Zurier RB, and Chen JD (2003) Activation and binding of peroxisome proliferator-activated receptor $\gamma$ by synthetic cannabinoid ajulemic acid. Mol Pharmacol 63:983-992.

Lobo MK, Cui Y, Ostlund SB, Balleine BW, and Yang XW (2007) Genetic control of instrumental conditioning by striatopallidal neuron-specific S1P receptor GPR6. Nat Neurosci 10:1395-1397.

Loría F, Petrosino S, Hernangómez M, Mestre L, Spagnolo A, Correa F, Di Marzo V, Docagne F, and Guaza C (2010) An endocannabinoid tone limits excitotoxicity in vitro and in a model of multiple sclerosis. Neurobiol Dis 37:166-176.

Lo Verme J, Fu J, Astarita G, La Rana G, Russo R, Calignano A, and Piomelli D (2005a) The nuclear receptor peroxisome proliferator-activated receptor- $\alpha$ mediates the antiinflammatory actions of palmitoylethanolamide. Mol Pharmacol 67: $15-19$.

Lo Verme J, Gaetani S, Fu J, Oveisi F, Burton K, and Piomelli D (2005b) Regulation of food intake by oleoylethanolamide. Cell Mol Life Sci 62:708-716.

LoVerme J, Russo R, La Rana G, Fu J, Farthing J, Mattace-Raso G, Meli R, Hohmann A, Calignano A, and Piomelli D (2006) Rapid broad-spectrum analgesia through activation of peroxisome proliferator-activated receptor- $\alpha$. $J$ Pharmacol Exp Ther 319:1051-1061.

Lozovaya N, Yatsenko N, Beketov A, Tsintsadze T, and Burnashev N (2005) Glycine receptors in CNS neurons as a target for nonretrograde action of cannabinoids. $J$ Neurosci 25:7499-7506.

Lunn CA, Reich EP, Fine JS, Lavey B, Kozlowski JA, Hipkin RW, Lundell DJ, and Bober L (2008) Biology and therapeutic potential of cannabinoid $\mathrm{CB}_{2}$ receptor inverse agonists. Br J Pharmacol 153:226-239.

Maccarrone M, Pauselli R, Di Rienzo M, and Finazzi-Agrò A (2002) Binding, degradation and apoptotic activity of stearoylethanolamide in rat C6 glioma cells Biochem J 366:137-144.

Mackie K (2005) Cannabinoid receptor homo- and heterodimerization. Life Sci 77: 1667-1673.

Maingret F, Patel AJ, Lazdunski M, and Honoré E (2001) The endocannabinoid anandamide is a direct and selective blocker of the background $\mathrm{K}^{+}$channel TASK-1. EMBO $J$ 20:47-54.

Maione S, Bisogno T, de Novellis V, Palazzo E, Cristino L, Valenti M, Petrosino S, Guglielmotti V, Rossi F, and Di Marzo V (2006) Elevation of endocannabinoid levels in the ventrolateral periaqueductal grey through inhibition of fatty acid amide hydrolase affects descending nociceptive pathways via both cannabinoid receptor type 1 and transient receptor potential vanilloid type- 1 receptors. J Pharmacol Exp Ther 316:969-982.

Maneuf YP and Brotchie JM (1997) Paradoxical action of the cannabinoid WIN $55,212-2$ in stimulated and basal cyclic AMP accumulation in rat globus pallidus slices. Br J Pharmacol 120:1397-1398.

Marcellino D, Carriba P, Filip M, Borgkvist A, Frankowska M, Bellido I, Tanganelli $\mathrm{S}$, Müller CE, Fisone G, Lluis C, et al. (2008) Antagonistic cannabinoid $\mathrm{CB}_{1} /$ dopamine $\mathrm{D}_{2}$ receptor interactions in striatal $\mathrm{CB}_{1} / \mathrm{D}_{2}$ heteromers. A combined neurochemical and behavioral analysis. Neuropharmacology 54:815-823.

Martin BR, Stevenson LA, Pertwee RG, Breivogel CS, Williams W, Mahadevan A, and Razdan RK (2002) Agonists and silent antagonists in a series of cannabinoid sulfonamides, in 12th Annual Symposium of the Cannabinoids; 2002 Jul 10-14; Pacific Grove, CA. p. 2. International Cannabinoid Research Society, Burlington, Vermont.

Matias I, Gonthier MP, Orlando P, Martiadis V, De Petrocellis L, Cervino C, Petrosino S, Hoareau L, Festy F, Pasquali R, et al. (2006) Regulation, function, and dysregulation of endocannabinoids in models of adipose and $\beta$-pancreatic cells and in obesity and hyperglycemia. J Clin Endocrinol Metab 91:3171-3180.

Matsuda LA, Lolait SJ, Brownstein MJ, Young AC, and Bonner TI (1990) Structure of a cannabinoid receptor and functional expression of the cloned cDNA. Nature 346:561-564.

Mazzola C, Medalie J, Scherma M, Panlilio LV, Solinas M, Tanda G, Drago F, Cadet JL, Goldberg SR, and Yasar S (2009) Fatty acid amide hydrolase (FAAH) inhibition enhances memory acquisition through activation of PPAR- $\alpha$ nuclear receptors. Learn Mem 16:332-337.
McDonald HA, Neelands TR, Kort M, Han P, Vos MH, Faltynek CR, Moreland RB, and Puttfarcken PS (2008) Characterization of A-425619 at native TRPV1 receptors: a comparison between dorsal root ganglia and trigeminal ganglia. Eur $J$ Pharmacol 596:62-69.

McHugh D, Hu SS, Rimmerman N, Juknat A, Vogel Z, Walker JM, and Bradshaw HB (2010) $N$-arachidonoyl glycine, an abundant endogenous lipid, potently drives directed cellular migration through GPR18, the putative abnormal cannabidiol receptor. BMC Neurosci. 11:44.

McKemy DD (2005) How cold is it? TRPM8 and TRPA1 in the molecular logic of cold sensation. Mol Pain 1:16.

McPartland JM, Matias I, Di Marzo V, and Glass M (2006) Evolutionary origins of the endocannabinoid system. Gene 370:64-74.

Mechoulam R, Ben-Shabat S, Hanus L, Ligumsky M, Kaminski NE, Schatz AR, Gopher A, Almog S, Martin BR, and Compton DR (1995) Identification of an endogenous 2-monoglyceride, present in canine gut, that binds to cannabinoid receptors. Biochem Pharmacol 50:83-90.

Melis M, Pillolla G, Luchicchi A, Muntoni AL, Yasar S, Goldberg SR, and Pistis M (2008) Endogenous fatty acid ethanolamides suppress nicotine-induced activation of mesolimbic dopamine neurons through nuclear receptors. J Neurosci 28:1398513994.

Meschler JP and Howlett AC (2001) Signal transduction interactions between CB $_{1}$ cannabinoid and dopamine receptors in the rat and monkey striatum. Neurophar macology 40:918-926.

Michalik L, Auwerx J, Berger JP, Chatterjee VK, Glass CK, Gonzalez FJ, Grimaldi PA, Kadowaki T, Lazar MA, O'Rahilly S, et al. (2006) International Union of Pharmacology. LXI. Peroxisome proliferator-activated receptors. Pharmacol Rev 58:726-741.

Milligan G and Smith NJ (2007) Allosteric modulation of heterodimeric G-proteincoupled receptors. Trends Pharmacol Sci 28:615-620.

Milman G, Maor Y, Abu-Lafi S, Horowitz M, Gallily R, Batkai S, Mo FM, Offertaler L, Pacher P, Kunos G, et al. (2006) $N$-arachidonoyl L-serine, an endocannabinoidlike brain constituent with vasodilatory properties. Proc Natl Acad Sci USA 103:2428-2433.

Miyauchi S, Hirasawa A, Iga T, Liu N, Itsubo C, Sadakane K, Hara T, and Tsujimoto $\mathrm{G}$ (2009) Distribution and regulation of protein expression of the free fatty acid receptor GPR120. Naunyn Schmiedebergs Arch Pharmacol 379:427-434.

Mo FM, Offertáler L, and Kunos G (2004) Atypical cannabinoid stimulates endothelial cell migration via a $\mathrm{G}_{\mathrm{i}} / \mathrm{G}_{\mathrm{o}}$-coupled receptor distinct from $\mathrm{CB}_{1}, \mathrm{CB}_{2}$ or EDG-1. Eur J Pharmacol 489:21-27.

Molderings GJ, Bönisch H, Hammermann R, Göthert M, and Brüss M (2002) Noradrenaline release-inhibiting receptors on PC12 cells devoid of $\alpha_{2}$ - and $\mathrm{CB}_{1}$ receptors: similarities to presynaptic imidazoline and edg receptors. Neurochem Int 40:157-167.

Molderings GJ, Likungu J, and Göthert M (1999) Presynaptic cannabinoid and imidazoline receptors in the human heart and their potential relationship. Nau nyn-Schmiedebergs Arch Pharmacol 360:157-164.

Monory K, Tzavara ET, Lexime J, Ledent C, Parmentier M, Borsodi A, and Hanoune $\mathrm{J}$ (2002) Novel, not adenylyl cyclase-coupled cannabinoid binding site in cerebellum of mice. Biochem Biophys Res Commun 292:231-235.

Moreno-Galindo EG, Barrio-Echavarría GF, Vásquez JC, Decher N, Sachse FB, Tristani-Firouzi M, Sánchez-Chapula JA, and Navarro-Polanco RA (2010) Molec ular basis for a high-potency open-channel block of Kv1.5 channel by the endocannabinoid anandamide. Mol Pharmacol 77:751-758.

Morgese MG, Cassano T, Cuomo V, and Giuffrida A (2007) Anti-dyskinetic effects of cannabinoids in a rat model of Parkinson's disease: role of CB1 and TRPV1 receptors. Exp Neurol 208:110-119.

Movahed P, Jönsson BA, Birnir B, Wingstrand JA, Jørgensen TD, Ermund A Sterner O, Zygmunt PM, and Högestätt ED (2005) Endogenous unsaturated C18 $\mathrm{N}$-acylethanolamines are vanilloid receptor (TRPV1) agonists. J Biol Chem 280: 38496-38504.

Mukhopadhyay S, Chapnick BM, and Howlett AC (2002) Anandamide-induced vasorelaxation in rabbit aortic rings has two components: G protein dependent and independent. Am J Physiol Heart Circ Physiol 282:H2046-H2054.

Mukhopadhyay S, McIntosh HH, Houston DB, and Howlett AC (2000) The CB cannabinoid receptor juxtamembrane C-terminal peptide confers activation to specific G proteins in brain. Mol Pharmacol 57:162-170.

Munro S, Thomas KL, and Abu-Shaar M (1993) Molecular characterization of a peripheral receptor for cannabinoids. Nature 365:61-65.

Murakami M, Shiraishi A, Tabata K, and Fujita N (2008) Identification of the orphan GPCR, P2Y 10 receptor as the sphingosine-1-phosphate and lysophosphatidic acid receptor. Biochem Biophys Res Commun 371:707-712.

Navarro HA, Howard JL, Pollard GT, and Carroll FI (2009) Positive allosteric modulation of the human cannabinoid (CB1) receptor by RTI-371, a selective inhibitor of the dopamine transporter. Br J Pharmacol 156:1178-1184.

Németh B, Ledent C, Freund TF, and Hájos N (2008) $\mathrm{CB}_{1}$ receptor-dependent and -independent inhibition of excitatory postsynaptic currents in the hippocampus by WIN 55,212-2. Neuropharmacology 54:51-57.

Nicholson RA, Liao C, Zheng J, David LS, Coyne L, Errington AC, Singh G, and Lees G (2003) Sodium channel inhibition by anandamide and synthetic cannabimimetics in brain. Brain Res 978:194-204.

Nilius B, Owsianik G, Voets T, and Peters JA (2007) Transient receptor potentia cation channels in disease. Physiol Rev 87:165-217.

Nilius B and Voets T (2005) TRP channels: a TR(I)P through a world of multifunctional cation channels. Pflugers Arch 451:1-10.

Nilsson NE, Kotarsky K, Owman C, and Olde B (2003) Identification of a free fatty acid receptor, FFA2R, expressed on leukocytes and activated by short-chain fatty acids. Biochem Biophys Res Commun 303:1047-1052.

Noguchi K, Ishii S, and Shimizu T (2003) Identification of P2y9/GPR23 as a novel G protein-coupled receptor for lysophosphatidic acid, structurally distant from the edg family. J Biol Chem 278:25600-25606. 
Norrod AG and Puffenbarger RA (2007) Genetic polymorphisms of the endocannabinoid system. Chem Biodivers 4:1926-1932.

Offertáler L, Mo FM, Bátkai S, Liu J, Begg M, Razdan RK, Martin BR, Bukoski RD, and Kunos G (2003) Selective ligands and cellular effectors of a G protein-coupled endothelial cannabinoid receptor. Mol Pharmacol 63:699-705.

Oh DY, Yoon JM, Moon MJ, Hwang JI, Choe H, Lee JY, Kim JI, Kim S, Rhim H, O'Dell DK, et al. (2008) Identification of farnesyl pyrophosphate and $\mathrm{N}$ arachidonylglycine as endogenous ligands for GPR92. J Biol Chem 283:2105421064

Ohno-Shosaku T, Tsubokawa H, Mizushima I, Yoneda N, Zimmer A, and Kano M (2002) Presynaptic cannabinoid sensitivity is a major determinant of depolarization-induced retrograde suppression at hippocampal synapses. $J$ Neurosci 22: $3864-3872$.

Oka S, Nakajima K, Yamashita A, Kishimoto S, and Sugiura T (2007) Identification of GPR55 as a lysophosphatidylinositol receptor. Biochem Biophys Res Commun 362:928-934

Oka S, Toshida T, Maruyama K, Nakajima K, Yamashita A, and Sugiura T (2009) 2-Arachidonoyl-sn-glycero-3-phosphoinositol: a possible natural ligand for GPR55. $J$ Biochem 145:13-20.

Okada Y, Imendra KG, Miyazaki T, Hotokezaka H, Fujiyama R, Zeredo JL, Miyamoto T, and Toda K (2005) Biophysical properties of voltage-gated $\mathrm{Na}^{+}$channels in frog parathyroid cells and their modulation by cannabinoids. $J$ Exp Biol 208 4747-4756.

Oliver D, Lien CC, Soom M, Baukrowitz T, Jonas P, and Fakler B (2004) Functional conversion between A-type and delayed rectifier $\mathrm{K}^{+}$channels by membrane lipids. Science 304:265-270

O'Sullivan SE, Bennett AJ, Kendall DA, and Randall MD (2006) Cannabinoid ligands as activators of peroxisome proliferator-activated receptor gamma (PPAR $\gamma)$, in 16th Annual Symposium of the Cannabinoids; 2006 Jun 25-28; Budapest, Hungary. p. 59. International Cannabinoid Research Society, Burling ton, Vermont.

O'Sullivan SE, Kendall DA, and Randall MD (2009a) Time-dependent vascular effects of endocannabinoids mediated by peroxisome proliferator-activated receptor gamma (PPAR $\gamma$ ). PPAR Res 2009:425289.

O'Sullivan SE, Sun Y, Bennett AJ, Randall MD, and Kendall DA (2009b) Timedependent vascular actions of cannabidiol in the rat aorta. Eur $J$ Pharmaco 612:61-68.

O'Sullivan SE, Tarling EJ, Bennett AJ, Kendall DA, and Randall MD (2005) Novel time-dependent vascular actions of $\Delta^{9}$-tetrahydrocannabinol mediated by peroxisome proliferator-activated receptor $\gamma$. Biochem Biophys Res Commun 337:824831.

Overton HA, Babbs AJ, Doel SM, Fyfe MC, Gardner LS, Griffin G, Jackson HC, Procter MJ, Rasamison CM, Tang-Christensen M, et al. (2006) Deorphanization of a $\mathrm{G}$ protein-coupled receptor for oleoylethanolamide and its use in the discovery of small-molecule hypophagic agents. Cell Metab 3:167-175.

Owsianik G, D'hoedt D, Voets T, and Nilius B (2006) Structure-function relationship of the TRP channel superfamily. Rev Physiol Biochem Pharmacol 156:61-90.

Oz M, Jackson SN, Woods AS, Morales M, and Zhang L (2005) Additive effects of endogenous cannabinoid anandamide and ethanol on $\alpha_{7}$-nicotinic acetylcholine receptor-mediated responses in Xenopus oocytes. J Pharmacol Exp Ther 313:12721280

Oz M, Ravindran A, Diaz-Ruiz O, Zhang L, and Morales M (2003) The endogenous cannabinoid anandamide inhibits $\alpha_{7}$ nicotinic acetylcholine receptor-mediated responses in Xenopus oocytes. J Pharmacol Exp Ther 306:1003-1010.

Oz M, Tchugunova Y, and Dinc M (2004b) Differential effects of endogenous and synthetic cannabinoids on voltage-dependent calcium fluxes in rabbit T-tubule membranes: comparison with fatty acids. Eur J Pharmacol 502:47-58.

Oz M, Tchugunova YB, and Dunn SM (2000) Endogenous cannabinoid anandamide directly inhibits voltage-dependent $\mathrm{Ca}^{2+}$ fluxes in rabbit T-tubule membranes. Eur J Pharmacol 404:13-20.

Oz M, Yang KH, Dinc M, and Shippenberg TS (2007) The endogenous cannabinoid anandamide inhibits cromakalim-activated $\mathrm{K}^{+}$currents in follicle-enclosed Xenopus oocytes. J Pharmacol Exp Ther 323:547-554

Oz M, Zhang L, and Morales M (2002) Endogenous cannabinoid, anandamide, acts as a noncompetitive inhibitor on $5-\mathrm{HT}_{3}$ receptor-mediated responses in Xenopus oocytes. Synapse 46:150-156.

Oz M, Zhang L, Ravindran A, Morales M, and Lupica CR (2004a) Differential effects of endogenous and synthetic cannabinoids on $\alpha_{7}$-nicotinic acetylcholine receptormediated responses in Xenopus oocytes. J Pharmacol Exp Ther 310:1152-1160.

Pacheco MA, Ward SJ, and Childers SR (1993) Identification of cannabinoid receptors in cultures of rat cerebellar granule cells. Brain Res 603:102-110.

Pagano C, Pilon C, Calcagno A, Urbanet R, Rossato M, Milan G, Bianchi K, Rizzuto R, Bernante P, Federspil G, et al. (2007) The endogenous cannabinoid system stimulates glucose uptake in human fat cells via phosphatidylinositol 3-kinase and calcium-dependent mechanisms. J Clin Endocrinol Metab 92:4810-4819.

Pan X, Ikeda SR, and Lewis DL (1998) SR 141716A acts as an inverse agonist to increase neuronal voltage-dependent $\mathrm{Ca}^{2+}$ currents by reversal of tonic CB1 cannabinoid receptor activity. Mol Pharmacol 54:1064-1072.

Parker HE, Habib AM, Rogers GJ, Gribble FM, and Reimann F (2009) Nutrientdependent secretion of glucose-dependent insulinotropic polypeptide from primary murine K cells. Diabetologia 52:289-298.

Parmar N and Ho WS (2010) $N$-arachidonoyl glycine, an endogenous lipid that acts as a vasorelaxant via nitric oxide and large conductance calcium-activated potassium channels. Br J Pharmacol 160:594-603.

Pasternack SM, von Kügelgen I, Aboud KA, Lee YA, Rüschendorf F, Voss K, Hillmer AM, Molderings GJ, Franz T, Ramirez A, et al. (2008) G protein-coupled receptor P2Y5 and its ligand LPA are involved in maintenance of human hair growth. Nat Genet 40:329-334

Paugh SW, Cassidy MP, He H, Milstien S, Sim-Selley LJ, Spiegel S, and Selley DE (2006) Sphingosine and its analog, the immunosuppressant 2-amino-2-(2-[4- octylphenyl]ethyl)-1,3-propanediol, interact with the CB1 cannabinoid receptor. Mol Pharmacol 70:41-50.

Pertwee RG (1999) Pharmacology of cannabinoid receptor ligands. Curr Med Chem 6:635-664.

Pertwee RG (2004) Novel pharmacological targets for cannabinoids. Curr Neuropharmacol 2:9-29.

Pertwee RG (2005a) Pharmacological actions of cannabinoids. Handb Exp Pharmacol 168:1-51.

Pertwee RG (2005b) The therapeutic potential of drugs that target cannabinoid receptors or modulate the tissue levels or actions of endocannabinoids. AAPS $J$ 7:E625-E654

Pertwee RG (2005c) Inverse agonism and neutral antagonism at cannabinoid $\mathrm{CB}_{1}$ receptors. Life Sci 76:1307-1324

Pertwee RG (2008a) The diverse $\mathrm{CB}_{1}$ and $\mathrm{CB}_{2}$ receptor pharmacology of three plant cannabinoids: $\Delta^{9}$-tetrahydrocannabinol, cannabidiol and $\Delta^{9}$-tetrahydrocannabivarin. Br J Pharmacol 153:199-215.

Pertwee RG (2008b) Ligands that target cannabinoid receptors in the brain: from THC to anandamide and beyond. Addict Biol 13:147-159.

Pertwee RG and Ross RA (2002) Cannabinoid receptors and their ligands. Prostaglandins Leukot Essent Fatty Acids 66:101-121.

Peters JM, Lee SS, Li W, Ward JM, Gavrilova O, Everett C, Reitman ML, Hudson LD, and Gonzalez FJ (2000) Growth, adipose, brain, and skin alterations resulting from targeted disruption of the mouse peroxisome proliferator-activated receptor $\beta(\delta)$. Mol Cell Biol 20:5119-5128.

Pickel VM, Chan J, Kash TL, Rodríguez JJ, and MacKie K (2004) Compartmentspecific localization of cannabinoid 1 (CB1) and $\mu$-opioid receptors in rat nucleus accumbens. Neuroscience 127:101-112.

Pickel VM, Chan J, Kearn CS, and Mackie K (2006) Targeting dopamine D2 and cannabinoid-1 (CB1) receptors in rat nucleus accumbens. J Comp Neurol 495:299 313

Pietr M, Kozela E, Levy R, Rimmerman N, Lin YH, Stella N, Vogel Z, and Juknat A (2009) Differential changes in GPR55 during microglial cell activation. FEBS Lett 583:2071-2076.

Poling JS, Rogawski MA, Salem N Jr, and Vicini S (1996) Anandamide, an endog enous cannabinoid, inhibits Shaker-related voltage-gated $\mathrm{K}^{+}$channels. Neuropharmacology 35:983-991.

Porter AC, Sauer JM, Knierman MD, Becker GW, Berna MJ, Bao J, Nomikos GG Carter P, Bymaster FP, Leese AB, et al. (2002) Characterization of a nove endocannabinoid, virodhamine, with antagonist activity at the CB1 receptor. $J$ Pharmacol Exp Ther 301:1020-1024.

Price MR, Baillie GL, Thomas A, Stevenson LA, Easson M, Goodwin R, McLean A McIntosh L, Goodwin G, Walker G, et al. (2005a) Allosteric modulation of the cannabinoid $\mathrm{CB}_{1}$ receptor. Mol Pharmacol 68:1484-1495.

Price TJ, Patwardhan AM, Flores CM, and Hargreaves KM (2005b) A role for the anandamide membrane transporter in TRPV1-mediated neurosecretion from trigeminal sensory neurons. Neuropharmacology 49:25-39.

Price TJ, Patwardhan A, Akopian AN, Hargreaves KM, and Flores CM (2004) Modulation of trigeminal sensory neuron activity by the dual cannabinoidvanilloid agonists anandamide, $\mathrm{N}$-arachidonoyl-dopamine and arachidonyl-2 chloroethylamide. Br J Pharmacol 141:1118-1130.

Qin N, Neeper MP, Liu Y, Hutchinson TL, Lubin ML, and Flores CM (2008) TRPV2 is activated by cannabidiol and mediates CGRP release in cultured rat dorsal root ganglion neurons. $J$ Neurosci 28:6231-6238.

Rashid MH, Inoue M, Bakoshi S, and Ueda H (2003a) Increased expression of vanilloid receptor 1 on myelinated primary afferent neurons contributes to the antihyperalgesic effect of capsaicin cream in diabetic neuropathic pain in mice. J Pharmacol Exp Ther 306:709-717.

Rashid MH, Inoue M, Kondo S, Kawashima T, Bakoshi S, and Ueda H (2003b) Novel expression of vanilloid receptor 1 on capsaicin-insensitive fibers accounts for the analgesic effect of capsaicin cream in neuropathic pain. $J$ Pharmacol Exp The 304:940-948.

Rinaldi-Carmona M, Barth F, Millan J, Derocq JM, Casellas P, Congy C, Oustric D, Sarran M, Bouaboula M, Calandra B, et al. (1998) SR 144528, the first potent and selective antagonist of the CB2 cannabinoid receptor. J Pharmacol Exp Ther 284:644-650.

Rios C, Gomes I, and Devi LA (2006) Mu opioid and CB1 cannabinoid receptor interactions: reciprocal inhibition of receptor signaling and neuritogenesis. $\mathrm{Br}$ Pharmacol 148:387-395.

Roberts LA, Christie MJ, and Connor M (2002) Anandamide is a partial agonist at native vanilloid receptors in acutely isolated mouse trigeminal sensory neurons. Br J Pharmacol 137:421-428.

Roche M, Kelly JP, O’Driscoll M, and Finn DP (2008) Augmentation of endogenous cannabinoid tone modulates lipopolysaccharide-induced alterations in circulating cytokine levels in rats. Immunology 125:263-271.

Rockwell CE and Kaminski NE (2004) A cyclooxygenase metabolite of anandamide causes inhibition of interleukin-2 secretion in murine splenocytes. $J$ Pharmaco Exp Ther 311:683-690.

Rockwell CE, Snider NT, Thompson JT, Vanden Heuvel JP, and Kaminski NE (2006) Interleukin-2 suppression by 2 -arachidonyl glycerol is mediated through peroxisome proliferator activated receptor $\gamma$ independently of cannabinoid receptors and 2. Mol Pharmacol 70:101-111.

Rodriguez JJ, Mackie K, and Pickel VM (2001) Ultrastructural localization of the CB1 cannabinoid receptor in $\mu$-opioid receptor patches of the rat caudate putamen nucleus. J Neurosci 21:823-833.

Ross HR, Gilmore AJ, and Connor M (2009) Inhibition of human recombinant T-type calcium channels by the endocannabinoid $\mathrm{N}$-arachidonoyl dopamine. $\mathrm{Br} J \mathrm{Phar}$ macol 156:740-750.

Ross HR, Napier I, and Connor M (2008) Inhibition of recombinant human T-type calcium channels by $\Delta^{9}$-tetrahydrocannabinol and cannabidiol. J Biol Chem 283 $16124-16134$. 
Ross RA (2009) The enigmatic pharmacology of GPR55. Trends Pharmacol Sci 30:156-163.

Ross RA, Brockie HC, Stevenson LA, Murphy VL, Templeton F, Makriyannis A, and Pertwee RG (1999) Agonist-inverse agonist characterization at $\mathrm{CB}_{1}$ and $\mathrm{CB}_{2}$ cannabinoid receptors of L759633, L759656 and AM630. Br J Pharmacol 126:665672 .

Ross RA, Coutts AA, McFarlane SM, Anavi-Goffer S, Irving AJ, Pertwee RG, MacEwan DJ, and Scott RH (2001a) Actions of cannabinoid receptor ligands on rat cultured sensory neurones: implications for antinociception. Neuropharmacology 40:221-232.

Ross RA, Gibson TM, Brockie HC, Leslie M, Pashmi G, Craib SJ, Di Marzo V, and Pertwee RG (2001b) Structure-activity relationship for the endogenous cannabinoid, anandamide, and certain of its analogues at vanilloid receptors in transfected cells and vas deferens. Br J Pharmacol 132:631-640.

Rossi F, Siniscalco D, Luongo L, De Petrocellis L, Bellini G, Petrosino S, Torella M, Santoro C, Nobili B, Perrotta S, et al. (2009) The endovanilloid/endocannabinoid system in human osteoclasts: possible involvement in bone formation and resorption. Bone 44:476-484.

Rubino T, Realini N, Castiglioni C, Guidali C, Viganó D, Marras E, Petrosino S, Perletti G, Maccarrone M, Di Marzo V, et al. (2008) Role in anxiety behavior of the endocannabinoid system in the prefrontal cortex. Cereb Cortex 18:1292-1301.

Ruiu S, Pinna GA, Marchese G, Mussinu JM, Saba P, Tambaro S, Casti P, Vargiu R and Pani L (2003) Synthesis and characterization of NESS 0327: a novel putative antagonist of the $\mathrm{CB}_{1}$ cannabinoid receptor. J Pharmacol Exp Ther 306:363-370.

Ryberg E, Larsson N, Sjögren S, Hjorth S, Hermansson NO, Leonova J, Elebring T, Nilsson K, Drmota T, and Greasley PJ (2007) The orphan receptor GPR55 is a novel cannabinoid receptor. Br J Pharmacol 152:1092-1101.

Sade H, Muraki K, Ohya S, Hatano N, and Imaizumi Y (2006) Activation of largeconductance, $\mathrm{Ca}^{2+}$-activated $\mathrm{K}^{+}$channels by cannabinoids. Am J Physiol Cell Physiol 290:C77-C86.

Sagan S, Venance L, Torrens Y, Cordier J, Glowinski J, and Giaume C (1999) Anandamide and WIN 55212-2 inhibit cyclic AMP formation through G-proteincoupled receptors distinct from $\mathrm{CB} 1$ cannabinoid receptors in cultured astrocytes. Eur $J$ Neurosci 11:691-699.

Salio C, Fischer J, Franzoni MF, Mackie K, Kaneko T, and Conrath M (2001) CB1-cannabinoid and $\mu$-opioid receptor co-localization on postsynaptic target in the rat dorsal horn. Neuroreport 12:3689-3692.

Sasso O, La Rana G, Vitiello S, Russo R, D'Agostino G, Iacono A, Russo E, Citraro R, Cuzzocrea S, Piazza PV, et al. (2010) Palmitoylethanolamide modulates pentobarbital-evoked hypnotic effect in mice. Involvement of allopregnanolone biosynthesis. Eur Neuropsychopharmacol 20:195-206.

Savinainen JR, Järvinen T, Laine K, and Laitinen JT (2001) Despite substantial degradation, 2-arachidonoylglycerol is a potent full efficacy agonist mediating $\mathrm{CB}_{1}$ receptor-dependent G-protein activation in rat cerebellar membranes. $\mathrm{Br} J \mathrm{Phar}$ macol 134:664-672.

Savinainen JR, Saario SM, Niemi R, Järvinen T, and Laitinen JT (2003) An optimized approach to study endocannabinoid signaling: evidence against constitutiv activity of rat brain adenosine $\mathrm{A}_{1}$ and cannabinoid $\mathrm{CB}_{1}$ receptors. $\mathrm{Br} J$ Pharmaco 140:1451-1459.

Sawzdargo M, Nguyen T, Lee DK, Lynch KR, Cheng R, Heng HH, George SR, and O'Dowd BF (1999) Identification and cloning of three novel human G protein coupled receptor genes GPR52, Psi GPR53 and GPR55: GPR55 is extensively expressed in human brain. Mol Brain Res 64:193-198.

Shapira M, Gafni M, and Sarne Y (1998) Independence of, and interactions between, cannabinoid and opioid signal transduction pathways in N18TG2 cells. Brain Res 806:26-35.

Shapira M, Vogel Z, and Sarne Y (2000) Opioid and cannabinoid receptors share a common pool of GTP-binding proteins in cotransfected cells, but not in cells which endogenously coexpress the receptors. Cell Mol Neurobiol 20:291-304.

Shaw G, Morse S, Ararat M, and Graham FL (2002) Preferential transformation of human neuronal cells by human adenoviruses and the origin of HEK 293 cells. FASEB J 16:869-871.

Shen M and Thayer SA (1998) The cannabinoid agonist Win55,212-2 inhibits calcium channels by receptor-mediated and direct pathways in cultured rat hippocampal neurons. Brain Res 783:77-84.

Shimasue K, Urushidani T, Hagiwara M, and Nagao T (1996) Effects of anandamide and arachidonic acid on specific binding of (+)-PN200-110, diltiazem and (-) desmethoxyverapamil to L-type $\mathrm{Ca}^{2+}$ channel. Eur J Pharmacol 296:347-350.

Showalter VM, Compton DR, Martin BR, and Abood ME (1996) Evaluation of binding in a transfected cell line expressing a peripheral cannabinoid receptor (CB2): identification of cannabinoid receptor subtype selective ligands. J Pharmacol Exp Ther 278:989-999.

Sim-Selley LJ, Goforth PB, Mba MU, Macdonald TL, Lynch KR, Milstien S, Spiegel S, Satin LS, Welch SP, and Selley DE (2009) Sphingosine-1-phosphate receptor mediate neuromodulatory functions in the CNS. J Neurochem 110:1191-1202.

Skaper SD, Buriani A, Dal Toso R, Petrelli L, Romanello S, Facci L, and Leon A (1996) The ALIAmide palmitoylethanolamide and cannabinoids, but not anandamide, are protective in a delayed postglutamate paradigm of excitotoxic death in cerebellar granule neurons. Proc Natl Acad Sci USA 93:3984-3989.

Smart D, Gunthorpe MJ, Jerman JC, Nasir S, Gray J, Muir AI, Chambers JK Randall AD, and Davis JB (2000) The endogenous lipid anandamide is a full agonist at the human vanilloid receptor (hVR1). Br J Pharmacol 129:227-230.

Smith NJ, Stoddart LA, Devine NM, Jenkins L, and Milligan G (2009) The action and mode of binding of thiazolidinedione ligands at free fatty acid receptor 1 . J Biol Chem 284:17527-17539.

Soga T, Ohishi T, Matsui T, Saito T, Matsumoto M, Takasaki J, Matsumoto S, Kamohara M, Hiyama H, Yoshida S, et al. (2005) Lysophosphatidylcholine en hances glucose-dependent insulin secretion via an orphan G-protein-coupled receptor. Biochem Biophys Res Commun 326:744-751.

Spivak CE, Lupica CR, and Oz M (2007) The endocannabinoid anandamide inhibits the function of $\alpha 4 \beta 2$ nicotinic acetylcholine receptors. Mol Pharmacol 72:10241032.

Starowicz K, Nigam S, and Di Marzo V (2007) Biochemistry and pharmacology of endovanilloids. Pharmacol Ther 114:13-33.

Steffens M, Zentner J, Honegger J, and Feuerstein TJ (2005) Binding affinity and agonist activity of putative endogenous cannabinoids at the human neocortical $\mathrm{CB}_{1}$ receptor. Biochem Pharmacol 69:169-178.

Stoddart LA, Smith NJ, and Milligan G (2008) International Union of Pharmacology. LXXI. Free fatty acid receptors FFA1, -2 , and -3 : pharmacology and pathophysiological functions. Pharmacol Rev 60:405-417.

Suardíaz M, Estivill-Torrús G, Goicoechea C, Bilbao A, and Rodríguez de Fonseca F (2007) Analgesic properties of oleoylethanolamide (OEA) in visceral and inflammatory pain. Pain 133:99-110.

Sugiura T, Kondo S, Sukagawa A, Nakane S, Shinoda A, Itoh K, Yamashita A, and Waku K (1995) 2-Arachidonoylglycerol: a possible endogenous cannabinoid receptor ligand in brain. Biochem Biophys Res Commun 215:89-97.

Sugo T, Tachimoto H, Chikatsu T, Murakami Y, Kikukawa Y, Sato S, Kikuchi K, Nagi T, Harada M, Ogi K, et al. (2006) Identification of a lysophosphatidylserine receptor on mast cells. Biochem Biophys Res Commun 341:1078-1087.

Suhara Y, Nakane S, Arai S, Takayama H, Waku K, Ishima Y, and Sugiura T (2001) Synthesis and biological activities of novel structural analogues of 2-arachidonoylglycerol, an endogenous cannabinoid receptor ligand. Bioorg Med Chem Lett 11: 1985-1988.

Suhara Y, Takayama H, Nakane S, Miyashita T, Waku K, and Sugiura T (2000) Synthesis and biological activities of 2-arachidonoylglycerol, an endogenous cannabinoid receptor ligand, and its metabolically stable ether-linked analogues. Chem Pharm Bull 48:903-907.

Sun Y, Alexander SP, Garle MJ, Gibson CL, Hewitt K, Murphy SP, Kendall DA, and Bennett AJ (2007a) Cannabinoid activation of PPAR $\alpha$; a novel neuroprotective mechanism. Br J Pharmacol 152:734-743.

Sun Y, O'Sullivan SE, Alexander SPH, Kendall D, and Bennett A (2007b) Both agonists and antagonists of cannabinoid receptors can activate PPAR $\alpha$, in 17th Annual Symposium of the Cannabinoids; 2007 Jun 26-Jul 1; St-Sauveur, Canada. p. 16. International Cannabinoid Research Society, Burlington, Vermont.

Szabo B and Schlicker E (2005) Effects of cannabinoids on neurotransmission. Handb Exp Pharmacol 168:327-365

Tanaka S, Ishii K, Kasai K, Yoon SO, and Saeki Y (2007) Neural expression of G protein-coupled receptors GPR3, GPR6, and GPR12 up-regulates cyclic AMP levels and promotes neurite outgrowth. J Biol Chem 282:10506-10515.

Tanaka S, Shaikh IM, Chiocca EA, and Saeki Y (2009) The $\mathrm{G}_{\mathrm{s}}$-linked receptor GPR3 inhibits the proliferation of cerebellar granule cells during postnatal development. PLoS ONE 4:e5922.

Tanaka T, Katsuma S, Adachi T, Koshimizu TA, Hirasawa A, and Tsujimoto G (2008) Free fatty acids induce cholecystokinin secretion through GPR120. Naunyn Schmiedebergs Arch Pharmacol 377:523-527.

Thomas A, Baillie GL, Phillips AM, Razdan RK, Ross RA, and Pertwee RG (2007) Cannabidiol displays unexpectedly high potency as an antagonist of $\mathrm{CB}_{1}$ and $\mathrm{CB}_{2}$ receptor agonists in vitro. $\mathrm{Br} J$ Pharmacol 150:613-623.

Tominaga M, Caterina MJ, Malmberg AB, Rosen TA, Gilbert H, Skinner K, Raumann BE, Basbaum AI, and Julius D (1998) The cloned capsaicin receptor integrates multiple pain-producing stimuli. Neuron 21:531-543.

Tóth A, Blumberg PM, and Boczán J (2009) Anandamide and the vanilloid receptor (TRPV1). Vitam Horm 81:389-419.

Turu G, Várnai P, Gyombolai P, Szidonya L, Offertaler L, Bagdy G, Kunos G, and Hunyady L (2009) Paracrine transactivation of the $\mathrm{CB}_{1}$ cannabinoid receptor by $\mathrm{AT}_{1}$ angiotensin and other $\mathrm{G}_{\mathrm{q} / 11}$ protein-coupled receptors. $J$ Biol Chem 284: 16914-16921.

Uhlenbrock K, Gassenhuber H, and Kostenis E (2002) Sphingosine-1-phosphate is a ligand of the human gpr3, gpr6 and gpr12 family of constitutively active G protein-coupled receptors. Cell Signal 14:941-953.

Valk P, Verbakel S, Vankan Y, Hol S, Mancham S, Ploemacher R, Mayen A Löwenberg B, and Delwel R (1997) Anandamide, a natural ligand for the peripheral cannabinoid receptor is a novel synergistic growth factor for hematopoietic cells. Blood 90:1448-1457.

Valverde O, Célérier E, Baranyi M, Vanderhaeghen P, Maldonado R, Sperlagh B, Vassart G, and Ledent C (2009) GPR3 receptor, a novel actor in the emotional-like responses. PLoS ONE 4:e4704.

Van den Bossche I and Vanheel B (2000) Influence of cannabinoids on the delayed rectifier in freshly dissociated smooth muscle cells of the rat aorta. $\mathrm{Br}$ J Pharmacol 131:85-93.

van der Stelt M, Trevisani M, Vellani V, De Petrocellis L, Schiano Moriello A, Camp B, McNaughton P, Geppetti P, and Di Marzo V (2005) Anandamide acts as an intracellular messenger amplifying $\mathrm{Ca}^{2+}$ influx via TRPV1 channels. EMBO 24:3026-3037.

Van Sickle MD, Duncan M, Kingsley PJ, Mouihate A, Urbani P, Mackie K, Stella N, Makriyannis A, Piomelli D, Davison JS, et al. (2005) Identification and functiona characterization of brainstem cannabinoid $\mathrm{CB}_{2}$ receptors. Science 310:329-332.

Vandevoorde S, Jonsson KO, Fowler CJ, and Lambert DM (2003) Modifications of the ethanolamine head in $\mathrm{N}$-palmitoylethanolamine: synthesis and evaluation of new agents interfering with the metabolism of anandamide. J Med Chem 46:1440 1448.

Vásquez C and Lewis DL (1999) The CB1 cannabinoid receptor can sequester G-proteins, making them unavailable to couple to other receptors. J Neurosc 19:9271-9280

Vaysse PJ, Gardner EL, and Zukin RS (1987) Modulation of rat brain opioid receptors by cannabinoids. J Pharmacol Exp Ther 241:534-539.

Veale EL, Buswell R, Clarke CE, and Mathie A (2007) Identification of a region in the TASK3 two pore domain potassium channel that is critical for its blockade by methanandamide. Br J Pharmacol 152:778-786.

Venkatachalam K and Montell C (2007) TRP channels. Annu Rev Biochem 76:387417. 
Venkataraman C and Kuo F (2005) The G-protein coupled receptor, GPR84 regulates IL-4 production by T lymphocytes in response to CD3 crosslinking. Immunol Lett 101:144-153.

Vennekens R, Owsianik G, and Nilius B (2008) Vanilloid transient receptor potential cation channels: an overview. Curr Pharm Des 14:18-31.

Vignali M, Benfenati V, Caprini M, Anderova M, Nobile M, and Ferroni S (2009) The endocannabinoid anandamide inhibits potassium conductance in rat cortical astrocytes. Glia 57:791-806.

Wager-Miller J, Westenbroek R, and Mackie K (2002) Dimerization of G proteincoupled receptors: CB1 cannabinoid receptors as an example. Chem Phys Lipids 121:83-89.

Waldeck-Weiermair M, Zoratti C, Osibow K, Balenga N, Goessnitzer E, Waldhoer M, Malli R, and Graier WF (2008) Integrin clustering enables anandamide-induced $\mathrm{Ca}^{2+}$ signaling in endothelial cells via GPR55 by protection against $\mathrm{CB}_{1}$-receptortriggered repression. J Cell Sci 121:1704-1717.

Wallace VC, Segerdahl AR, Lambert DM, Vandevoorde S, Blackbeard J, Pheby T, Hasnie F, and Rice AS (2007) The effect of the palmitoylethanolamide analogue, palmitoylallylamide (L-29) on pain behaviour in rodent models of neuropathy. $B r J$ Pharmacol 151:1117-1128.

Wang J, Simonavicius N, Wu X, Swaminath G, Reagan J, Tian H, and Ling L (2006b) Kynurenic acid as a ligand for orphan G protein-coupled receptor GPR35. J Biol Chem 281:22021-22028.

Wang J, Wu X, Simonavicius N, Tian H, and Ling L (2006a) Medium-chain fatty acids as ligands for orphan $\mathrm{G}$ protein-coupled receptor GPR84. J Biol Chem 281:34457-34464.

Watanabe H, Vriens J, Prenen J, Droogmans G, Voets T, and Nilius B (2003) Anandamide and arachidonic acid use epoxyeicosatrienoic acids to activate TRPV4 channels. Nature 424:434-438.

Wetter JA, Revankar C, and Hanson BJ (2009) Utilization of the Tango $\beta$-Arrestin Recruitment technology for cell-based EDG receptor assay development and interrogation. J Biomol Screen 14:1134-1141.

White R, Ho WS, Bottrill FE, Ford WR, and Hiley CR (2001) Mechanisms of anandamide-induced vasorelaxation in rat isolated coronary arteries. $\mathrm{Br} J \mathrm{Phar}$ macol 134:921-929.

Whyte LS, Ryberg E, Sims NA, Ridge SA, Mackie K, Greasley PJ, Ross RA, and Rogers MJ (2009) The putative cannabinoid receptor GPR55 affects osteoclast function in vitro and bone mass in vivo. Proc Natl Acad Sci USA 106:16511-16516.
Williams JR, Khandoga AL, Goyal P, Fells JI, Perygin DH, Siess W, Parrill AL, Tigyi G, and Fujiwara Y (2009) Unique ligand selectivity of the GPR92/LPA5 lysophosphatidate receptor indicates role in human platelet activation. J Biol Chem 284: 17304-17319.

Wotherspoon G, Fox A, McIntyre P, Colley S, Bevan S, and Winter J (2005) Peripheral nerve injury induces cannabinoid receptor 2 protein expression in rat sensory neurons. Neuroscience 135:235-245.

Xiong W, Hosoi M, Koo BN, and Zhang L (2008) Anandamide inhibition of 5- $\mathrm{HT}_{3 \mathrm{~A}}$ receptors varies with receptor density and desensitization. Mol Pharmacol 73: $314-322$.

Yamamoto I, Kimura T, Yoshida H, Watanabe K, and Yoshimura H (1992) Cannabinoid metabolite interacts with benzodiazepine receptor. Res Commun Subst Abuse 13:299-313.

Yan ZC, Liu DY, Zhang LL, Shen CY, Ma QL, Cao TB, Wang LJ, Nie H, Zidek W, Tepel M, et al. (2007) Exercise reduces adipose tissue via cannabinoid receptor type 1 which is regulated by peroxisome proliferator-activated receptor- $\delta$. Biochem Biophys Res Commun 354:427-433.

Yanagida K, Masago K, Nakanishi H, Kihara Y, Hamano F, Tajima Y, Taguchi R, Shimizu T, and Ishii S (2009) Identification and characterization of a novel lysophosphatidic acid receptor, p2y5/LPA6. J Biol Chem 284:17731-17741.

Yang Z, Aubrey KR, Alroy I, Harvey RJ, Vandenberg RJ, and Lynch JW (2008) Subunit-specific modulation of glycine receptors by cannabinoids and $N$ arachidonyl-glycine. Biochem Pharmacol 76:1014-1023.

Yin H, Chu A, Li W, Wang B, Shelton F, Otero F, Nguyen DG, Caldwell JS, and Chen YA (2009) Lipid G protein-coupled receptor ligand identification using $\beta$-arrestin PathHunter assay. J Biol Chem 284:12328-12338.

Zhang X, Maor Y, Wang JF, Kunos G, and Groopman JE (2010) Endocannabinoidlike $N$-arachidonoyl serine is a novel pro-angiogenic mediator. $\mathrm{Br} \mathrm{J}$ Pharmacol 160:1583-1594.

Zhang HT, Parker J, Shepherd N, and Creazzo TL (2009) Developmental expression of a functional TASK-I $2 \mathrm{P}$ domain $\mathrm{K}^{+}$channel in embryonic chick heart. J Biomed Sci 16:104.

Zygmunt PM, Petersson J, Andersson DA, Chuang H, Sørgård M, Di Marzo V, Julius $\mathrm{D}$, and Högestätt ED (1999) Vanilloid receptors on sensory nerves mediate the vasodilator action of anandamide. Nature 400:452-457. 